\title{
China: the Epidemiological and behavioral dynamos of the HIV epidemic in Guangxi Province
}

\author{
Synthesis Report
}

Human Development Unit

East Asia and Pacific Region

The World Bank

February 2007

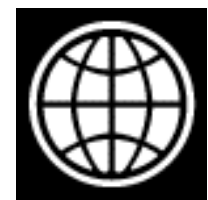

Document of the World Bank 


\section{Acknowledgements}

This report has been prepared by a team comprised by David Wilson from the World Bank.

The work was done under the supervision of Ana Revenga, Task Team Leader for the China AIDS AAA Program, and benefited from inputs from Shiyong Wang (World Bank), Emiko Masaki (ADB) 


\section{Table of Contents}

ACKNOWLEDGEMENTS .2

TABLE OF CONTENTS .3

EXECUTIVE SUMMARY .5

LIST OF ACRONYMS AND ABBREVIATIONS ........................................

CHAPTER 1: GENERAL SITUATION IN GUANGXI PROVINCE. .10

\section{CHAPTER 2: DESCRIPTION OF THE GUANGXI HIV AND STD} SURVEILLANCE SYSTEM ...............................................................12

2.1 Structure of the national and Guangxi local HIV surveillance system...............12

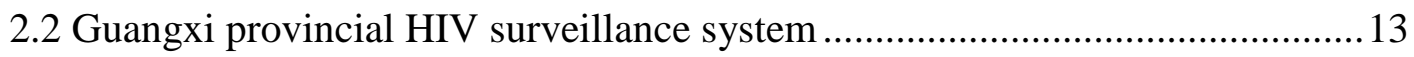

2.2.1 Surveillance components .................................................................... 13

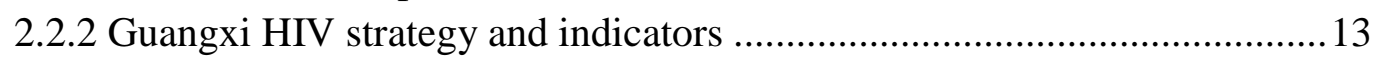

2.2.3 Surveillance sites and populations ...................................................... 14

2.2.4 National and provincial sentinel surveillance ............................................ 16

2.2.5 Comprehensive surveillance ................................................................ 21

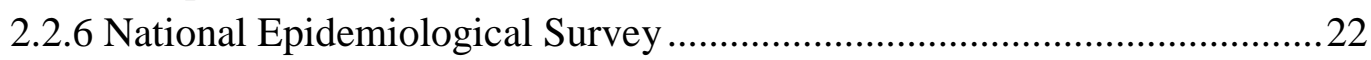

2.2.7 Provincial Behavioral Surveillance Surveys............................................24

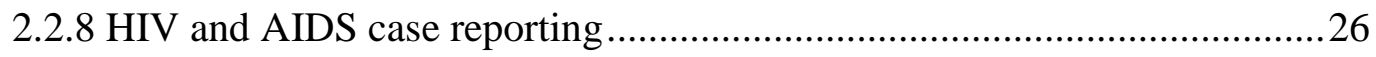

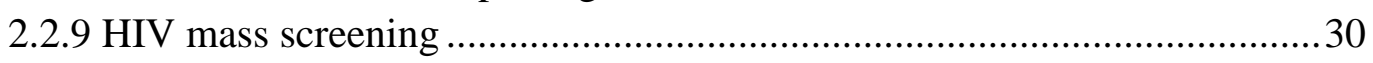

2.2.10 Size estimates of high-risk populations and persons living with HIV ......30

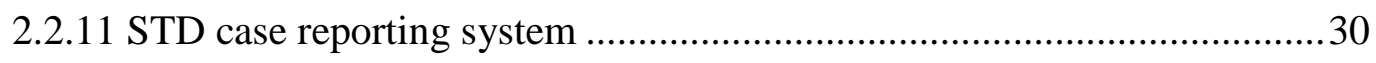

CHAPTER 3: THE HIV EPIDEMIC SITUATION IN GUANGXI.....................32

3.1 Growth and Evolution of the HIV Epidemic in Guangxi ..................................32

3.2 Injecting drug users are the most affected sub-population .................................38

3.3 The HIV epidemic had spread to female sex workers and clients ....................43

3.4 Men who have sex with men (MSM) are 'blind spot' in the understanding of the HIV epidemic in Guangxi .......................................................................... 46

\section{CHAPTER 4: THE EPIDEMIC OF SEXUALLY TRANSMITTED DISEASES}

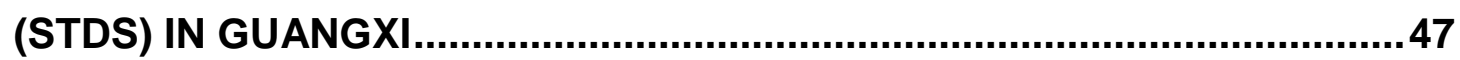

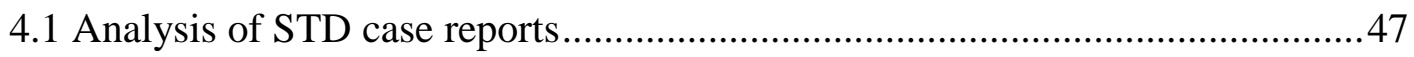

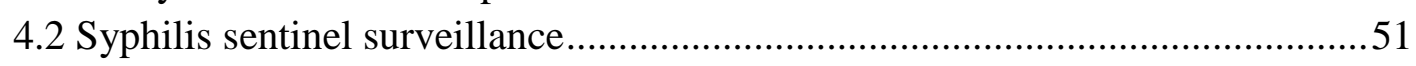


CHAPTER 5: THE RESPONSE AGAINST HIV AND AIDS IN GUANGXI ....56

5.1 Policies and environmental support for HIV prevention and control in Guangxi

5.1.1 Strengthen the leadership, improve the multi-sector collaboration network.

5.1.2 Supportive Policies and Documents

5.1.3 Increasing Funding Inputs

5.1.4 Government leading, multi-sector collaboration and whole society

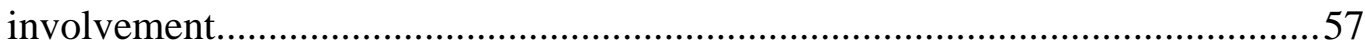

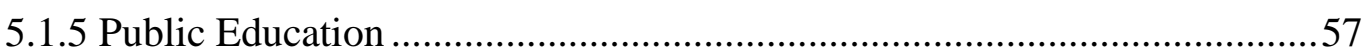

5.1.6 Intervention for High Risk Population and Vulnerable population ..............58

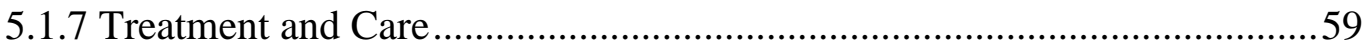

5.1.8 Intensifying the Surveillance for better Understanding the Trend of

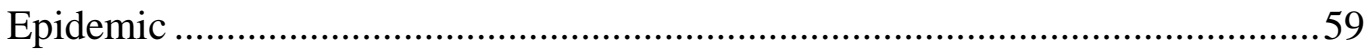

5.1.9 International Communication and Cooperation ...........................................59

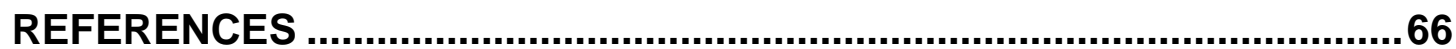




\section{List of Acronyms and Abbreviations}

$\begin{array}{ll}\text { AIDS } & \text { Acquired immune deficiency syndrome } \\ \text { ANC } & \text { Ante-natal clinic } \\ \text { ART } & \text { Antiretroviral therapy } \\ \text { CA } & \text { Condyloma Accuminatum } \\ \text { CDC } & \text { Centers for Disease Control and Prevention } \\ \text { DU } & \text { Drug user } \\ \text { ELISA } & \text { Enzyme linked immunosorbant assay } \\ \text { FSW } & \text { Female sex worker } \\ \text { FHI } & \text { Family Health International } \\ \text { GH } & \text { Genital herpes } \\ \text { HIV } & \text { Human immuno-deficiency virus } \\ \text { IDU } & \text { Injecting drug user } \\ \text { LGV } & \text { Lymphogranuloma venereum } \\ \text { MSM } & \text { Men who have sex with men } \\ \text { MSW } & \text { Male sex worker } \\ \text { NCAIDS } & \text { National Center for AIDS/STD Prevention and Control } \\ \text { NGU } & \text { Non-gonococcal urethritis } \\ \text { PLWHA } & \text { People living with HIV/AIDS } \\ \text { STD } & \text { Sexually transmitted disease } \\ \text { STI } & \text { Sexually transmitted infection } \\ \text { SW } & \text { Sex worker } \\ \text { TB } & \text { Tuberculosis } \\ \text { UNAIDS } & \text { Joint United Nations Programme on HIV/AIDS } \\ \text { VCT } & \text { Voluntary HIV Counseling and Testing } \\ \text { WHO } & \text { World Health Organization }\end{array}$




\section{Executive Summary}

Introduction: China has made significant progress developing its national policies on HIV/AIDS in recent years. This increased national commitment to fighting HIV/AIDS has been reflected in a rapidly expanding AIDS budget. Central government resources devoted to AIDS nearly tripled between 2004 and 2005, and have increased 60-fold relative to their level in 2000. The national leadership of the HIV/AIDS program and all of China's partners in this effort recognize a range of key challenges to be met as China works to translate its AIDS policies and objectives into action.

Need for further analysis: In three decades, we have learned how critical it is to ensure that HIV responses are based on a rigorous and objective understanding of the bio-behavioral determinants of HIV transmission. Globally, HIV responses have been undermined by generic approaches, which do not address the major local drivers of epidemics in each context, and by assumptions extrapolated from one region or country to others. It is vital to ensure that responses are tailored and prioritized to address the major drivers of transmission. China has numerous surveillance and research products that are yet to be analyzed in a rigorous, integrated manner. This analysis seeks to: provide a rigorous assessment of the HIV epidemic, its major transmission dynamics and its potential evolution in one province in China with a significant HIV incidence; analyze the current HIV responses in relation to the above analysis of the epidemic and its potential evolution; and identify major geographic and thematic priorities for greater emphasis.

Context: Guangxi Zhang Autonomous Region, referred to hereafter as Guangxi Province is situated in southern China and shares a border with Vietnam. It has 14 prefecture-level cities, seven county-level cities, 57 general counties and 12 ethnic minority autonomous counties in Guangxi, totaling 90 counties/cities. Although Guangxi has traditionally been one of the less developed provinces in China, there has been rapid economic growth in recent years, accompanied by a recent expansion of the provincial highway system. In 2005, a new modern highway was opened between the capital city of Nanning and Pingxiang on the China-Vietnam border, which allows much more efficient transportation to Guangxi's largest shipping port, Youyi. Rapid urbanization has accompanied economic growth. As of 2003, 14.11 million people, approximately one third of the population, were living in urban areas. In 2003, $17 \%$ of families in Guangxi province reported having a family member living outside the household for more than six months. 
Surveillance: In China, the government Center for Disease Control and Prevention (CDC) is responsible for HIV surveillance at national, provincial, prefecture and county levels. HIV case reporting began in 1986 in Guangxi, and sentinel surveillance was instituted in 1996. Core surveillance components include: HIV sentinel surveillance; behavioral surveillance; and HIV case reporting. Guangxi's surveillance system is expansive, and coverage reaches a majority of the urban hubs, some provincial locations, and areas along the main provincial transportation routes. The target populations of the sentinel surveillance surveys vary across sites and include drug users, sex workers, pregnant woman, STD clinic attendees, TB clinic patients and long distance truck drivers. By 2005, the surveillance surveys included the following: 44 drug user surveys in 28 sites; 27 sex workers surveys in 20 sites; 6 long distance truck drivers surveys in 5 sites; 5 migrant men surveys in 5 sites; 1 young student survey in 1 site; 6 pregnant women surveys in 6 sites; 3 tuberculosis patient surveys in 3 sites; 11 STD clinic attendee surveys in 11 sites; and 1 hospital patient survey in 1 site. Sentinel surveillance, comprised of HIV and syphilis serosurveillance and a short behavioral questionnaire, is the largest component of the Guangxi HIV surveillance system. In Guangxi, sentinel surveillance has been supported since 2002 by the World Bank Health 9 Project. The target populations of the sentinel surveillance surveys vary across sites and include drug users, sex workers, pregnant woman, STD clinic attendees, TB clinic patients and long distance truck drivers. Although surveillance is extensive, there are significant biases in the major sampling frames used. Sampling of drug users is limited to institutional populations, who may differ significantly from the wider population of drug users. Sex workers are sampled both in institutional settings and the community. In short, the major strength of the Guangxi surveillance system is its scope. The major limitation is qualitysampling is largely limited to detained populations of drug users and sex workers. Behavioral research is frequently vitiated by insufficient privacy, limited expertise in eliciting disclosure of sensitive injecting and sexual practices and insufficient training and support to interviewers. Since 2005, Guangxi Province has introduced what it refers to as comprehensive surveillance, to address the sampling and quality limitations of the existing surveillance system.

HIV epidemiology: Since the first HIV case was detected in a foreign student in 1989, the HIV epidemic in Guangxi has evolved through three distinct phases. During the first, the sporadic period from 1989 to 1995, only 10 cases were reported largely among visitors from other Chinese provinces or abroad. No HIV infections were found among Guangxi residents during this period. During the second epidemic phase, from 1996 to 1997, HIV cases were reported among injecting drug users in Guangxi and among Guangxi residents who had sold blood in China's central provinces. During the third phase of rapid growth, the annual number of reported HIV cases in Guangxi increased exponentially-from 530 cases in 1998 to 8,625 in 2005. Currently, the province has the third highest cumulative number of reported HIV infections in all China and the third highest estimated cumulative HIV prevalence. 
The cumulative total of 19,604 HIV cases reported through 2005 is a vast underestimate of the actual number of HIV cases in Guangxi province. The Guangxi Consultative Committee for AIDS Prevention and Control using the UNAIDS/WHO Workbook method ${ }^{2}$ estimated that there are roughly 50,000-105,000 persons living with HIV in the province during 2005 alone.

HIV cases have been detected among diverse populations including injecting drug users (IDU), female sex workers (FSWs), sexually transmitted disease (STD) clinic attendees, voluntary counseling and testing (VCT) clients, hospital inpatients, sailors, paid and unpaid blood donors and mobile populations (both persons coming from other provinces and local residents traveling to other provinces). While injecting drug use has been the predominant mode of HIV transmission in Guangxi since 1997, the proportion of reported HIV cases attributable to sexual transmission has also been increasing, from $7.1 \%$ in 2002 to $33.3 \%$ in 2004 . The male-to-female ratio of reported HIV cases has gradually decreased from about 9:1 between 1989 and 1996 to about $3: 1$ (22\% female) in 2004. The decreasing male-to-female ratio is probably related to increases in HIV infections among sex workers and the sexual partners of HIVinfected men.

Nevertheless, injecting drug use remains the main driver of Guangxi's HIV epidemic. Two major drug routes from the 'Golden Triangle' to Eastern China and international markets traverse the province. According to the Public Security Bureau, by the end of June 2004, there were about 50,000 registered drug users in Guangxi, the fifth largest number in China. HIV rates among injecting drug users are high. In Wuzhou, HIV prevalence rose from $0.5 \%$ in 1998 to $48.4 \%$ in 2003 . In Nanning and Qinzhou, HIV prevalence appears to have stabilized at 10-20\%. Geographic analysis shows that HIV is widely distributed among injecting drug users throughout Guangxi.

Although prostitution in China has been illegal since 1949, the commercial sex industry has flourished since the early 1980s with the adoption of a free market economy and 'open door' policy. Brothel-based commercial sex is far less common in China than in other parts of Asia although it still exists and informal transient sex work is far more common and often based out of establishments such as hairdressing salons, hotel bars, dance halls or directly from the street or other public venues. According to the public security agency there were at least 50,000 FSWs in Guangxi in 2001. Long-standing HIV surveillance among sex workers is limited to Nanning and shows that HIV prevalence has stabilized at 10\%-13\%. Many HIV-infected sex workers appear to be injecting drug users. However, the crucial nexus between drug injecting and commercial sex risk behavior has been understudied in Guangxi and China in general. HIV remains low among potential clients of sex workers - in at least three studies of over 1,000 long-distance truck drivers in Guangxi, only one has been found to be HIV-positive. However, rates are growing among STD patients, which suggests that sexual transmission of HIV is increasing. Some disturbingly high rates of HIV have been reported among some antenatal samples and further study of this 
group is clearly required. Men who have sex with men (MSM) are the 'blind spot' in the understanding of the HIV epidemic in Guangxi-there have been no HIV seroprevalence surveys conducted among MSM in the province.

Guangxi's response: Political commitment and financing to tackle AIDS have grown. Provincial AIDS spending rose from 1 million RMB in 1998 to 8 million $\mathrm{RMB}$ in 2005. Central government contributions rose from 9.85 million RMB in 2004 to 35.84 million RMB in 2005. Numerous multi-sectoral HIV awareness campaigns have been conducted among the general population. HIV risk group interventions have also grown. Clean needle/syringe exchange for injection drug users have been implemented in Luzhai, Tiandong, Ningming and Guigang. Methadone maintenance therapy is being offered in Nanning, Liuzhou, Wuzhou and Hechi.

Conclusions - a significant epidemic: It is clear that Guangxi faces a significant epidemic, which is widely dispersed among injecting drug users throughout the province. The epidemic is highly heterogeneous - understanding the diversity of the epidemic between and within prefectures and counties is a prerequisite for informed, prioritized, effective responses.

A preventable epidemic: Guangxi's HIV epidemic is serious, but eminently preventable. The future size of Guangxi's epidemic will depend above all on the scope and effectiveness of HIV prevention programs for injecting drug users and their sexual partners. Programs for sex workers and their clients and men having sex with men will also be crucial.

Prevention works: HIV prevention programs for injecting drug users, sex workers and men having sex with men in Asia work - to a large extent, we do know what to do and how to do it. Promising interventions for high risk groups in Guangxi are underway. However, coverage is the greatest challenge - high coverage of high impact interventions among populations engaged in high risk behaviors, and their sexual partners, are essential to reduce HIV transmission.

Prevention is cost-effective: HIV prevention among injecting drug users and their sexual partners, sex workers and clients and men having sex with men and their sexual partners, is relatively inexpensive and provides a high return on investment. Urgent, effective programs for injecting drug users, sex workers and men having sex with men and the sexual partners of these groups can still prevent HIV becoming widely established in the general population, and such actions will greatly reduce the costs of HIV prevention, care, treatment and other costs. 


\section{Chapter 1: General Situation in Guangxi Province}

Guangxi Zhang Autonomous Region, referred to as Guangxi Province in this report, is located in southern China and neighbors four other provinces - Guangdong, Yunnan, Guizhou and Hunan. The southwestern part of Guangxi shares a border with northern Vietnam, and the southeastern area is comprised of the Gulf of Tonkin coastline where major shipping ports handling more than 40 million tons of goods annually are located.

\section{Figure 1: Map of Guangxi Province}

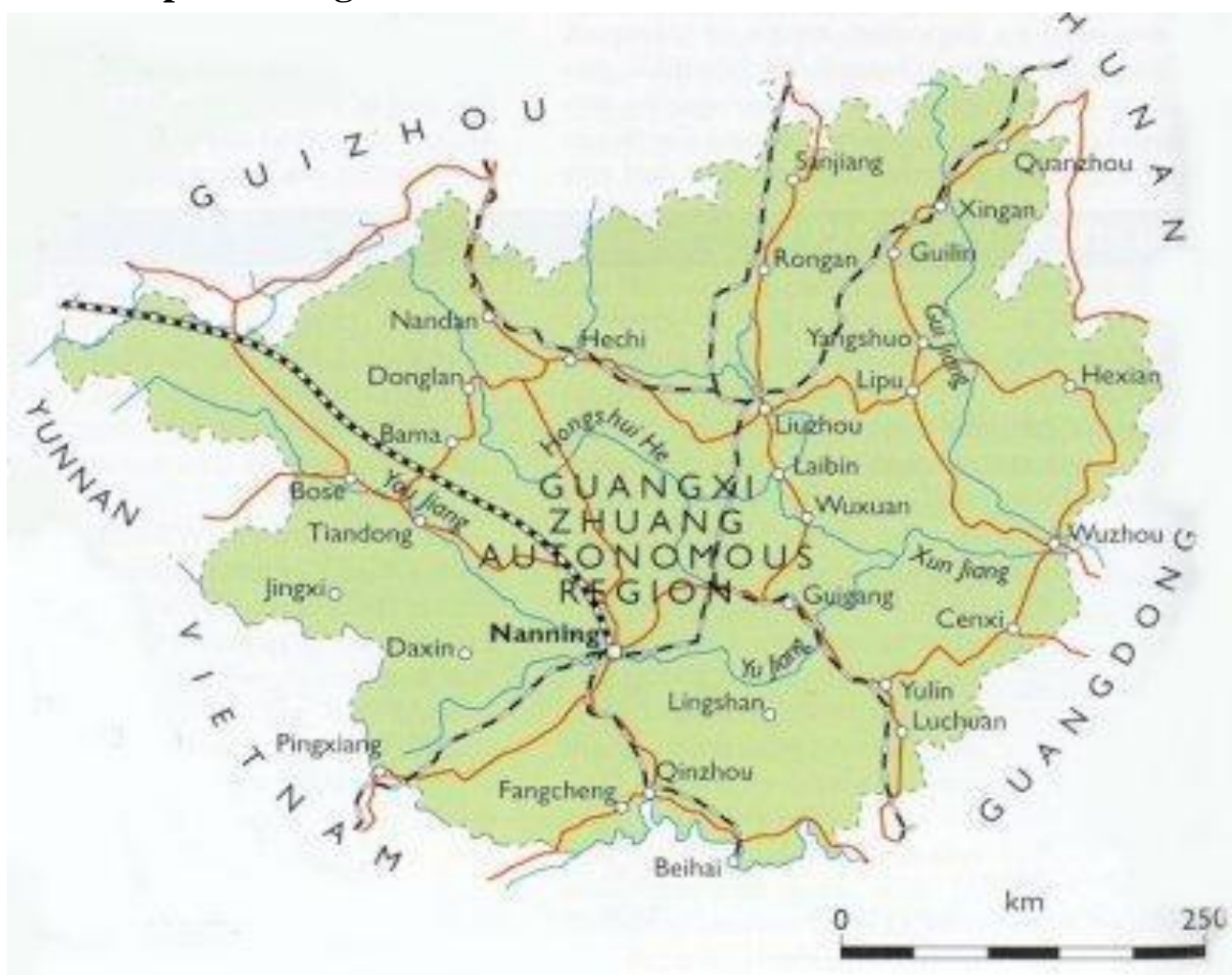

There are 14 prefecture-level cities, seven county-level cities, 57 general counties and 12 ethnic minority autonomous counties in Guangxi, totaling 90 counties/cities within the province. Guangxi has a land area of 236,700 square kilometers, and had a population of 48.6 million people as of 2003. The male population accounts for $52.3 \%$ of the total population while the female population accounts for $47.7 \%$. The average increase in population size is low with an annual growth rate of only $0.73 \%$. The population age structure is quite top heavy with persons aged 15 years and older representing $76.9 \%$ of the population.

Although Guangxi has traditionally been one of the less developed provinces in China, there has been rapid economic growth in recent years, accompanied by the expansion of the provincial highway system. In 2005, a new modern highway was 
opened between the capital city of Nanning and Pingxiang on the China-Vietnam border, which allows much more efficient transportation to Guangxi's largest shipping port, Youyi. In the late 1990s, the government opened the modern Nankun rail line that links Nanning with Kunming, the capital of Yunnan province and serves as an important alternative regional transportation hub.

Rapid urbanization has accompanied economic growth. As of 2003, 14.11 million people, approximately one third of the population, were living in urban areas, and rural-to-urban migration increased by $11.7 \%$ from 2002. In $2003,17 \%$ of families in Guangxi province reported having a family member leaving home for more than six months, going to other areas of Guangxi as well as to different provinces. There are no data on the proportion of Chinese migrants coming to work in Guangxi, but it is believed to be substantial. 


\section{Chapter 2: Description of the Guangxi HIV and STD Surveillance System}

\subsection{Structure of the national and Guangxi local HIV surveillance system}

In China, the government Center for Disease Control and Prevention (CDC) is the organization responsible for both active and passive HIV surveillance, and there are four levels of CDC involvement in the system.

At the national level, the China CDC is responsible for general oversight of the surveillance system including development of standardized protocols, methodologies and tools, technical and monitoring support, developing and maintaining the centralized databases, data management, national estimates of people living with HIV and the quarterly and annual summation and dissemination of surveillance data.

The Provincial CDC is then responsible for revising the national standardized protocols and tools for local use, local training and monitoring for data collection and laboratory testing, data entry for some components of surveillance, data analysis, web-based data management and case reporting for all prefectures, provincial data dissemination, and provincial estimates of the number of persons living with HIV. In addition, the Guangxi CDC itself collects surveillance data in some sentinel sites and conducts HIV and syphilis testing for counties that lack their own facilities.

All of the 14 prefectures in Guangxi are covered in the HIV surveillance system. The Prefecture CDCs are required by the national standard to participate in surveillance at the same level as the Provincial CDC; however in Guangxi they have less involvement when the surveillance sites are outside of the prefecture's main city. The Prefecture CDCs in Guangxi are primarily responsible for data collection and laboratory tests in the main cities, prefecture-level estimates of the size of high risk populations, and web-base data management and case reporting for all counties in their prefecture.

As of 2005, there were 29 counties/cities in Guangxi taking part in HIV sentinel surveillance. The 76 County/City CDCs are primarily responsible for biological and behavioral data collection, data entry for selected surveillance components, webbased data management and case reporting for their own sites, and case reporting to the country Public Health Bureau (PHB). Some County/City CDCs also conduct HIV and syphilis testing and analyze surveillance data for their own needs (though the later is not mandatory). 


\subsection{Guangxi provincial HIV surveillance system}

\subsubsection{Surveillance components}

HIV case reporting began in 1986 in Guangxi, and sentinel surveillance was instituted in 1996. As of 2005, 82 VCT sites were trained but only 22 sites currently provide free voluntary testing and counseling in the province. The Guangxi HIV surveillance system is currently comprised of five core and three supporting components as follows:

\section{Core surveillance components}

1. National and provincial HIV sentinel surveillance

2. Comprehensive Surveillance

3. Provincial Behavioral Surveillance Surveys

4. HIV case reporting

\section{Supporting surveillance components}

1. HIV mass screening

2. National Epidemiological Surveys

3. Size estimates of high risk population and PLWHA

4. STD case reporting

Each of these components is discussed in the following sections, which provide details on populations, sampling, periodicity, indicators, and funding sources.

\subsubsection{Guangxi HIV strategy and indicators}

The first Guangxi five-year action plan began in 1999 and ended in 2004. The second action plan is for the years 2005-2009 and was in the process of being finalized at the time this report was written. HIV indicators for Guangxi Province were set down at the start of the first action plan in 1999 in the Guangxi HIV/AIDS Regulation Summary Book by the Guangxi Health Bureau, Health 9 office. These indicators were developed to monitor the provincial mid and long-term action plan, and targets were set for 2002. These indicators are as follows:

1. HIV knowledge in urban areas, rural areas and high risk areas;

2. HIV, STD, and health-related education courses in different types of school systems;

3. HIV/AIDS/STD education messages included in mass media work plans;

4. HIV/AIDS/STD prevention education included in all correctional systems; 
5. Health promotion demonstration/pilot projects set up in seriously affected areas;

6. Health staff trained in HIV/AIDS/STDs;

7. Facility-based indicators including laboratory testing facilities, treatment capacity;

8. Surveillance system developed; and

9. Government regulation for blood stations for blood collection and provision

The provisional indicators include the development of a surveillance system, but no HIV prevalence, STI prevalence or behavioral indicators were established. The only indicator measured through behavioral surveys is HIV knowledge in urban, rural and high-risk areas.

\subsubsection{Surveillance sites and populations}

The Guangxi surveillance system is expansive, and coverage reaches a majority of the urban hubs, some provincial locations, and areas along the main provincial transportation routes. The surveillance surveys include the following:

- 44 drug user surveys in 28 sites

- 27 sex workers surveys in 20 sites

- 6 long distance truck drivers surveys in 5 sites

- 5 migrant men surveys in 5 sites

- 1 young student survey in 1 site

- 6 pregnant women surveys in 6 sites

- 3 tuberculosis patient surveys in 3 sites

- 11 STD clinic attendee surveys in 11 sites

- 1 hospital patient survey in 1 site

Figure 2 below presented the survey locations, populations and components, excluding the Health 9 Provincial BSS sites. 
Figure 2: Map of Guangxi surveillance surveys by site

Note: Health 9 BSS sites not included

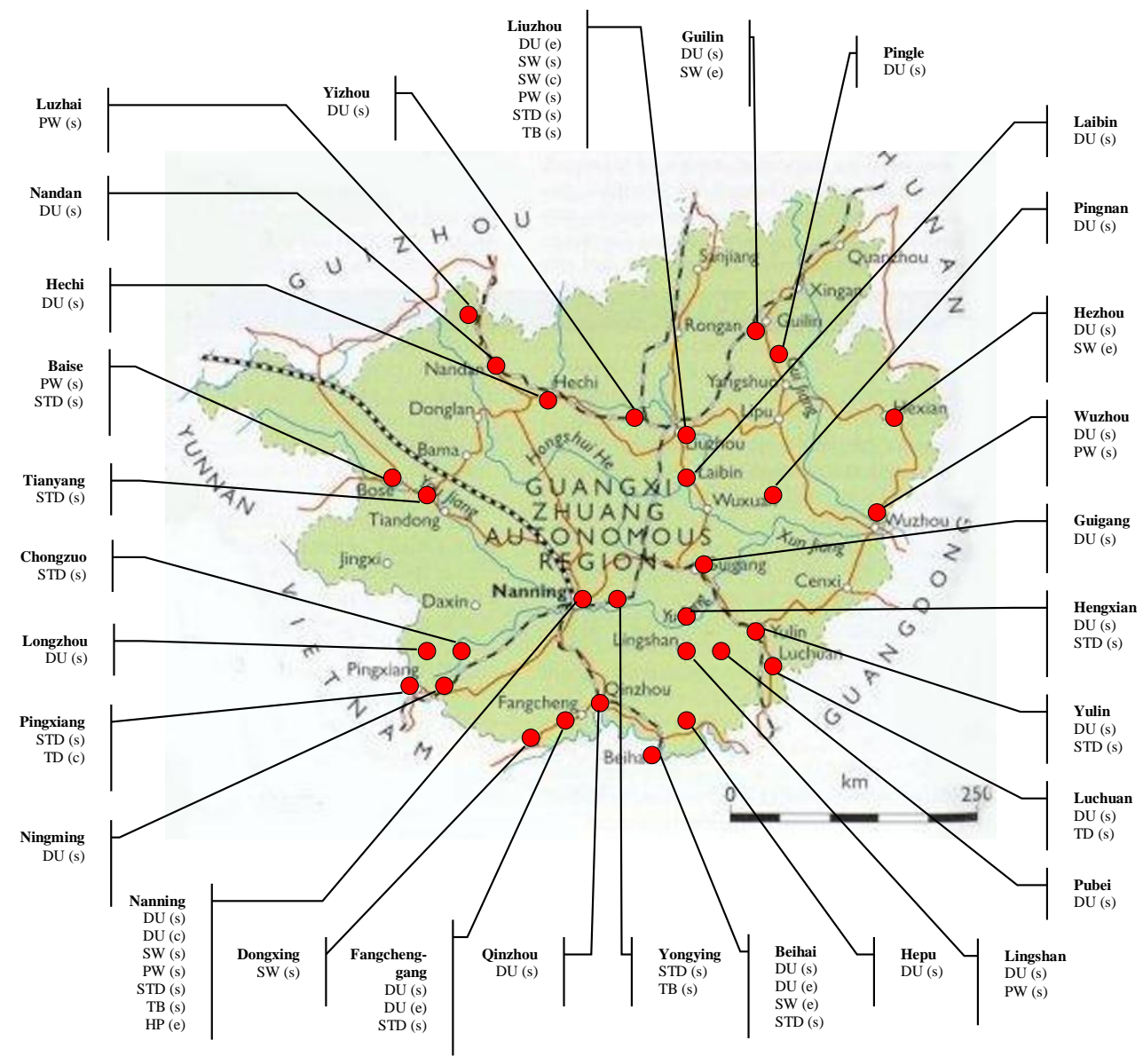

$\mathbf{D U}=$ male and female drug users

$\mathbf{S W}=$ female sex worker

$\mathbf{P W}=$ pregnant women

STD = male and female STD clinic attendees

$\mathbf{T D}=$ male long distance truck drivers

$\mathbf{T B}=$ male and female tuberculosis patients

$\mathbf{H P}=$ male and female hospital in-patients

(s) = national and provincial sentinel HIV surveillance

(e) = national epidemiological survey

(c) = comprehensive survey 


\subsubsection{National and provincial sentinel surveillance}

Sentinel surveillance, comprised of HIV and syphilis sero-surveillance and a short behavioral questionnaire, is the largest component of the Guangxi HIV surveillance system. Sentinel surveillance sites are funded by both China CDC and Guangxi CDC and the system is referred to as 'national and provincial sentinel surveillance'. However, all sites follow the same methodology. The national sentinel sites are required data collection sites, while the provincial sites are selected by the Guangxi CDC and are not mandatory under the national guidelines.

According to the China CDC standardized protocol, the objectives of national and provincial sentinel surveillance are the following:

1. To measure HIV/STD prevalence among different populations

2. To compare HIV/STD prevalence across different regions

3. To monitor HIV/STD epidemic trends among different populations in different regions

4. To better understand the risk factors for an HIV/STD epidemic among different populations in different regions

In Guangxi, provincial sentinel surveillance has been supported since 2002 by the World Bank Health 9 Project. The project was due to end in 2005 but has now been extended to 2008. At the closure of the Health 9 Project the provincial government was planning on continuing data collection at the provincial sites using other sources of funding.

The system begun in 1996 with three nationally funded sites. It has been expanded each year, reaching a total of 50 sites (22 national and 28 provincial) in Guangxi as of 2005. In 2006, the Guangxi CDC will add 25 provincial and three national sites to the already existing sentinel system bringing it to a total of 84 sites across the province. ${ }^{1}$

Sentinel sites and populations are selected based on a prefecture's or county's willingness and capacity for data collection. The prefecture or county applies to the Guangxi CDC justifying the expansion of sentinel sites and populations in the region. The applications are screened and sites are selected by the Guangxi CDC, and final national sites are approved by China CDC.

\footnotetext{
${ }^{1}$ While the national sentinel sites added in 2006 will be funded by China CDC, the provincial sites have not yet been funded and Guangxi CDC is awaiting approval for their inclusion. 
Table 1: National HIV sentinel surveillance sites in Guangxi

$\begin{array}{llllllll}\text { Year } & \begin{array}{l}\text { Drug } \\ \text { users }\end{array} & \begin{array}{l}\text { Sex } \\ \text { workers }\end{array} & \begin{array}{l}\text { STD clinic } \\ \text { attendees }\end{array} & \begin{array}{l}\text { Pregnant } \\ \text { women }\end{array} & \begin{array}{l}\text { Truck } \\ \text { drivers }\end{array} & \begin{array}{l}\text { TB clinics } \\ \text { patients }\end{array} & \text { Total } \\ 1996 & 1 & 1 & 1 & - & - & - & 3 \\ 1997 & 1 & 1 & 2 & - & - & - & 4 \\ 1998 & 1 & 1 & 4 & - & - & - & 6 \\ 1999 & 1 & 1 & 4 & - & - & - & 6 \\ 2000 & 1 & 1 & 4 & 1 & - & - & 7 \\ 2001 & 1 & 1 & 4 & 1 & - & - & 7 \\ 2002 & 3 & 2 & 6 & 2 & - & - & 13 \\ 2003 & 3 & 2 & 6 & 2 & - & - & 13 \\ 2004 & 5 & 3 & 6 & 3 & 2 & - & 22 \\ 2005 & 6 & 3 & 6 & 5 & 2 & - & 19\end{array}$

Table 2: Provincial HIV sentinel surveillance sites in Guangxi

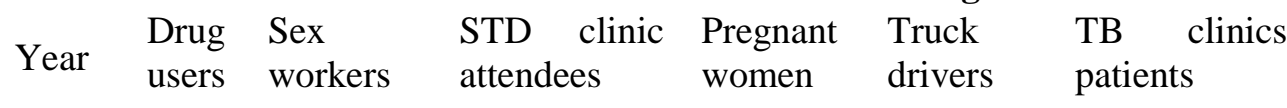

$\begin{array}{llllllll}2002 & 10 & 2 & 2 & 1 & 1 & - & 16 \\ 2003 & 10 & 2 & 2 & 1 & 1 & - & 16 \\ 2004 & 10 & 2 & 2 & 1 & - & - & 15 \\ 2005 & 17 & 2 & 5 & 1 & - & 3 & 28\end{array}$

Previously, national sentinel surveillance was conducted twice a year (April-June and October-December) and provincial sentinel surveillance was conducted once a year. Beginning in 2005, both surveys were conducted annually: the national sites from April-June and the provincial from March to August (usually finishing earlier).

\section{Population definitions and sampling methodology}

The target populations of the sentinel surveillance surveys vary across sites and include drug users, sex workers, pregnant woman, STD clinic attendees, TB clinic patients and long distance truck drivers.

Drug users include all male and female drug users, both injectors and non-injectors, who are newly arrested and sent to the detoxification center during the timeframe of 
the survey. Users who have been arrested in previous years are also eligible. Sampling is done consecutively until the target sample size of 250-400 is reached. If the desired sample size is not reached during the survey period, drug users in the detention who were brought in before March, but in the same year of the survey can be incorporated. Data cannot be collected twice from the same individual.

Detoxification centers are run by the Public Security Bureau (PSB) and provide mandatory detoxification for all persons arrested using drugs, with only a small number of drug users in the facilities who may be self-referred. Detoxification centers have a regimented agenda including education and labor and entertainment. Conditions differ widely from center to center, and some centers in Guangxi provide payment-based methadone treatment.

Drug users who have been arrested are sent to the detoxification center closest to their homes and stay an average of 3-6 months. Approximately three-fourths of arrested drug users are injectors, although the exact proportion can vary. ${ }^{2}$ In addition, the proportion of arrested drug users who are women can fluctuate from site to site and year to year. ${ }^{3}$

There are potential biases that can be introduced by this method of institutional sampling of drug users because only those who have been arrested can be recruited into the survey, thus restricting the ability to generalize findings to the entire drug using community. If arrest patterns change over time, the composition of the population may change as well. In addition, injecting and non-injecting drug users are combined as a single sample population. Because injecting drug users (IDUs) have been shown to have much higher HIV seroprevalence and behavioral risk than their non-injecting counterparts, the fluctuating proportion of IDUs in the "drug user" sample biases the ability to compare the survey data across sites and to analyze trends over time for the same site.

There is some evidence that the behaviors of drug users who have been arrested and those who have not can be significantly different. A survey of drug users in Tiandong county comparing behaviors from a community-based sample and those in institutions found that a higher proportion of frequent injectors ( 3 or more times a day) had been arrested, but no other significant behavioral differences were found. In this survey, an estimated $50 \%$ of drug users in the community-based sample of the survey reported they had never been arrested. ${ }^{1}$ It is necessary to analyze available data from

\footnotetext{
${ }^{2}$ The proportion of IDU among drug users in the sentinel surveillance system has varied between $58 \%$ and $100 \%$.

${ }^{3}$ The proportion of females among IDUs in the sentinel surveillance system is typically been $10-20 \%$ has varied between $0 \%$ and $54 \%$.
} 
community and institutional samples to better understand the differences in prevalence and risk taking behaviors.

In China, June $26^{\text {th }}$ is the International Drug Control Day and there is an annual national police sweep during which wide-scale arrests occur called the Strictly Strike Campaign. The dates for police sweeps are consistent from year to year, so they should not influence the composition of the populations found at institutions during surveillance data collection.

Since 2003 there has been a national methadone maintenance treatment program in Guangxi. Currently four sites are operational (Nanning, Liuzhou City, Wuzhou City and Hechi City) and the inclusion of an additional 15 sites has been approved. The selection criteria for enrolment in methadone programs is that the drug user must have been arrested at least twice, have used drugs for at least two years, and have obtained a certificate from a detoxification center. It is anticipated that 100-200 drug users will be recruited into the maintenance program per site. Because these are longer term drug users with a history of arrest, it will be necessary to analyze whether their exclusion from the sampling pool will alter the survey population significantly.

Female Sex workers are sampled from both the re-education centers and the community. In Nanning and Liuzhou, the only cities in the province with reeducation centers for women, sex workers surveyed include all women who sell sex that have been newly arrested and placed in a female re-education center during the period of April to June. If a sex worker is also a drug user, she is sent to either a reeducation center or a detoxification center based on the reason for her arrest. Sex workers sampled in the community are identified in a variety of locations where women sell sex. These locations vary from site to site, but none is a brothel.

Re-education centers take in women have been arrested for committing minor crimes, including selling sex, and are run by the Public Security Bureau (PSB). Sex workers stay for an average of three years in re-education centers. Sex workers are not transported to one of these centers if they are arrested outside the vicinity that they cover (they are released with a fine). Hence, the sex workers sampled in the centers in Nanning and Liuzhou are residing in the local communities.

Sampling in re-education centers is done consecutively until the target sample size of 250-400 is reached. Sex workers who have been arrested in previous years are eligible. If the required sample size cannot be reached during this period, sex workers who were brought before March, but in the same year of the survey can be included. Recruitment in the community-based sites (Dongxing and Hezhou) is done using convenience sampling until the desired sample size of $250-400$ is reached. Data cannot be collected twice in the same year from the same individual. 
Biases introduced through this type of sampling strategy are similar to those for the drug users' one. Policies and program that affect which sex workers are arrested and when may change the composition of the samples at the re-education centers. In addition, the sampling mechanism used in communities is not a probability sampling methodology, so trends cannot be accurately studied over time.

Pregnant women in sentinel surveillance are women who come for their first prenatal check-up at the Maternal and Child Health clinic or hospital as well as women that come to the clinic for an abortion. They are continuously sampled with no exclusion criteria until the sample size of 250-400 is reached. There is high utilization of health clinics during pregnancy in all urban areas and most rural areas, and it is uncommon for women to not access a government-funded health center during pregnancy.

STD clinic attendees are all men and women over the age of 13 years who come to an STD clinic for the first time during the recruitment period to seek treatment for a symptom of a sexually transmitted infection, regardless of whether they are diagnosed with an infection. They are continuously sampled until the sample size of 250-400 is reached. People who come for counseling on pregnancy or general sexual health are not included in the survey. Approximately $60 \%$ of the clinic attendees are men.

Truck drivers are men who drive long distance truck routes. According to the China CDC guidelines, truck drivers may be recruited over a 6 month period when they come to a physical examination station for the annual renewal of their driver's license. However, in Guangxi, truck drivers are recruited at the parking areas using snowball sampling.

TB patients are all men and women over the age of 13 years who come to a TB clinic for the first time during the recruitment period to seek treatment. They are continuously sampled until the sample size of 250-400 is reached.

\section{Strengths of sentinel surveillance}

As shown in Tables 1 and 2, the national and provincial sentinel surveillance in Guangxi includes many of the high risk populations in the province and has been expanded geographically in recent years. It has been continuously collected over time with increasing coverage each year. Sentinel surveillance is considered a routine responsibility in the locations where it is conducted, and hence has been 'institutionalized', ensuring its status as an on-going, sustainable activity. If biases in data collection at facilities remain consistent over time, then it can be used to track prevalence and behavioral trends. 


\section{Limitations of sentinel surveillance}

While population and geographic coverage has expanded over time in recent years, there are relatively few sentinel sites for which repeated survey rounds have been conducted in the past. This limits the external validity of existing trend analysis. Moreover, there is no established system for assessing epidemiologically important populations and areas for inclusion in sentinel surveillance. Little is known about characteristics and behaviors of drug users and sex workers in institutions compared to those who have not been arrested. Where community samples are available, they are not sampled using probability sampling methods, making interpretation difficult. Because both injecting and non-injecting drug users are recruited in a single sample, it is difficult to differentiate between the sub-populations and their differing behavioral risks in both single year and trend analyses. Limited behavioral indicators are collected in sentinel surveillance. However, the wording of the questions is inconsistent across populations and many do not contain the time reference periods necessary for measuring trends. Although a great deal of data does exist, it is yet to be fully analyzed.

\subsubsection{Comprehensive surveillance}

In order to obtain more in-depth behavioral information on high risk populations, China CDC developed comprehensive surveillance surveys that include a more detailed questionnaire than those of sentinel surveillance as well as a measurement of HIV and syphilis prevalence. These surveys are intended to be implemented periodically in order to complement the sentinel system, and there is no duplication with already established sentinel surveillance sites. Comprehensive surveillance is funded by China CDC.

First instituted in 2004, one round of comprehensive surveillance was conducted from July to September. Three sites in Guangxi conducted comprehensive surveillance including Nanning (drug users from the detoxification center), Liuzhou (sex workers from the female re-education center and community) and Pingxiang (long distance truck drivers drawn mainly from Puzhai port bordering Vietnam).

Three additional sites are planned for 2006 including sex workers in Beihai and Baise, and STD clinic attendees in Hezhou and Luzhai.

\section{Population definitions and sampling methodology}

The sample size for all populations is $360-400$.

Drug users include all male and female drug users, both injectors and non-injectors. Sampling is done primarily using snowball recruitment from the community. If a large enough sample size cannot be obtained in the community, it is supplemented 
from drug users who have newly entered the detoxification center (arrested in the past 3 months). According to the protocol, drug users in detoxification centers should not account for more than one half of the total sample size.

Sex workers are women who provide commercial sex services. They are sampled from the entertainment sites in the community including saunas, public baths, nightclubs, karaoke, hotels, restaurants, foot washing, beauty shops, barbers, and small guesthouses on the street. Women who work in these venues but do not sell sex are excluded from the survey. If a large enough sample size cannot be obtained in the community, it is supplemented from sex workers who have newly entered the reeducation center (arrested in the past month). Sex workers in re-education centers should not account for more than one third of the total sample size.

Long distance truck drivers are defined as men who during the last 3 months drove trucks carrying goods outside of their hometown for at least 24 hours or more in one trip. Truck drivers were identified for participation by survey staff handing out pamphlets and going among truck drivers to recruit.

\section{Strengths of comprehensive surveillance}

In addition to HIV and syphilis testing, comprehensive surveillance collects detailed information on behavioral risks, knowledge and attitudes, and access to interventions. For the most part, the indicators have time reference periods and the language and partner definitions are clear, making interpretation of the data as well as measurements of trends over time and comparisons across sites, provinces and countries more accurate. While only one round of comprehensive surveillance data has been collected to date, it is intended to be a routinely collected source of information.

\section{Limitations of comprehensive surveillance}

While comprehensive surveillance is designed to be a community-based sample, it does not use a probability-based sampling methodology. Use of snowball referral methods which are then supplemented by facility-based sampling decrease the capacity for externally valid (representative) measurements which can be replicated in order to measure changes in prevalence and behavioral risks. The number of sites included in comprehensive surveillance is also limited, encompassing only three highrisk populations, though three additional sites will be added in 2006.

\subsubsection{National Epidemiological Survey}

In order to implement the China five-year action place (2001-2005), the Ministry of Health decreed that a National Epidemiological Survey should be implemented among selected populations. 
The survey, conducted in September 2003, included HIV prevalence and a short behavioral questionnaire, and it will not be repeated. The National Epidemiological Survey protocol and tools were developed by the National Center for AIDS/STD Prevention and Control (NCAIDS) under the guidance of the Ministry of Health. Survey populations included sex workers in Beihai and Guilin, drug users in Beihai and Liuzhou, and hospital patients in Nanning. The selection of populations and geographic areas for the survey was made by China CDC based on an analysis of the epidemic and a literature review.

\section{Population definitions and sampling methodology}

Drug users included all male and female drug users, both injectors and non-injectors. The sample size was 300 in each site, and sampling was done in the Baise, Beihai, and Liuzhou detoxifications centers as well as through stratified random sampling combined with purposive sampling in the community.

Sex workers were women who sold sex in Beihai and Guilin. The sample size was 300 in each site, and sampling was done using stratified random sampling in the community, combined with purposive sampling, from saunas, nightclubs, karaoke, ballrooms, baths, hotels, foot and hand washing venues, barbers, and from the streets.

Hospital patients were male and female in- and out- patients from general medicine, internal medicine, gynecology, pediatrics, infectious diseases and other departments. Blood was drawn and tested from those patients who presented with non-HIV related illnesses. The sample size was 2,000 and was conducted in Nanning only at the Guangxi Medical University (provincial hospital), Yongning County People's Hospital (county hospital), and Nanning Municipal Red Cross Hospital (city hospital).

\section{Strengths of the National Epidemiological Survey}

The National Epidemiological Survey provided an opportunity to collect data on populations and geographic areas not already included in other surveillance components. The data on hospital patients with non-HIV-related illnesses also provides valuable information on HIV prevalence among general population members who do not present at the site for reasons related to having unprotected sex, unlike STD clinic attendees and pregnant women.

\section{Limitations of the National Epidemiological Survey}

While the surveys included community-based sampling strategies, all sampling was done purposively and does not provide data that can be used to statistically track trends over time. Like the sentinel surveillance surveys, the sample frame included both injecting and non-injecting drug users, thus limiting the ability to accurately 
analyze changes in prevalence and risk behaviors in the different groups. In addition, because sampling was mixed between facilities and the community, potential biases that would have resulted from the methods are difficult to measure. Finally, the surveys will not be repeated.

\subsubsection{Provincial Behavioral Surveillance Surveys}

The first round of Guangxi Provincial Behavioral Surveillance Surveys (BSS) was conducted in 2000, and a second round was conducted in 2005. The surveys included a medium-length questionnaire (though shorter than that of comprehensive surveillance) with no biomarkers. Provincial BSS is part of the Health 9 Project, funded through a World Bank loan. The project was to end in 2005, but has now been extended to 2008 .

There are six target populations in BSS: injection drug users (18 counties), sex workers (20 counties), long distance truck drivers (4 counties), migrant men (4 counties), miners (1 county), and students (1 county).

Data are collected between May and August, and if a sentinel surveillance survey is planned for the same population and site, data collection for the two surveys may be done concurrently. The results of Provincial BSS are reported aggregated by population and not by individual counties/cities. The data can be analyzed by county, but because the sample size is quite small in some sites, disaggregated analysis can provide results with very wide confidence intervals.

\section{Population definitions and sampling methodology}

Injecting drug users are male and female injection drug users. According to the protocol, all non-injectors were to be screened out of the survey; however some counties did recruit drug users who were non-injectors. There was no mandatory sample size, and the sample size for drug users ranged from 16-299 per site in 2000. Sampling took place in both detoxification centers and communities, and the sampling methodology varied by site (in communities snowball sampling was used).

Sex workers are women who sell sex for money. Sex workers were identified by the place where they work including hotels, guest rooms, saunas baths, barbershops, small restaurants and the street. There was no mandatory sample size, and the sample size for sex workers ranged from 20-220 per site in 2000 .

Women were initially screened by data collection staff in order to recruit only those women selling sex, however if the staff thought that the women were sex workers they would be recruited even if they did not admit it during the screening process. The national BSS protocol recommends data collection among sex workers only in reeducation centers. However, there are only two such centers in Guangxi Province, so 
most sampling was done in the community. Sampling was sometimes done by stratifying and sample selection by different types of entertainment venues, but as in the case of injection drug users sampling methods differed between sites.

Long distance truck drivers included men who drove at least one full day in a single route in the last three months. They were recruited from Guigang, Liuzhou, Luchuan and Nanning counties with a total sample size of 734 in 2000 (ranging from 100-245 per site). Non-probability sampling methods were used to sample long distance truck drivers, but no specifics were available regarding the precise methods.

Migrant populations were, for the most part, male construction workers. However a few female construction workers were also recruited. They were sampled from Baise, Guilin and Wuzhou counties with a total sample size of 700 in 2000 (ranging from 222-250 per site). Non-probability sampling methods were used to sample construction workers, but no specifics were available regarding the precise methods.

Miners were male coal miners who worked in pits in Nandan. Either they were single or their families were not living in the same site as them. The sample size of miners was 254 in 2000. Non-probability sampling methods were used, but no specifics were available regarding the precise methods.

Students were young males and females studying at six universities, professional schools and colleges in Nanning. The sample size was 3,014 over all six sites. Sampling was done by selecting individual classes as clusters and then surveying all students in each selected class.

\section{Strengths of Provincial BSS}

The Provincial BSS includes a pre-surveillance assessment, unlike the other components of the Guangxi surveillance system, which is important for improving the understanding of the survey populations and designing strong sampling methods. The questionnaire of the Provincial BSS is also more expansive then that of sentinel surveillance and the National Epidemiological Survey (although shorter than the comprehensive surveillance and does not include access to intervention questions).

\section{Limitations of Provincial BSS}

A great deal of data are collected from the pre-surveillance assessment-sometimes with duplicated questions across the various forms - and it is not clear how the information is used or if it poses an undue burden on the survey staff. Many of the revised questions in the Provincial BSS are unique to this surveillance component and cannot be compared across surveys. Because there is no fixed sample size for these surveys, some sites have only a small number of participants and the data must be aggregated for analysis. In addition, the sampling methodology varies between sites 
and these variations are not well-documented, diminishing the ability to interpret the data and conduct statistically accurate analyses.

\subsubsection{HIV and AIDS case reporting}

The Guangxi provincial HIV and AIDS case reporting system has evolved and been substantially enhanced over time. It is currently conducted using an innovative intranet-based system that uses nationally standardized and systematic reporting procedures and data elements for HIV and AIDS case reporting and AIDS-related outcomes and deaths reporting.

Initial Phase: 1986 - 2001

The initial HIV and AIDS case reporting system started in 1986 and the first HIV case was detected in 1989. The system was designed by National CDC in Beijing and the data flow of all case reports was managed in the following manner from township to the provincial level: Local townships $\rightarrow$ county level $\rightarrow$ prefecture level $\rightarrow$ provincial level (Guangxi CDC) $\rightarrow$ national level. During this time period there was not a specifically designated division or unit to manage and coordinate HIV/AIDS related case reporting and all notifiable infectious disease reporting was centralized in the Department of Virology. As a result, there were only a couple of computers in the Department with only one data manager in charge of all tasks related to infectious disease surveillance. During this time, the HIV and AIDS case reporting system had the following reporting elements:

- A limitation of this reporting method was that unless AIDS was specifically written into an open-ended narrative field or highlighted on the HIV case report line listing described above it may not have been recorded. Due to this and the novelty of reporting a relatively new virus, it is believed that AIDS cases were substantially under-reported during this time period.

- The HIV case ID number was not systematically collected as well, which hampered follow-up AIDS reporting. If this was recorded, then the staff at the Provincial CDC would actively follow-up with the reporting source to make sure that all the details were completed as accurately as possible. The AIDS case report form did not contain the HIV case report, and no electronic records of AIDS cases were maintained at the Provincial Office.

AIDS-related deaths case report form: Reports were sent from the county and provincial levels to the Provincial CDC office in Nanning on a separate form for AIDS deaths. The report form included the following variables: HIV case ID number, AIDS case ID number, gender, age, date of first HIV+ laboratory result, date of death, cause of death, HIV case IDNO, year reported HIV+, organization name and location, and date. Reporting was done to the provincial office via a paper-based method and 
the forms were subsequently faxed, posted, hand-delivered or sent via email. These forms were then entered into Excel spreadsheets and the print-outs sent to the national CDC office in Beijing on a quarterly basis.

\section{The Second Phase: $2001-2004$}

In 2001, the Guangxi Center for HIV/AIDS Prevention and Control was officially designated as a separate division of the Provincial CDC Office. The major structural change made to the case reporting system during this phase was that a new computerized reporting system was introduced using a nationally standardized database file structure for HIV, AIDS, and AIDS-related death reporting. While a paper-based system was still being implemented for the reporting of cases to the Provincial CDC from the county and prefecture levels, provincial staff now began inputting these hardcopy reports using dBase software and sending them via email to the national level. This greatly improved data management at the provincial and the national level. However, two major limitations remained: 1) The fact that the paperbased forms were still being sent to the provincial-level for data entry created a huge burden on the provincial staff despite its slightly increased staff size, and 2) the unencrypted emailing of sensitive data to the national-level was not an ideal mechanism because personal identifiers were being reported for AIDS cases. During this time, minor modifications were also made to the case reporting system.

\section{Third Phase: 2005 to present}

The current phase of the case reporting system was introduced in April 2005 and entailed a major overhaul of the existing format, policies and procedures. The National CDC instituted a web-based intranet system for the reporting of all mandatory infectious and non-infectious diseases and health conditions including HIV and AIDS case reporting. This also represents the first time that personal identifiers have been systematically used for HIV and AIDS case reporting.

Under this format, health institutions (hospital, health centers, clinics, etc.), local CDC offices (both at the county and provincial level), and blood collection and provision organizations were required to enter case report data directly into a webbased system that can only be accessed by authorized personnel using the designated site-specific user names and passwords. Designated users can only access intranetbased case report records at their structural level (institution, county or prefecture), and provincial CDC staff are the only ones who can access all reported data.

This system was designed to alleviate the enormous burden of case report data entry at the provincial level, but hard-copy report forms and blood samples are still sent to the CDC Provincial Office in Nanning for laboratory testing validation. Provincial CDC staff review the hard-copy and electronic records for accuracy and completeness 
and then actively follow-up with local users where further information or clarification is required.

This web-based system includes the direct data input for 1,412 out of 1,482 (95.3\%) township health institutions. The remaining 70 local institutions without current intranet access send case report forms directly to the designated county CDC office for data input there. The intranet-based computer system is used for direct input covering 539 of 572 county-level institutions (94.2\%). All CDC offices throughout Guangxi province are covered under this reporting system, but facilities without intranet access send paper-based forms to their designated county CDC office where they are subsequently entered.

With the introduction of the intranet-based reporting system based on unique identifiers, a single comprehensive reporting form was devised for the reporting of HIV cases, AIDS cases, and AIDS-related outcomes. The concept is that the data entry screen used to report HIV cases is also linked for the subsequent update of data related to the diagnosis of AIDS and AIDS-related outcomes over time. In this way, instead of entering discrete case reports for HIV, AIDS and AIDS-related deaths, records for each HIV-identified individual are all linked longitudinally and kept in the same overall record. One of the sections of this overall form includes an AIDS-related follow-up that is intended to be updated every six months.

The number of variables contained in the comprehensive case report system was also greatly expanded. For each of these case report forms certain fields are designated as mandatory and others are voluntary (to be entered assuming that data are available).

\section{Strengths of HIV and AIDS case reporting}

The current intranet-based reporting system is a hugely ambitious undertaking, is state-of-the-art in principle, and has advantages over previous versions of the system, including the following:

- All case report forms have personal identifiers on them (full name and national registration ID number). As a result, the system can avoid duplicated data entry because if a record has already been entered it will turn up and the intranet system will be notified that it is already in the system.

- Updating of AIDS-related illnesses/outcomes and deaths is done by revising the current records in the intranet-based system. In this way, each record represents an individual who is tracked longitudinally over the course of his/her HIV diagnosis.

- The intranet-based reporting system allows for data entry at the local level, which alleviates the burden on the provincial CDC office.

- Case reporting to the national-level is now automated, and designated staff at the national CDC can automatically access all case report data in the country. 
- More complete data are available in a nationally standardized way than in previous versions of the system. A short survey of high-risk behavior is included as well.

- Data review, editing and basic analysis can now be performed at the local level by staff in the county and prefecture offices. This allows for greater data use and dissemination locally. In the past, hardcopy records were simply forwarded to the provincial CDC office and never used or analyzed systematically. At the same time, the provincial CDC office lacked the human resources to provide feedback to the lower reporting levels in a routinized manner.

\section{Limitations of HIV and AIDS case reporting}

- There are still many technical issues that are currently being dealt with in regard to the intranet-based case reporting system. While an overview of the system was provided by the national CDC to key staff in the provincial CDC office, a lot of training and communication is required to address queries from the multitude of reporting institutions throughout the province.

- The provincial CDC office is struggling to keep up with the demand despite having recently hired a dedicated staff person for follow-up related to this system. There is still currently a backlog of some 20,000 case reports in Guangxi that need to be entered retrospectively. The national CDC requires that all case reports going back to 1989 are entered retroactively into the intranet-based system. This is a mammoth task and there are not adequate staff dedicated for this function and no additional funding or ancillary staff was provided by the national CDC to help with this data entry effort.

- The unique identifier is based around the national registration ID number assigned to all Chinese nationals who come in contact with government services. Allowing this number to serve as a key variable helps avoid case report data entry duplication and update HIV and AIDS-related information longitudinally over time. However, this ID number is not always available at the time of registration (and, hence, is not a required data entry variable). In this case, triangulating duplicate cases or records for updating reports using the person's full name and other identifying information is more complex due to the potential for differences in spelling and other issues.

- Private clinics have not been included in the case reporting network because they do not have HIV testing capacity or certification. However, it is believed that persons fearing stigma and discrimination upon contact with government services often access private clinics and health care providers for health-related concerns. These individuals are likely to be under-reported in the current system. Therefore the inclusion of private health facilities should be considered.

- While national case reporting protocols recommend that county-level CDC offices actively contact institutions that do HIV testing to remind them to 
report identified cases this is believed not to occur in many settings because of the multitude of competing responsibilities and activities. Active case finding should be increased.

- In the same way, the provincial CDC office should be actively following up with reporting institutions to ensure that accurate and complete case report data are collected. However, due to staff shortages this activity has been difficult to conduct systematically.

- The instructions for completing intranet-based data entry are not always clear and the category 'target population' has raised difficulties because the category options are not mutually exclusive yet only one answer choice is required.

- The current system requires follow-up of persons diagnosed with AIDS every six months for longitudinal data entry of AIDS-related outcomes and deaths. This appears to be an overly-ambitious reporting requirement given its complexity, particularly for PLWHA not enrolled in ART programs. It is felt that many PLWHA will not want to be followed up repeatedly and will avoid contact with reporting institutions as a result.

- There has been a strongly expressed desire at the provincial and local levels for further capacity-building related to data management, analysis and use.

\subsubsection{HIV mass screening}

The first round of the national HIV Mass Screening Project in Guangxi began in 2004 and finished in August 2005. Screening mainly included prisoners in jail and lawbreakers in labor education units, and blood donors. It is unlikely that the mass screening activity will be repeated. Instead, it will be mandatory for all persons newly entering the centers to be tested and reported to the HIV and AIDS case reporting system (see above).

\subsubsection{Size estimates of high-risk populations and persons living with HIV}

Size estimates of high-risk populations are calculated by each prefecture which then reports them to the Guangxi CDC. The Guangxi CDC then calculates the estimated number of PLWHA using the revised 2005 WHO/UNAIDS Workbook methodology. ${ }^{2}$ These estimates are then provided to China CDC for their use in calculating the national estimates of persons living with HIV.

\subsubsection{STD case reporting system}

The STD case reporting in Guangxi province started in 1982. Currently, there are eight STDs that are considered mandatory for reporting to the China CDC including HIV, syphilis, gonorrhea, chancroid, lymphogranuloma venereum (LGV), condylomata accuminata (genital warts), non-gonococcal urethritis (NGU) and genital herpes. 
At public and private local institutions, the health professionals who diagnose reportable STDs are responsible for completing official STD case report forms and filing them. These report cards are then filed at the county level which subsequently sends the reports to the prefecture level on a quarterly basis. Finally, the STD case reports are reported to the Guangxi STD Center in Nanning. Here, the hard-copy STD case report forms are filed and entered into an electronic database using dBase software and then forwarded to the National STD Center which, for historical reasons, has not been centralized within the Ministry of Health in Beijing and is based in Nanjing, the capital city of Jiangsu province.

The introduction of a national web-based intranet disease and health event reporting system by CDC in 2005 included STD reporting, and in this sense there are currently two parallel STD reporting systems. However, in this web-based reporting system only six of the eight reportable STDs listed captured in the long-standing reporting system above are covered — chancroid and LGV are not. Under the web-based system, clinics, institutions, and CDC offices at all levels are required to directly input case reports directly into the web-based system (as was described for HIV and AIDS case reporting) and the hard-copy report forms forwarded to the Guangxi STD Center in Nanning as described above. The Guangxi STD Center can only access STD case report data from Nanning city and this is currently under review at the national level.

HIV or AIDS cases picked up by the STD case reporting system are also required to be reported separately into the web-based HIV and AIDS case reporting system. In this case, blood samples are required to be sent to the provincial CDC office for confirmation as well. However, HIV cases picked up by the HIV and AIDS reporting system appear to be rarely transferred to the STD case reporting system. This is also complicated because it would only make sense to do this for HIV cases for which the suspected route of transmission is sexual.

Syphilis cases identified via sentinel surveillance activities are all required for transfer into the STD case reporting system. Indeed, the proportion of syphilis cases out of the overall STD case reports in Guangxi is apparently substantially higher than the national average and one reason for this may be a detection bias related to the syphilis case reports being picked up via syphilis sentinel surveillance. The Guangxi STD Center is planning to conduct a special study to investigate this during 2006. 


\section{Chapter 3: The HIV Epidemic Situation in Guangxi}

\subsection{Growth and Evolution of the HIV Epidemic in Guangxi}

Since the first HIV case was detected in a foreign student in 1989, the HIV epidemic in Guangxi has evolved through three distinct phases, as defined by the Guangxi Center for Disease Control and Prevention (CDC).

The sporadic period (1989-1995)

During this seven year period, only ten HIV cases were reported, all of whom were foreign students or business persons from other provinces. No HIV infections were found among Guangxi residents during this period.

\section{The epidemic period (1996-1997)}

In 1996, the first HIV case in a Guangxi resident, an injecting drug user (IDU) in Pingxiang City on the border with Vietnam, was reported. ${ }^{3}$ In total, 44 HIV cases were reported in 1996, and this figure increased nearly four-fold to 195 cases during 1997. Many of the initial cases among Guangxi residents were paid blood donors who sold their blood in other provinces, and HIV infections were identified in 25 counties and cities. Over 95\% of reported HIV infections identified in Guangxi in 1997 were identified among IDUs.

During this period, localized outbreaks of HIV were reported among IDUs from two main areas of Guangxi Province, Baise City bordering Yunnan Province and Pingxiang City bordering northern Vietnam. Studies have shown that both of these cities are key regional transit areas for heroin export from the "Golden Triangle" areas of Myanmar and Laos to Hong Kong and then onto countries in the west. Heroin transported by road from Yunnan, where IDU-related HIV cases were first reported, must pass through the Baise city on the Yunnan-Guangxi border. The other major route of heroin trafficking into Guangxi is from Myanmar and Laos to northern Vietnam and then across the China-Vietnam border. ${ }^{4,5}$

The generalized spread period (1998 - present)

Over a six year time period, the annual number of reported HIV cases in Guangxi increased exponentially-from 530 cases in 1998 to 8,625 in 2005 (Figure 3). With the recent increases in population movement driven by the emerging market economy, improved transportation infrastructures and rapid urbanization, the reach of HIV has grown and HIV had been reported in 88 of Guangxi's 90 counties/cities as of 2004. Figure 5 shows the progressive and rapid spread of reported HIV cases from 1996 to 
2004 throughout the various counties of Guangxi - both in terms of geographical spread and increasing case burden. In the south the epidemic had spread along the major transportation routes from the Vietnamese border to Pingxiang, Ningming, and Fusui to Nanning. In the western region of Guangxi, the epidemic has spread from Longlin, Baise, Tianyang, and Tiandong to Nanning. Currently, the province has the third highest cumulative number of reported HIV infections in all China and the third highest estimated cumulative HIV prevalence (Figure 4). ${ }^{6}$

Figure 3: No. of reported HIV and AIDS cases by year, Guangxi

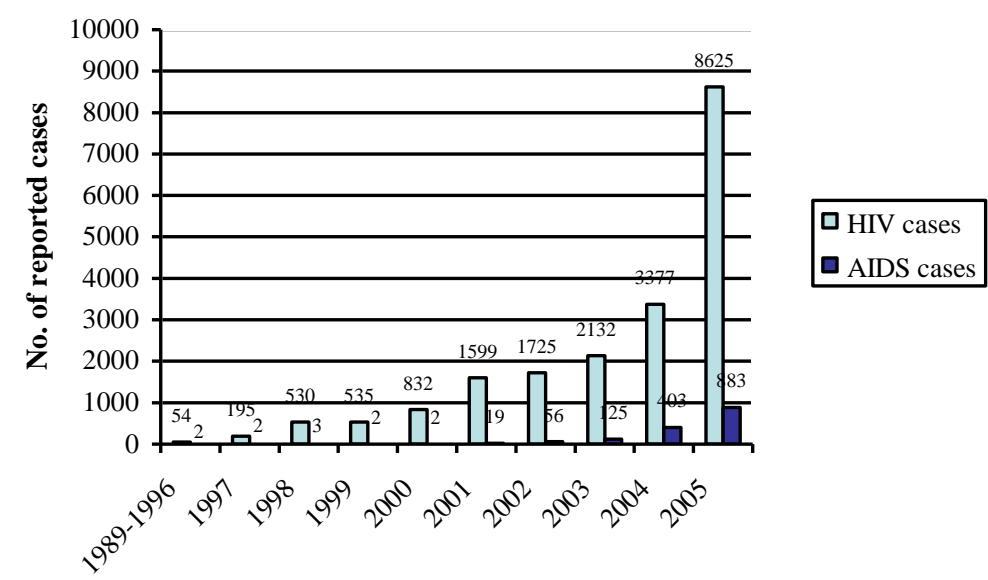

The cumulative total of 19,604 HIV cases reported through 2005 is a vast underestimate of the actual number of HIV cases in Guangxi province. The Guangxi Consultative Committee for AIDS Prevention and Control using the UNAIDS/WHO Workbook method ${ }^{2}$ estimated that there were roughly 50,000-105,000 persons living with HIV in the province during 2005 alone. A study in Gansu province found that the ratio of reported to detected cases was about $1:$. $^{7}$

Figure 4: The HIV epidemic situation in China, September 2004

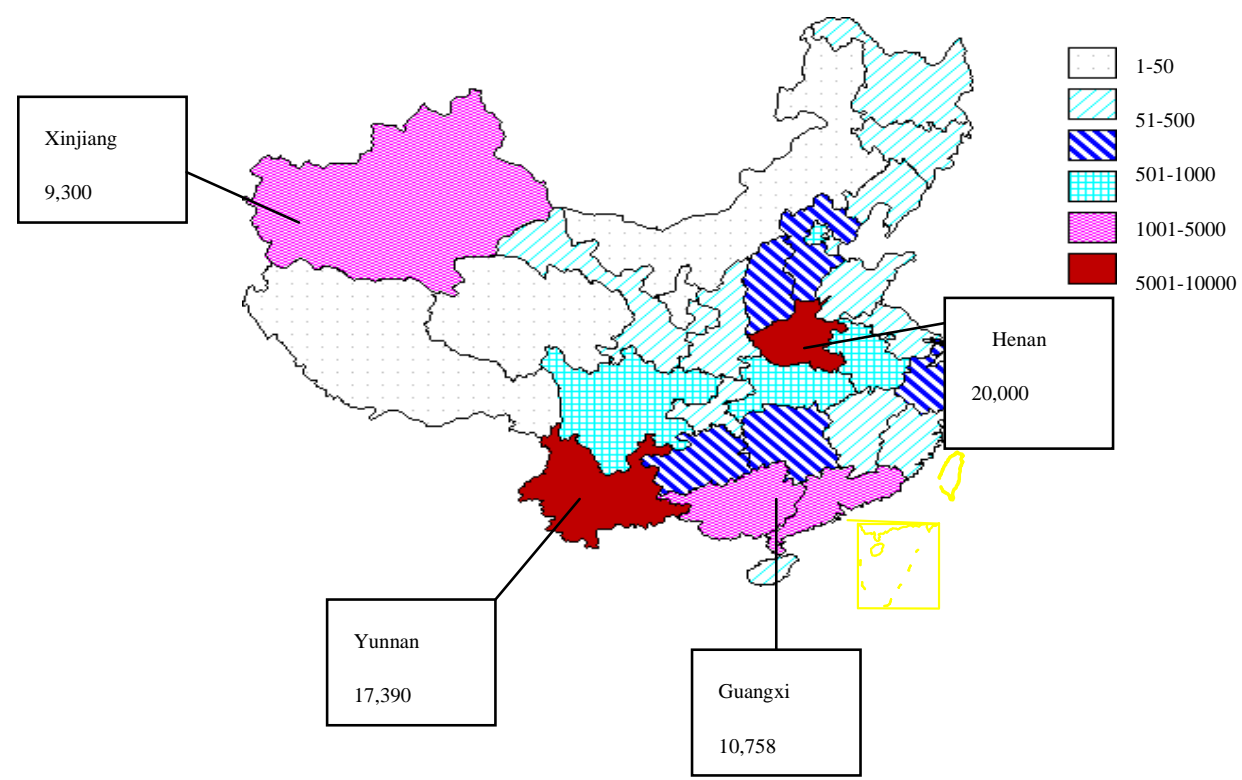


Figure 5: Geographical distribution of reported HIV cases in Guangxi, 1996-2004
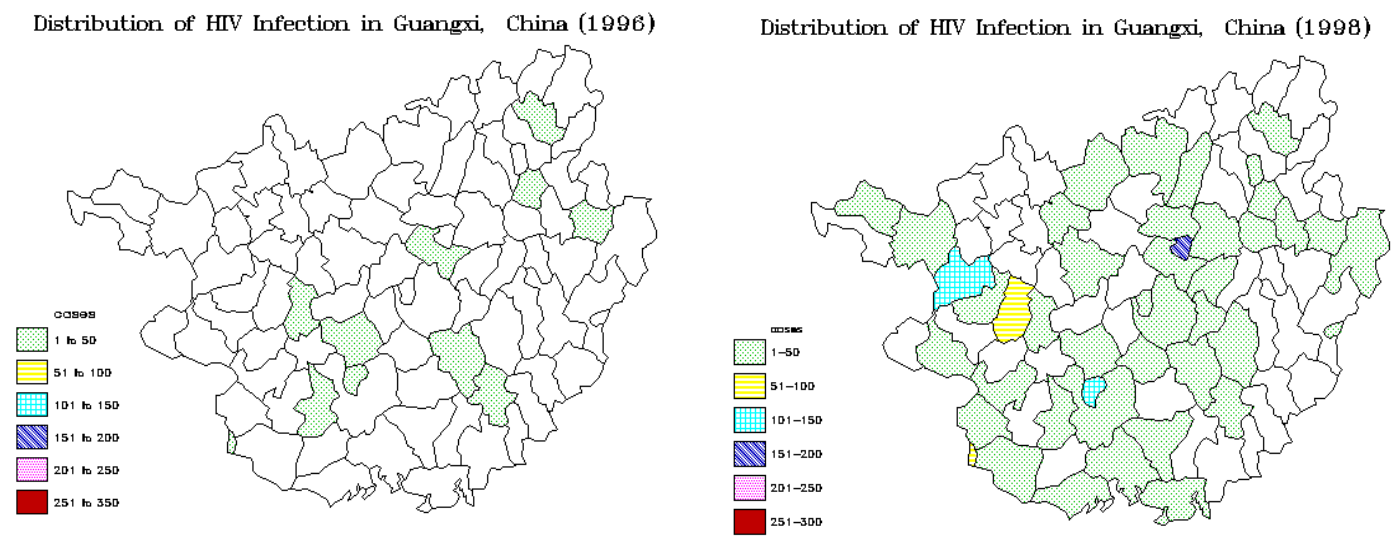

Distribution of HIV Infection in Guangxi, China (2000)

Distribution of HIV Infection in Guangxi, China (2002)
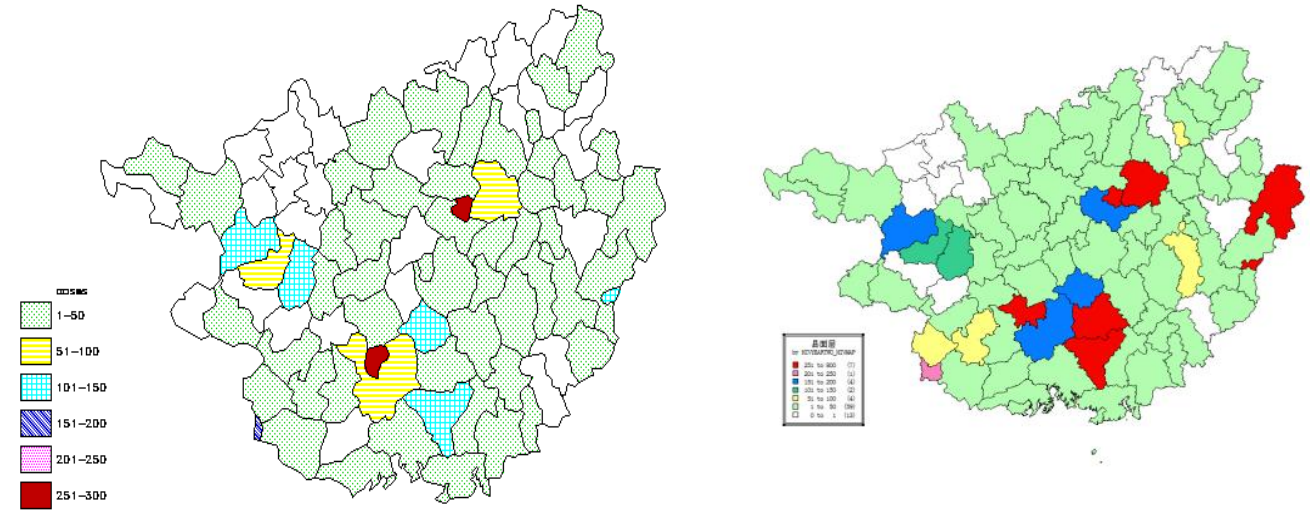

Distribution of HIV Infection in Guangxi, China (2004)

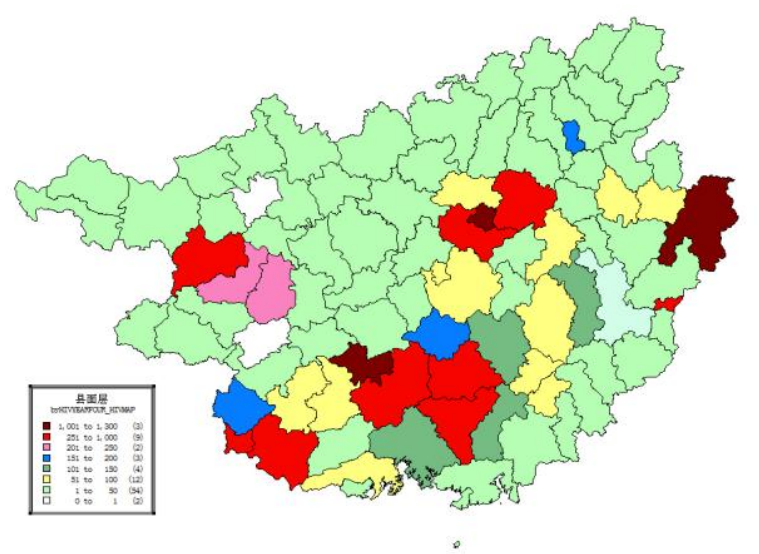

Only 2-3 cases of AIDS were reported annually in Guangxi until 2001 when 19 cases were reported (Figure 3). This is not surprising given that the time-lag between HIV seroconversion and AIDS diagnosis is estimated to be approximately nine years. ${ }^{8}$ 
Since 2001, the number of reported AIDS cases in the province has roughly doubled every year reaching 883 in 2005 . While the actual number of reported AIDS cases is also vastly under-reported, the exponentially increasing trend in reported cases is now keeping pace with the earlier HIV case reports. It is expected that the number of AIDS cases will increase dramatically in the near future meaning that it is crucial that care and treatment services are rapidly scaled-up in the province.

Table 3 shows the HIV prevalence in each of Guangxi's prefectures based on HIV case reported in 2004 and adjusted for adult population sizes. Note that while these prefecture-specific HIV prevalence rates are vastly underestimated they help show the relative burden of HIV in each of prefectures. As with the county-level geographic analysis in Figure 5, this table shows widespread geographic distribution with no specific geographic clustering except that north-central region of Guangxi which is relatively unaffected. This is probably because this region is not on any major drugtrafficking transportation route.

Table 3: HIV prevalence by prefecture based on HIV cases reports in 2004, Guangxi

\begin{tabular}{llll}
\hline Prefecture & $\begin{array}{l}\text { No. of reported HIV } \\
\text { cases in 2004 }\end{array}$ & $\begin{array}{l}\text { Size of adult (15-49 } \\
\text { years) population }\end{array}$ & HIV prevalence (\%) \\
\hline Liuzhou & 2417 & $1,949,785$ & $0.12 \%$ \\
Hezhou & 1196 & $1,307,702$ & $0.09 \%$ \\
Chongzuo & 942 & $1,162,444$ & $0.08 \%$ \\
Wuzhou & 696 & $1,048,120$ & $0.07 \%$ \\
Qinzhou & 924 & $1,232,845$ & $0.07 \%$ \\
Nanning & 1883 & $3,464,995$ & $0.05 \%$ \\
Baise & 938 & $2,102,286$ & $0.04 \%$ \\
Fangchenggang & 128 & 480,157 & $0.03 \%$ \\
Beihai & 55 & 236,551 & $0.02 \%$ \\
Liabin & 264 & $1,262,437$ & $0.02 \%$ \\
Guigang & 337 & $2,204,563$ & $0.02 \%$ \\
Yulin & 198 & $2,737,789$ & $0.01 \%$ \\
Hechi & 190 & $2,160,592$ & $0.01 \%$ \\
Guilin & 332 & $3,377,588$ & $0.01 \%$ \\
\hline Guangxi Province & $\mathbf{1 0 , 5 0 0}$ & $\mathbf{2 4 , 7 2 6 , 8 5 4}$ & $\mathbf{0 . 0 4 \%}$ \\
\hline
\end{tabular}

Table 4 shows that reported HIV cases in Guangxi only represented $0.3 \%$ of reported cases in China during 1989-1995 when HIV was first being introduced into Guangxi during the early phase of the epidemic. During 1996-1998, the proportion of HIV cases reported in Guangxi increased rapidly from $1.7 \%$ to $16 \%$ as the epidemic gained a foothold in the province. The proportion of national cases reported from Guangxi decreased below $10 \%$ only in 2004 as HIV cases are now being reported more widely from other provinces throughout China as the virus is being spread throughout the country.

HIV cases have been detected among diverse populations including female sex workers (FSWs), sexually transmitted disease (STD) clinic attendees, voluntary counseling and testing (VCT) clients, hospital inpatients, sailors, paid and unpaid blood donors and mobile populations (both persons coming from other provinces and 
local residents traveling to other provinces). While injecting drug use has been the predominant mode of HIV transmission in Guangxi since 1997, the proportion of reported HIV cases attributable to sexual transmission has also been increasing since 2000 (Figure 6). Sexual transmission is probably underestimated because it is mainly being captured through the category "other/unknown" due to the stigma associated with this transmission mode. This hypothesis is supported by the fact that the proportion of cases in the "other/unknown" category has increased dramatically in recent years

Table 4: Reported HIV cases in Guangxi as a proportion of the number of HIV tests conducted and as a proportion of reported HIV cases in China, 1989-2005.

\begin{tabular}{|l|l|l|l|l|l|l|l|l|l|l|l|}
\hline Year & $\begin{array}{l}\mathbf{1 9 8 9}- \\
\mathbf{1 9 9 5}\end{array}$ & $\mathbf{1 9 9 6}$ & $\mathbf{1 9 9 7}$ & $\mathbf{1 9 9 8}$ & $\mathbf{1 9 9 9}$ & $\mathbf{2 0 0 0}$ & $\mathbf{2 0 0 1}$ & $\mathbf{2 0 0 2}$ & $\mathbf{2 0 0 3}$ & $\mathbf{2 0 0 4}$ & $\mathbf{2 0 0 5}$ \\
\hline $\begin{array}{l}\text { No. of HIV cases } \\
\text { reported in GX }\end{array}$ & 10 & 44 & 195 & 530 & 535 & 832 & 1,599 & 1,725 & 3,132 & 3,377 & 8,625 \\
\hline $\begin{array}{l}\text { No. of HIV cases } \\
\text { reported in China }\end{array}$ & 3,335 & 2,649 & 3,343 & 3,306 & 4,677 & 5,201 & 8,219 & 9,732 & 12,691 & 47,805 & $? ? ?$ \\
\hline $\begin{array}{l}\% \text { of HIV cases } \\
\text { reported from GX }\end{array}$ & $0.3 \%$ & $1.7 \%$ & $5.8 \%$ & $16.0 \%$ & $11.4 \%$ & $16.0 \%$ & $19.5 \%$ & $17.7 \%$ & $24.7 \%$ & $7.1 \%$ & $? ? ?$ \\
\hline
\end{tabular}

Figure 6: Changes in reported HIV transmisison modes by year, Guangxi

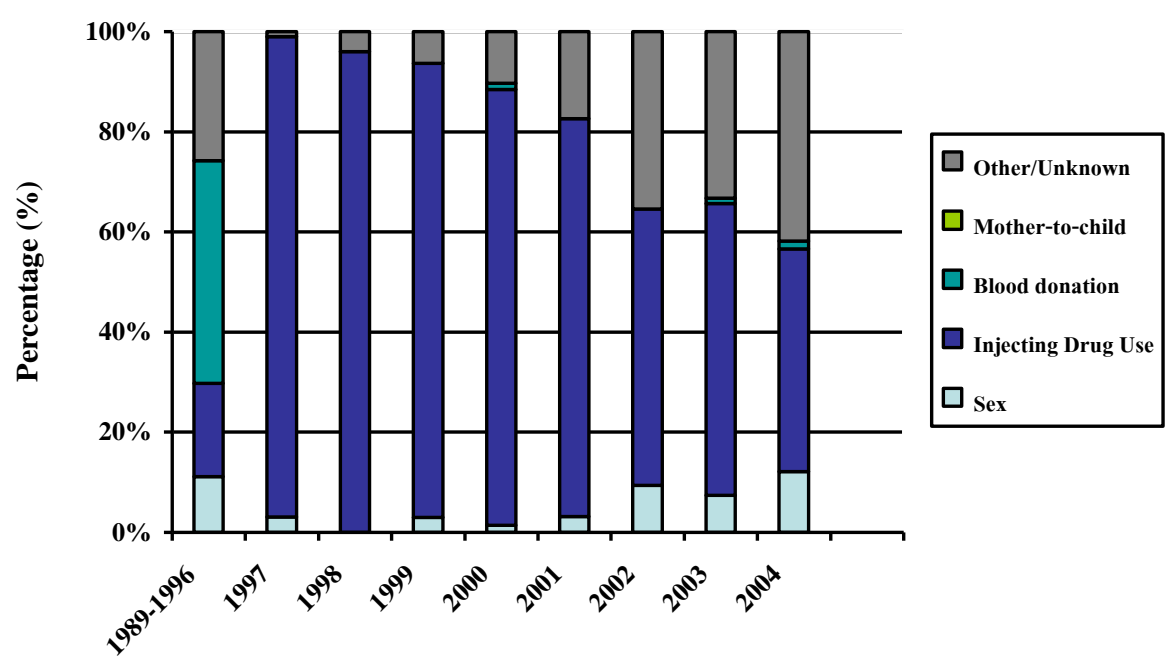

Figure 7 shows the transmission modes reported by AIDS cases during 2002-2004. These data also show that the proportion of AIDS cases transmitted sexually has increased dramatically during each of these three years from $7.1 \%$ in 2002 to $33.3 \%$ in 2004. The finding that the AIDS cases show a higher proportion of sexual transmission than the HIV cases implies that HIV case reporting may be oversampling IDUs. Indeed, according to the Guangxi CDC, most HIV case reports were derived from surveillance and testing among IDUs. AIDS case reporting is based on people who are seriously ill and is therefore usually a better indicator of past transmission. 
Figure 7: Changes in reported HIV transmission modes among AIDS cases by year, Guangxi

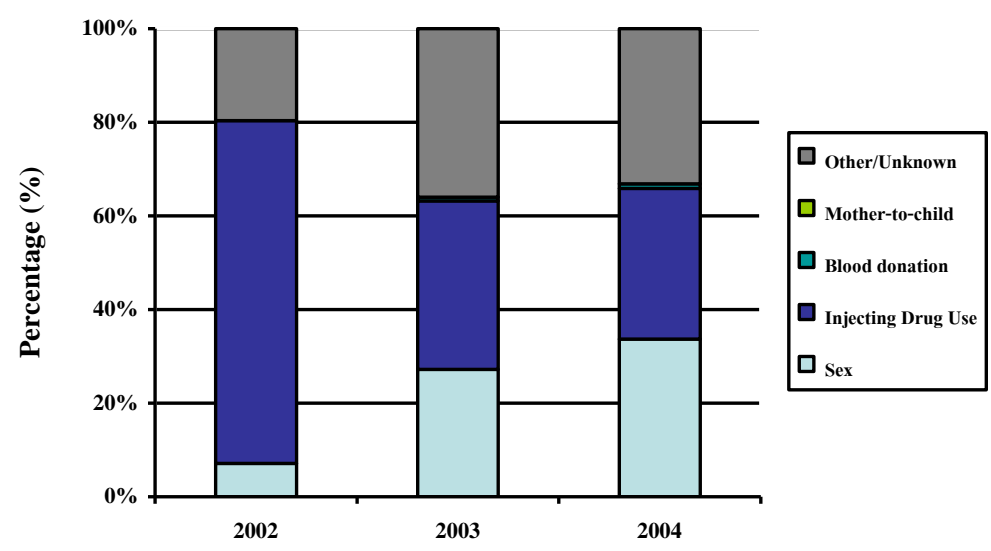

Figure 8 shows the male-to-female ratio of reported HIV cases has gradually decreased from one about 9:1 during 1989-1996 to about 3:1 (22\% female) in 2004.

Figure 8: Gender distribution of HIV cases by year, Guangxi

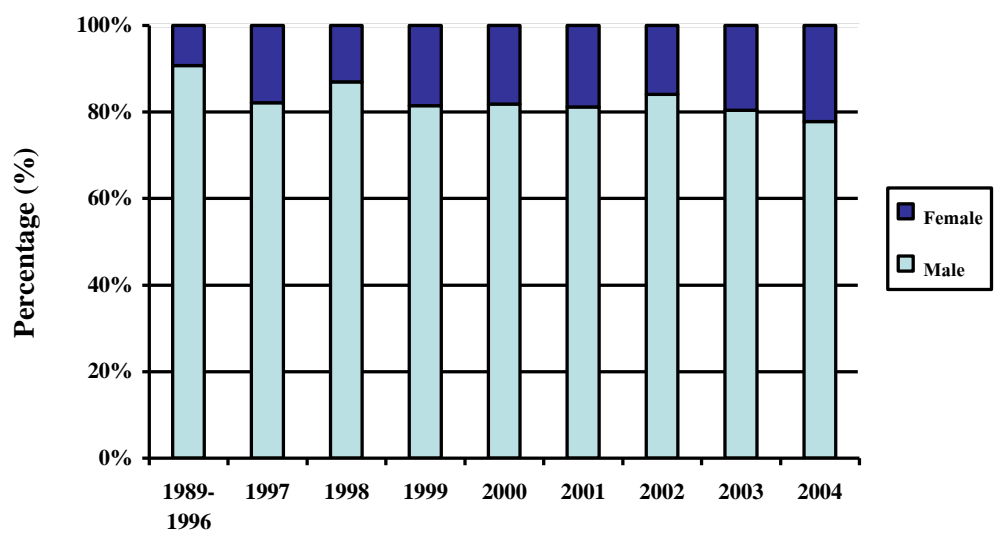

All AIDS cases through 2000 were reported exclusively among males and since 2001 the proportion of cases has increased to the point that by 2004 this ratio had decreased to around 3:1 (Figure 9). This analysis corroborates the gender distribution patterns observed among HIV cases. Collectively, the analysis of HIV and AIDS case reporting data strongly indicate that the HIV epidemic in Guangxi is evolving from an epidemic concentrated on IDUs to a broader epidemic based increasingly in sexual transmission.

The decreasing male-to-female ratio is probably related to increases in HIV infections among FSWs and an increasing number of new infections reported among the wives and girlfriends of HIV-infected men. 
Figure 9: Gender distribution of AIDS cases by year, Guangxi

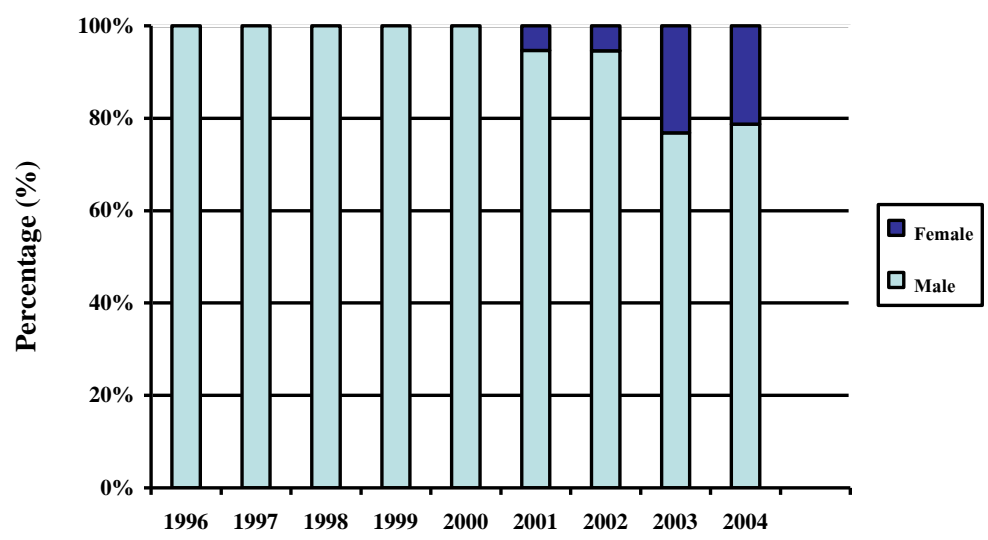

HIV cases are increasingly reporting that they got married in recent years. This also suggests that FSWs and the wives of their clients are increasingly being infected with the virus as the epidemic is becoming increasingly driven by sexual transmission (Figure 10).

Figure 10: Marriage Distribution of HIV infection in Guangxi, China

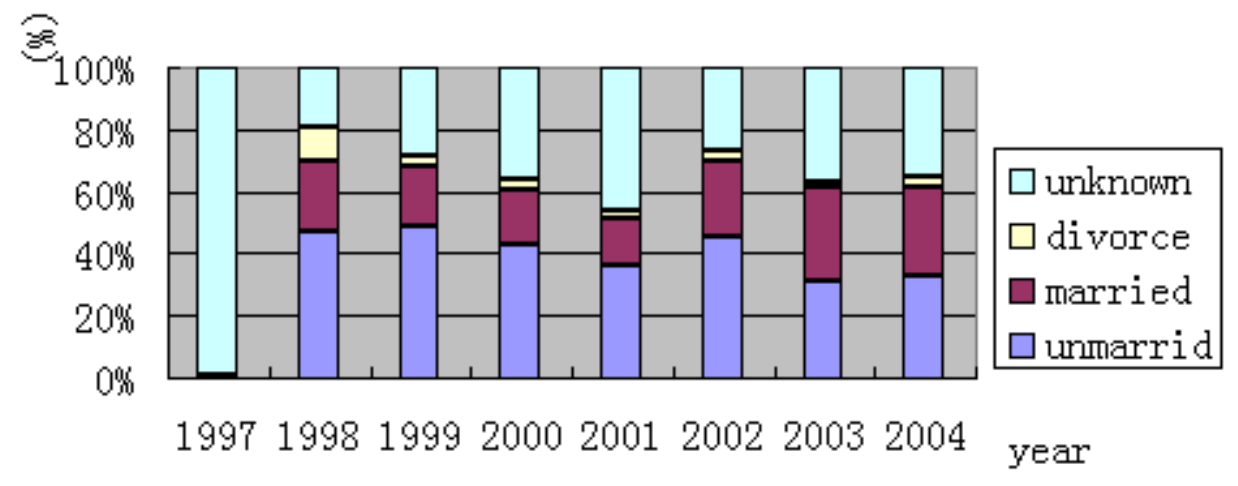

\subsection{Injecting drug users are the most affected sub-population}

As shown schematically in the map in Figure 11, Guangxi is a well-established drug transportation channel with two major routes from the 'Golden Triangle' to eastern provinces, Hong Kong and international markets. One route goes from Yunnan to Baise and Nanning and the other goes through northern Vietnam to Pingxiang and Nanning. ${ }^{5,9,10}$ 
Figure 11: Heroin trafficking routes in south-east Asia and Guangxi from the opium-growing 'golden triangle' regions in Myanmar and Laos ${ }^{10}$

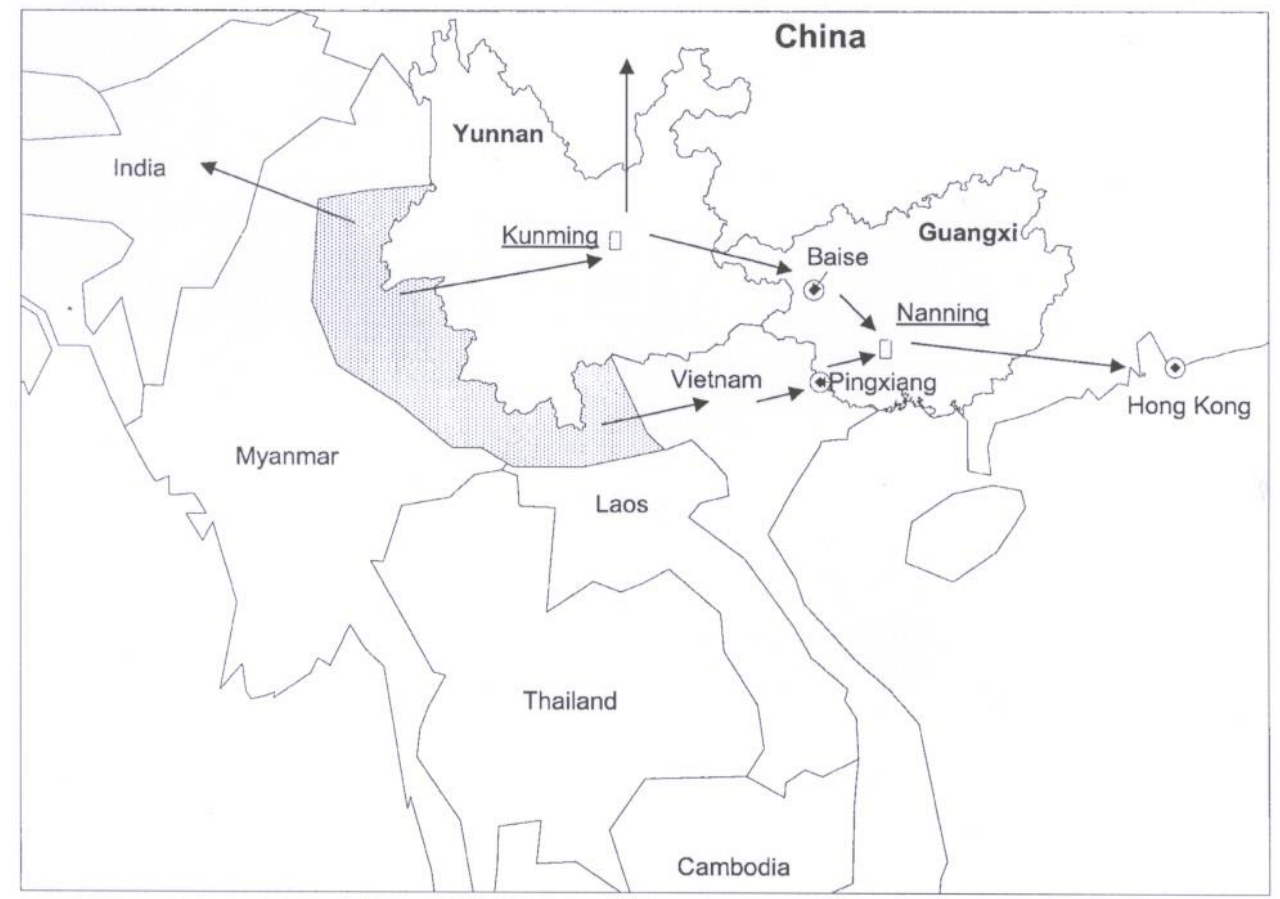

Source: Piyasirisilip et al., 2005

Since 1998 more than 2,000 kilograms of heroin have been confiscated by authorities of which $80 \%$ was supposedly bound for Guangdong and other provinces. Guangxi also has a well-established and active drug consumption market. According to the Public Security Bureau, by the end of June 2004, there were about 50,000 registered drug users in Guangxi and the rate of annual increase in new drug users was estimated to be $2 \%$. Compared with other provinces, Guangxi ranks fifth in China.

Molecular epidemiologic studies have shown that IDUs in Pingxiang and other areas around the border with Vietnam are infected with HIV-1 subtype E (CRF01_AE), and a close relationship has been established between these viruses and the increases of HIV prevalence in IDU populations. ${ }^{4,10-15}$ On the other hand, numerous reports have demonstrated that IDUs in the western cities of Baise, Tianyang, and Tiandong and the central cities of Nanning and Binyang are infected with CRF08_BC virus strains. $5,10,13,16-19$

Since the first case of HIV infection of an IDU was reported in 1996, HIV infection rates has been increasing dramatically in Guangxi. ${ }^{3,4,15,20-24}$ Increases in the rates of new HIV infections among IDUs were demonstrated directly in prospective cohort studies that can directly measure HIV incidence. In Pingxiang, HIV incidence more than doubled from 2.4 per 100 persons and year to 6.9 per 100 persons and year during 1998-1999. ${ }^{25}$ Another 12-month cohort study of IDUs in Heng County ${ }^{4}$ during

\footnotetext{
${ }^{4}$ Located in rural Nanning prefecture.
} 
2002-2003 found an HIV incidence rate of 3.1 per 100 persons and year ${ }^{26}$ which also indicates high rates of HIV transmission. A 2002 cohort study among IDUs in Sichuan province found a comparable HIV incidence of 3.17 per 100 persons and year. $^{27}$

Long-standing drug user HIV surveillance available at three sentinel sites in Guangxi shows that HIV prevalence increased rapidly, most strikingly, in Wuzhou where HIV prevalence increased steadily from $0.5 \%$ in 1998 to $48.4 \%$ in 2003 (Figure 12). The increases in HIV prevalence among drug users in Nanning and Qinzhou were less dramatic and stabilized between $10 \%$-to- $20 \%$ at both sites.

Figure 12: Trends in HIV prevalence among drug users at select sentinel sites by year, Guangxi

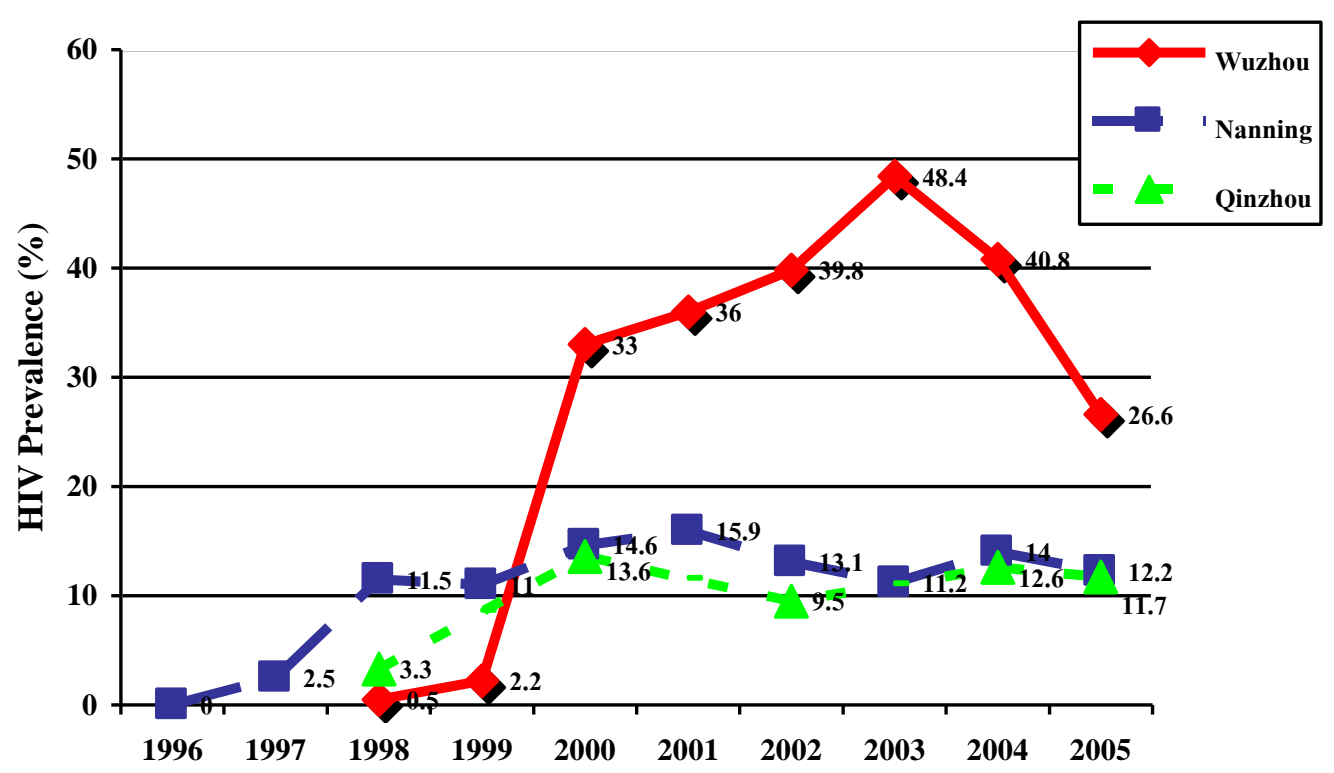

Figure 13 shows HIV prevalence trends for sentinel sites where IDU surveillance data could be disaggregated from non-injecting drug users to help reduce the bias associated with the inclusion of this much lower risk group in Figure 12. There is substantial geographical variation in HIV prevalence patterns at the sites. Surveillance trend data for IDUs before 2002 are only available at the Nanning site where HIV prevalence increased from $0 \%$ to $12.8 \%$ between 1996 and 1998 and then subsequently stabilized between $10 \%$-to- $20 \%$. HIV prevalence measured at the Ningming site has also been maintained in this range at the Ningming site after reaching a peak value of $19.7 \%$ in 2003 . HIV prevalence data from the Nandan and Guigang sentinel sites shows that IDU prevalence has stabilized at levels below $10 \%$. HIV prevalence rates greater than $50 \%$ were observed at both the Wuzhou and Longzhou sentinel sites before falling precipitously to below $30 \%$ during 2005 . Such rapid declines of this magnitude seem implausible given what is known about the 
epidemiology of HIV in this population and further exploration is needed to determine whether potential explanations may lie in changes in the surveillance populations in these areas (e.g., in- or out-migration) at these sites or in surveillance sampling procedures.

Figure 13: Trends in HIV prevalence among injecting drug users at select sites by year, Guangxi

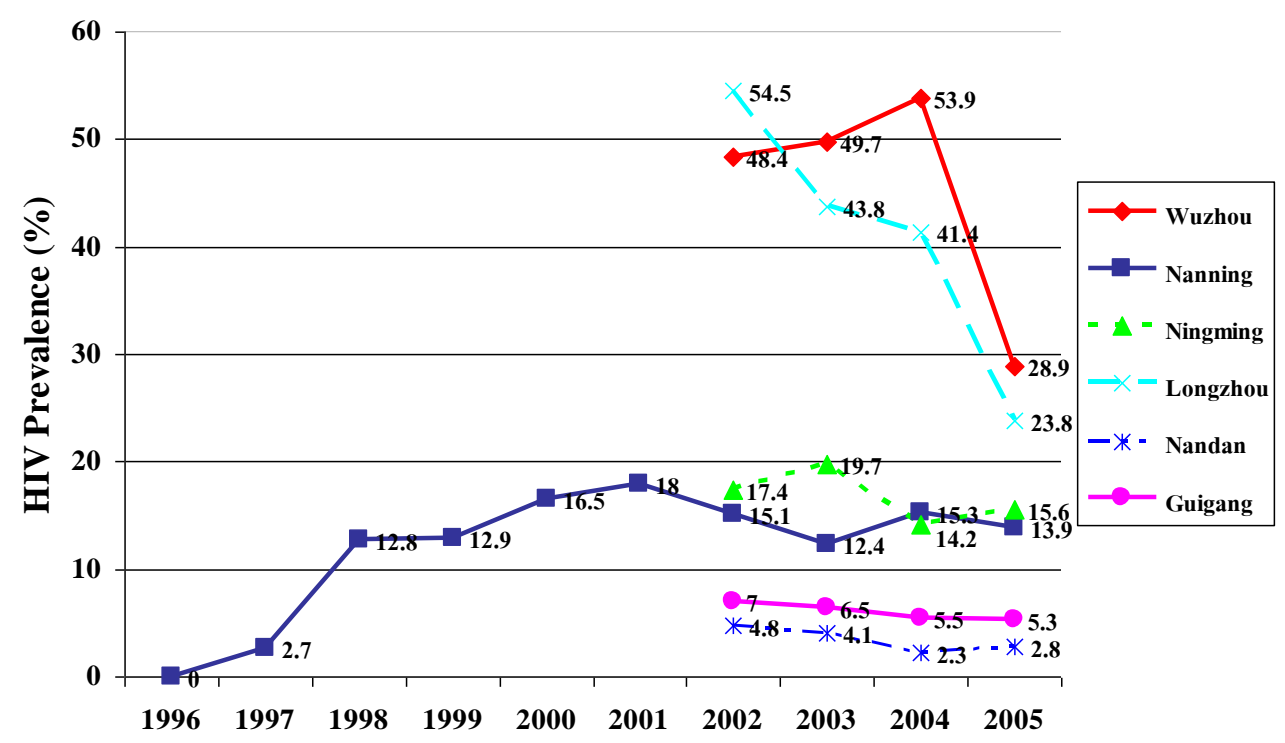

Figure 14 shows the results of an analysis of available prefecture-specific HIV sentinel surveillance data upon which prefectures were categorized as 'high' 'medium' or 'low' based on the levels of HIV prevalence observed. Prefectures in which HIV prevalence had been repeatedly measured at $>40 \%$ at some point in time were considered 'high'; prefectures for which HIV prevalence was repeatedly measured between 10-40\% were considered 'medium'; and those with rates less than $10 \%$ were considered 'low'. The results show that there is substantial geographical variation with 'high' prefectures located in the east, west and southern parts of the province which indicate that HIV transmission among IDUs is widely disseminated throughout Guangxi. Among other things, geographic differences may be explained by the timing of HIV introduction, levels of injecting frequency, needle-sharing, and the size and dynamics of IDU needle-sharing networks. ${ }^{28}$

The results presented in Table 5 show that there are high rates of HIV prevalence throughout the numerous recently added IDU sentinel surveillance sites. This is also indicative of the widespread dissemination of the virus throughout this subpopulation in Guangxi - albeit with extensive geographic variation as well. 
Figure 14: The categorization of the prefectures of Guangxi based on surveillance-based HIV prevalence data among IDUs.

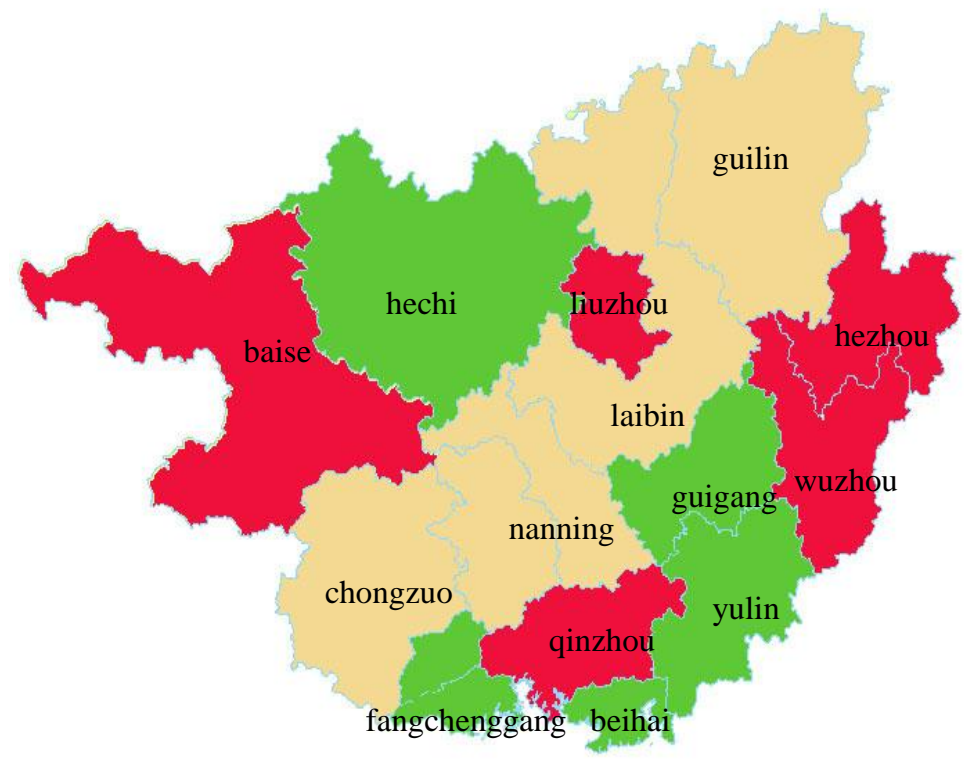

\begin{tabular}{|l|l|l|l|l|l|l|}
\hline High & $\mathbf{> 4 0 \%}$ & Baise & Liuzhou & Qinzhou & Wuzhou & Hezhou \\
\hline Middle & $\mathbf{1 5 - 4 0 \%}$ & Chongzuo & Laibing & Nanning & Guilin & \\
\hline Low & $<\mathbf{1 5}$ & Beihai & Fangchenggang & Guigang & Hechi & Yulin \\
\hline
\end{tabular}

Table 5: Most recently reported HIV prevalence among IDUs at various surveillance sites in Guangxi, 2002-2005. [will convert this table into a map if possible]

\begin{tabular}{llll}
\hline Prefecture & City/County & HIV Prevalence (\%) & $\begin{array}{l}\text { Year of most recent } \\
\text { surveillance survey }\end{array}$ \\
\hline Baise & & 2004 \\
Hezhou & Baise & $54.3 \%$ & 2005 \\
Liuzhou & Hezhou & $50.7 \%$ & 2003 \\
Liuzhou & Liuzhou & $23.5 \%$ & 2002 \\
Wuzhou & Luzhai & $57.1 \%$ & 2005 \\
Qinzhou & Wuzhou & $28.9 \%$ & 2005 \\
Qinzhou & Qinzhou & $10.7 \%$ & 2005 \\
Qinzhou & Lingshan & $74.4 \%$ & 2005 \\
Nanning & Pubei & $11.1 \%$ & 2005 \\
Nanning & Nanning & $13.9 \%$ & 2005 \\
Chongzuo & Hengxian & $27.2 \%$ & 2004 \\
Chongzuo & Piangxiang & $27.8 \%$ & 2005 \\
Chongzuo & Ningming & $15.6 \%$ & 2005 \\
Guilin & Longzhou & $23.8 \%$ & 2004 \\
Guilin & Guilin & $10.2 \%$ & 2004 \\
Laibin & Pingle & $29.4 \%$ & 2005 \\
Yulin & Laibin & $10.1 \%$ & 2005 \\
Beihai & Yulin & $3.9 \%$ & 2005 \\
Beihai & Beihai & $4.2 \%$ & 2005 \\
Fangchenggang & Hepu & $2.4 \%$ & 2005 \\
Guigang & Fangchenggang & $5.7 \%$ & 2005 \\
Guigang & Guigang & $5.3 \%$ & 2005 \\
Hechi & Pingnan & $36.6 \%$ & 2005 \\
Hechi & Hechi & $11.0 \%$ & 2005 \\
Hechi & Yizhou & $0.5 \%$ & 2005
\end{tabular}




\subsection{The HIV epidemic had spread to female sex workers and clients}

Although prostitution in China has been illegal since 1949, the commercial sex industry has been thriving since the early 1980s with the adoption of a free market economy and 'open door' policy. ${ }^{29,30}$ Brothel-based commercial sex is far less common in China than in other parts of Asia although it still exists, ${ }^{31}$ and informal transient sex work is far more common and often based out of establishments such as hairdressing salons, hotel bars, dance halls or directly from the street or other public venues. ${ }^{6,31}$ According to the public security agency there were at least 50,000 FSWs in Guangxi in 2001 and this number has undoubtedly increased since then as the provincial economy has boomed, and transportation networks, tourism and international exposure expanded. ${ }^{32}$ The majority of women involved in commercial sex are thought to have migrated from rural areas, be poorly educated and lack awareness of HIV/AIDS. ${ }^{29,33}$

Figure 15 shows that long-standing HIV surveillance had only been conducted at the Nanning sentinel site where prevalence increased rapidly and steadily between 1996 and has stabilized between 10\%-to-13\% since 1999. Sentinel surveillance among FSWs at more recently added sentinel sites have also detected HIV infections but at much lower levels than in Nanning. The explanation for this is believed to be that FSWs picked up at the Nanning sentinel re-education site were often also injecting drugs. Indeed, the proportion of IDUs who are female in Guangxi is believed to be quite high, between 10 and $20 \%$ on the basis of sentinel surveillance data and other reports. ${ }^{34}$ Many of these female IDUs are believed to financially support their habit through sex trade ${ }^{1,24}$ and a survey conducted in Nanning, Liuzhou and Guilin found that $3 \%$ of FSWs reported using drugs. ${ }^{33}$.

The crucial issue of drug injecting and commercial sex risk behavior overlapping has been understudied in Guangxi, and in China in general, although there is wide agreement that FSWs are playing an important role in the HIV epidemic in terms of 'bridging' the predominantly injecting epidemic heterosexually. FSWs who inject drugs and share needles are at high risk of being infected with HIV and, in turn, further spreading the virus to their clients and sex partners. ${ }^{6,29,35}$

A survey of 482 FSWs in Baise City failed to detect a single HIV case. ${ }^{36}$ This was despite the fact that $7 \%$ of these women reported injecting drugs at least once in the past year, HIV prevalence among IDUs in this city had been reported to be as high as $80 \%$ and $20 \%$ of IDUs were estimated to be female. This finding supports the theory of some experts who argue that there is still a window of opportunity to intervene programmatically as the bridging of the two primary risk behaviors has not yet fully occurred. $^{37}$. 
Figure 15: Trends in HIV prevalence among female sex workers at select sentinel sites by year, Guangxi

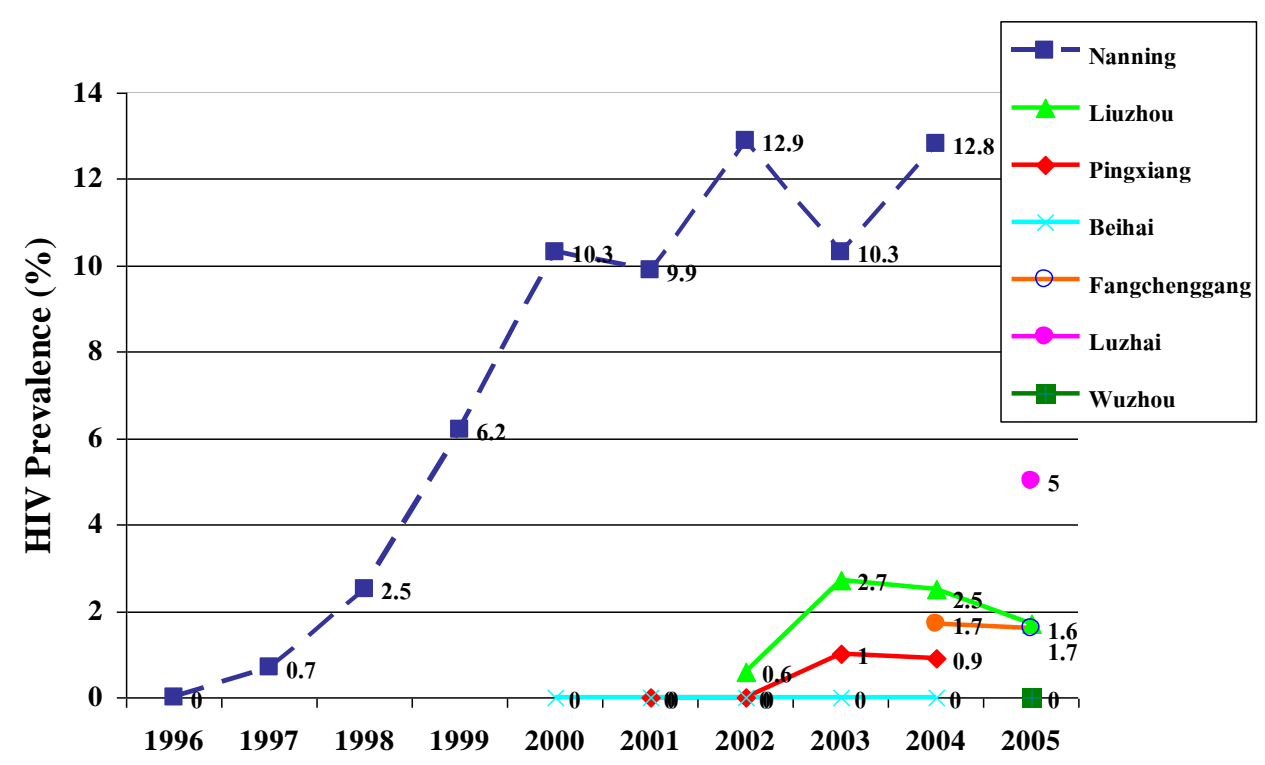

There are no HIV prevalence data available directly on the clients of FSWs in Guangxi but sentinel surveillance among long-distance truckers, an occupational proxy group for clients, only identified a single case of HIV infection $(0.2 \%$ prevalence) in Luchuan (Yulin prefecture). No HIV infections have been found in three years of truck drivers' surveillance in Pingxiang. A recent survey of 550 longdistance trucker drivers in Tongling (Anchu province) also failed to find any HIV infections. $^{38}$

Figure 16 shows that HIV infection rates among STD clinic attendees, albeit still at relatively low levels, have been increasing over time at multiple sentinel surveillance sites in Guangxi. These data suggest that heterosexual transmission of HIV is beginning to increase in Guangxi as these clinic attendees represent persons engaging in high-risk sex in the general population, including clients of sex workers. 
Figure 16: Trends in HIV prevalence among STD Clinic Attendees at select sites by year, Guangxi

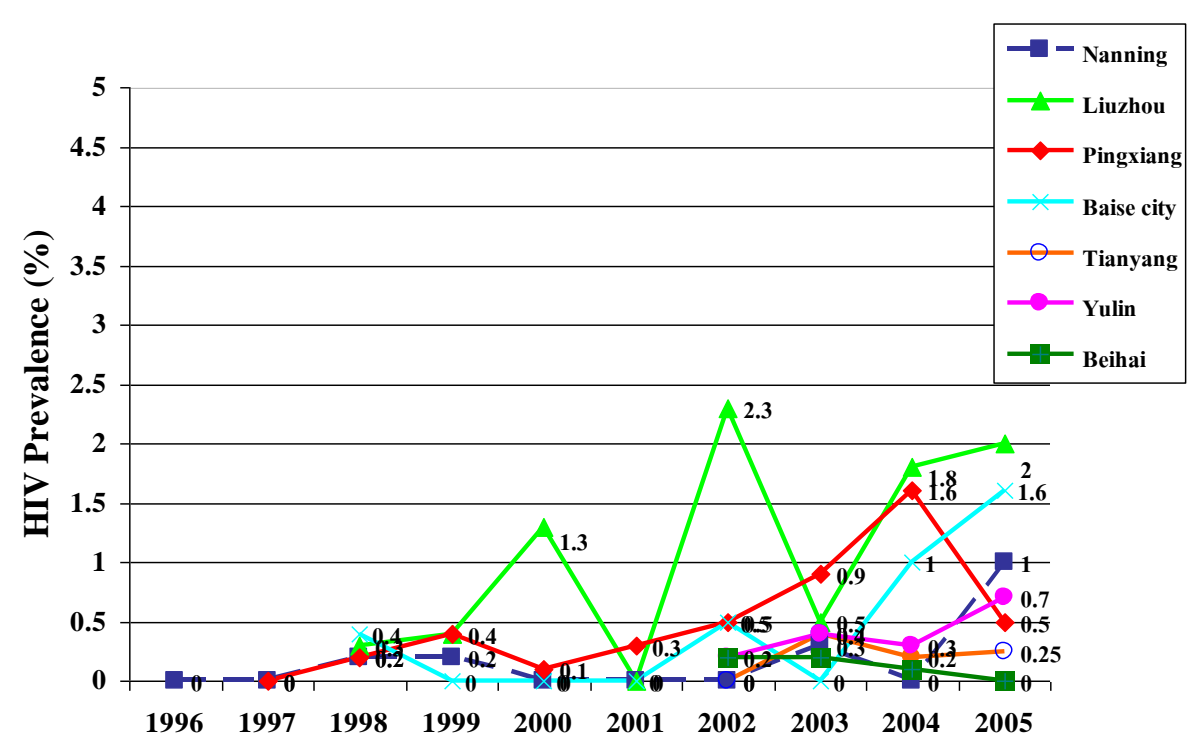

\subsection{Some evidence of limited spread to the general population}

No HIV prevalence household surveys have been conducted in Guangxi. However, antenatal care (ANC) clinic data among pregnant women, a sentinel group to monitor the spread to the general women population, indicates that HIV infection has been detected at four sentinel sites. At the Luzhai sentinel site (Liuzhou prefecture) it has increased to $1.8 \%$ in 2005 (Figure 17). While no other sentinel site reached HIV infection levels higher than $0.5 \%$ at any point in time, these Liuzhou data are worrisome and require further exploration. For example, it would be good to know whether these infected women were IDUs given the very high HIV prevalence (57.1\%) found among IDUs at this site in 2004 (Table 5). The high HIV prevalence found in Liuzhou among STD clinic attendees suggests that these women may be getting HIV-infected sexually through sex work and/or from their husbands (Figure 16). Collectively, these ANC data suggests that women in the general population are getting infected sexually and the epidemic is beginning to spread to relatively low-risk segments.

A China CARES evaluation of blood donor data conducted in Baise during 2004 failed to identify any cases of HIV infection (0/120). Moreover, a 2004 surveillance survey of university students in Yulin also found no evidence of HIV infection $(0 / 107)$. 
Figure 17: Trends in HIV prevalence among pregnant women at select antenatal clinic surveillance sites by year, Guangxi

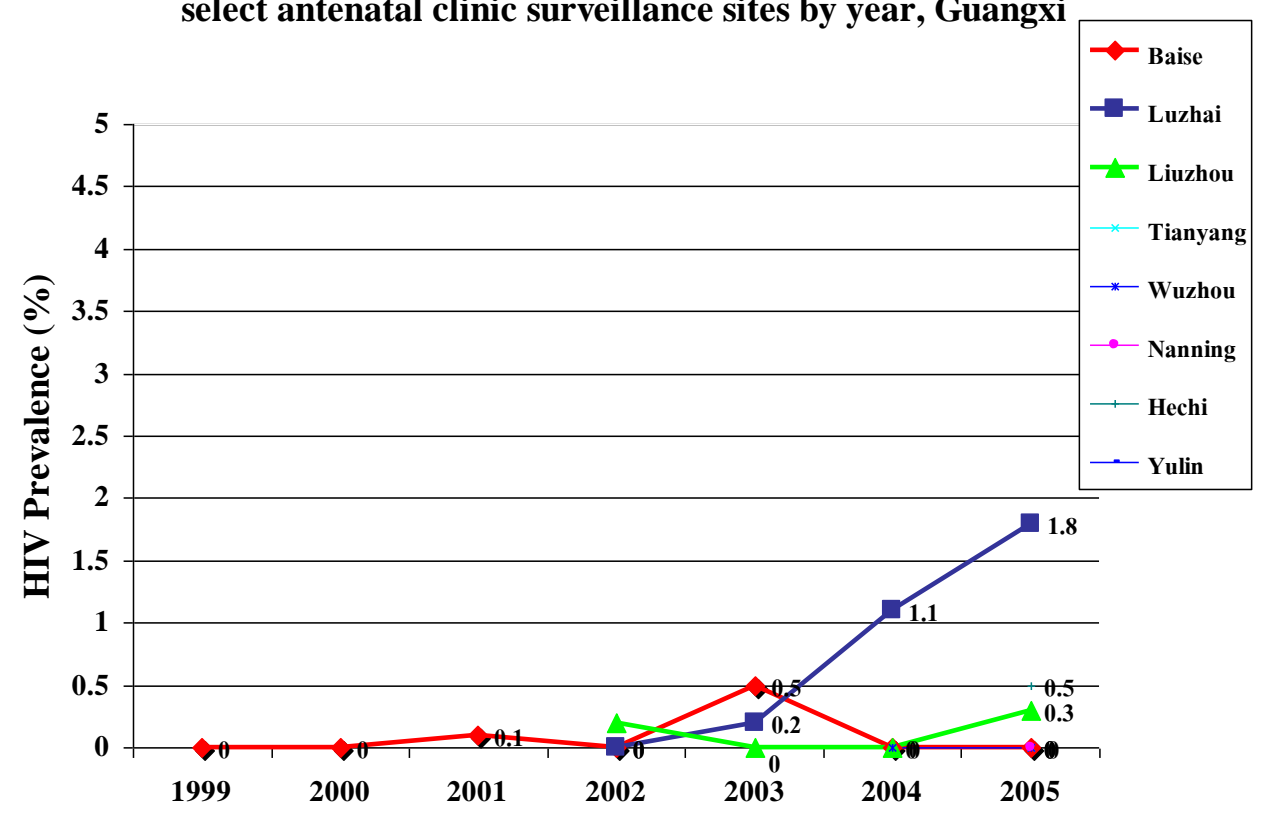

\subsection{Men who have sex with men (MSM) are 'blind spot' in the understanding of the HIV epidemic in Guangxi}

There have been no HIV seroprevalence surveys conducted among MSM in Guangxi although studies conducted in China and throughout Asia demonstrate that this subpopulation is at high-risk for HIV infection ${ }^{6,39}$. While MSM behavior is not officially illegal in China it is not generally considered socially acceptable in mainland China. In 2000 an anonymous mail survey throughout mainland China found that $0.35 \%$ of 857 respondents self-reported testing positive for $\mathrm{HIV} .{ }^{40}$ A more recent convenience survey conducted in Beijing in 2002 found that $3.1 \%$ of 481 men tested were HIV-positive. ${ }^{41}$ A subsequent molecular epidemiological study has found a predominance of subtype B among Beijing MSM suggesting that it has been recently imported from Australia, Europe, the United States or selected Asian cities. ${ }^{42}$

Chinese MSM have been found to have diverse sexual networks with both male and female sex partners and often engage in unsafe sex practices. Epidemiologically, MSM may bridge the epidemic to their heterosexual partners. For example, married MSM may acquire HIV from their high-risk male sex partners and transmit them to their wives. Alternatively, MSM may become infected when having sex with highrisk female partners. Due to the 'underground' nature of MSM behavior it is often difficult to conduct population-based surveys or other research which has limited the amount of data available to review. 


\section{Chapter 4: Sexually Transmitted Diseases (STDs) Epidemic in Guangxi}

\subsection{Analysis of STD case reports}

The STD case reporting system is described in section 2.2.11. Due to the passive nature of this system it is widely recognized that there is considerable underreporting. A detailed review of medical, pharmacy and laboratory records in 86 departments within 36 medical institutions in Guangxi during 2002 found p-athat the overall under-reporting rate was $47.3 \%$ for five STDs (syphilis, gonorrhea, chancroid, nongonococcal urethritis (NGU) and genital herpes). ${ }^{43}$ A multi-factor analysis of the reasons for STD case under-reporting concluded that the main reasons for this were low physician knowledge and awareness of the importance of STD case reporting and lack of adequate supervision by health authorities. ${ }^{44}$ Private clinics were not included in this evaluation although many patients are known to seek STD treatment in the private sector. It is believed that the rate of under-reporting in these clinics is between $90 \%-100 \%$

Figure 18: No. of reported STD cases by year, Guangxi

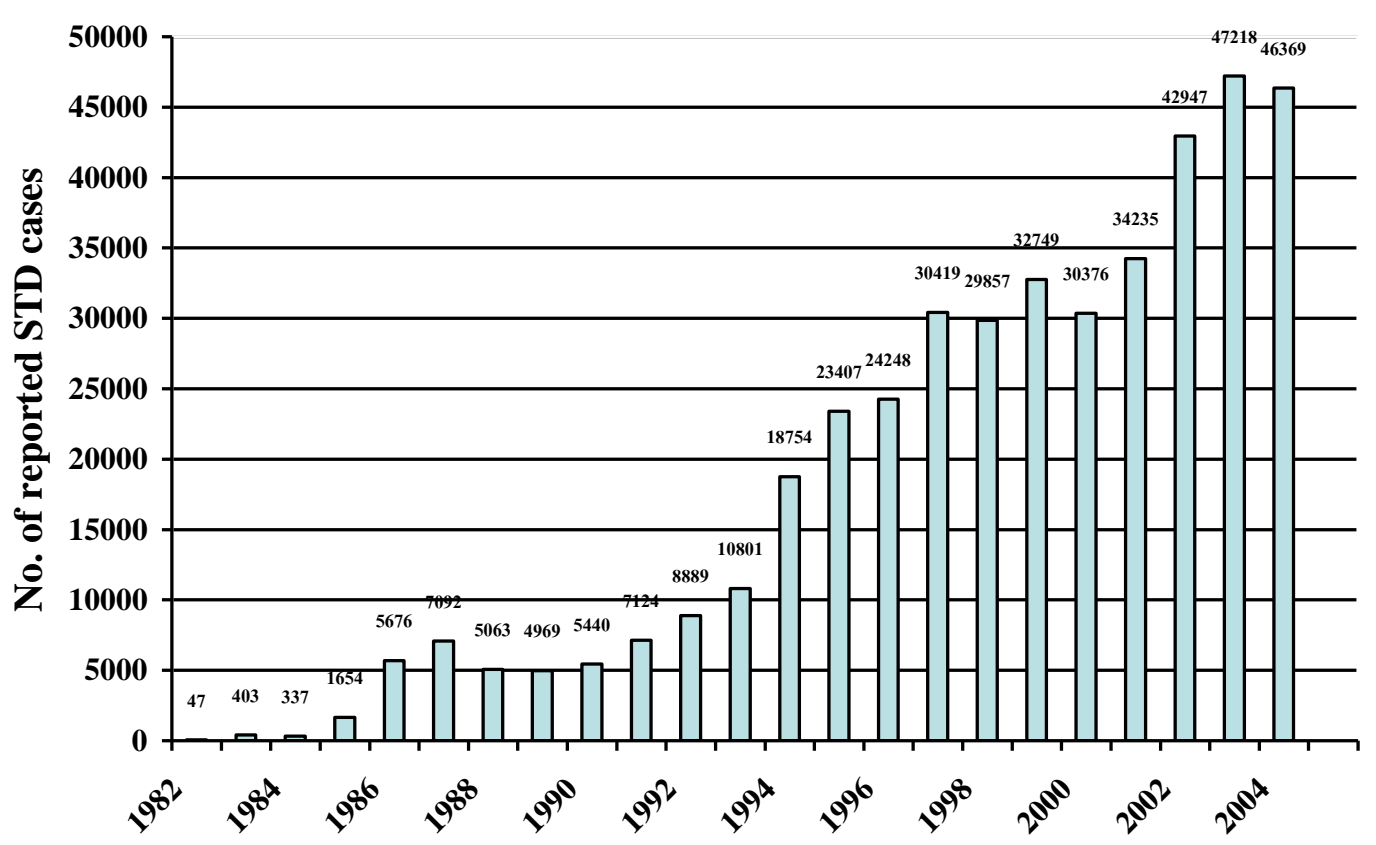


Since STD case reporting was initiated in Guangxi in 1982 there has been a steep increase in reported annual cases over time (Figure 18). This increase probably is explained by Guangxi's expanding commercial sex industry that has led to increased heterosexual STD transmission over time. A total of 416,432 cases have been reported through 2004 alone.

Table 6: Reported STD cases by type and adjusted adult (15-49 years) STD incidence in Guangxi, 1982-2004.

\begin{tabular}{|c|c|c|c|c|c|c|c|c|c|c|c|}
\hline Year & Gonorrhea & Syphilis & NGU* & CA* & GH* & $\begin{array}{l}\text { Chan- } \\
\text { croid }\end{array}$ & LGV* & Others & HIV & Total & $\begin{array}{l}\text { Adult STD } \\
\text { Incidence** }\end{array}$ \\
\hline 1982 & 45 & 0 & 0 & 0 & 0 & 2 & 0 & 0 & 0 & 2029 & $0.00 \%$ \\
\hline 1983 & 402 & 1 & 0 & 0 & 0 & 0 & 0 & 0 & 0 & 2386 & $0.02 \%$ \\
\hline 1984 & 336 & 1 & 0 & 0 & 0 & 0 & 0 & 0 & 0 & 2321 & $0.01 \%$ \\
\hline 1985 & 1647 & 1 & 0 & 4 & 0 & 2 & 0 & 0 & 0 & 3639 & $0.05 \%$ \\
\hline 1986 & 5620 & 14 & 0 & 30 & 5 & 7 & 0 & 0 & 0 & 7662 & $0.15 \%$ \\
\hline 1987 & 6607 & 7 & 101 & 361 & 15 & 0 & 1 & 0 & 0 & 9079 & $0.17 \%$ \\
\hline 1988 & 4258 & 0 & 37 & 739 & 5 & 0 & 0 & 24 & 0 & 7051 & $0.10 \%$ \\
\hline 1989 & 4012 & 4 & 228 & 660 & 19 & 0 & 0 & 42 & 4 & 6958 & $0.09 \%$ \\
\hline 1990 & 4050 & 8 & 164 & 1130 & 45 & 8 & 5 & 29 & 1 & 7430 & $0.09 \%$ \\
\hline 1991 & 5085 & 12 & 98 & 1880 & 32 & 17 & 0 & 0 & 0 & 9115 & $0.10 \%$ \\
\hline 1992 & 6077 & 44 & 266 & 2388 & 111 & 2 & 1 & 0 & 0 & 10881 & $0.11 \%$ \\
\hline 1993 & 7365 & 66 & 653 & 2564 & 146 & 5 & 0 & 0 & 2 & 12794 & $0.12 \%$ \\
\hline 1994 & 9551 & 166 & 4060 & 4640 & 317 & 17 & 3 & 0 & 0 & 20748 & $0.18 \%$ \\
\hline 1995 & 9642 & 483 & 8273 & 4488 & 475 & 39 & 7 & 0 & 0 & 25402 & $0.20 \%$ \\
\hline 1996 & 9861 & 617 & 7533 & 5544 & 682 & 11 & 0 & 0 & 0 & 26244 & $0.19 \%$ \\
\hline 1997 & 9990 & 1423 & 12259 & 5835 & 879 & 28 & 1 & 0 & 4 & 32416 & $0.21 \%$ \\
\hline 1998 & 10414 & 1880 & 10965 & 5505 & 1046 & 45 & 2 & 0 & 0 & 31855 & $0.19 \%$ \\
\hline 1999 & 9290 & 3032 & 12776 & 6296 & 1251 & 56 & 5 & 0 & 43 & 34748 & $0.19 \%$ \\
\hline 2000 & 9349 & 3106 & 10670 & 5777 & 1317 & 57 & 7 & 0 & 93 & 32376 & $0.16 \%$ \\
\hline 2001 & 10388 & 4291 & 11991 & 5603 & 1548 & 85 & 23 & 0 & 306 & 36236 & $0.17 \%$ \\
\hline 2002 & 12022 & 5840 & 16551 & 5872 & 2116 & 54 & 20 & 0 & 472 & 44949 & $0.20 \%$ \\
\hline 2003 & 13585 & 7227 & 16836 & 6279 & 2642 & 40 & 15 & 0 & 594 & 49221 & $0.20 \%$ \\
\hline 2004 & 12154 & 7043 & 17294 & 6151 & 2638 & 31 & 10 & 0 & 1048 & 48373 & $0.20 \%$ \\
\hline Total & 161750 & 35266 & 130755 & 71746 & 15289 & 506 & 100 & 95 & 2567 & 463913 & \\
\hline
\end{tabular}

Table 6 shows adult STD incidence rates estimated based on the reported number of STD cases and annum-specific 15-49 year population size and annual growth rate. One can see that STD incidence in Guangxi has actually held steady between 180-200 cases per 100,000 people since the mid-1990s after increasing rapidly during the 1980s and early 1990s. There is also a wide variation in the distribution of specific STD types over time (Figure 19). Gonorrhea was the dominant STD reported until late-1980s when there was a greater diversification of reported STDs with NGU, syphilis and genital herpes all increasing proportionately over time. Although HIV still makes up a small fraction of reported STD cases, this proportion has been 
increasing dramatically and HIV accounted for $2.3 \%$ of all reported STD cases by 2004.

Table 7 shows the socio-demographic characteristics of reported STD cases during 2002-2004. Statistical breakdowns of STD patients before 2002 are not possible. The overall male-to-female ratio is $1.27: 1$ during this time period. Unfortunately, genderspecific analyses of reported sources of STDs over time are not possible but extramarital sex is the most common way of transmission accounting for approximately two-thirds of reported cases (Figure 20). The majority of men are probably infected this way and commercial sex is likely to figure prominently as the source of these infections. While FSWs seeking STD services are likely to report extra-marital sex as a transmission mode, it is known that a larger proportion of women report spousal sex (reported by a fifth of overall STD patients) as the source of their infections because women in the general population are most commonly infected with STDs via their husbands.

Figure 19: Distribution of reported STDs by type in Guangxi, 1982-2004

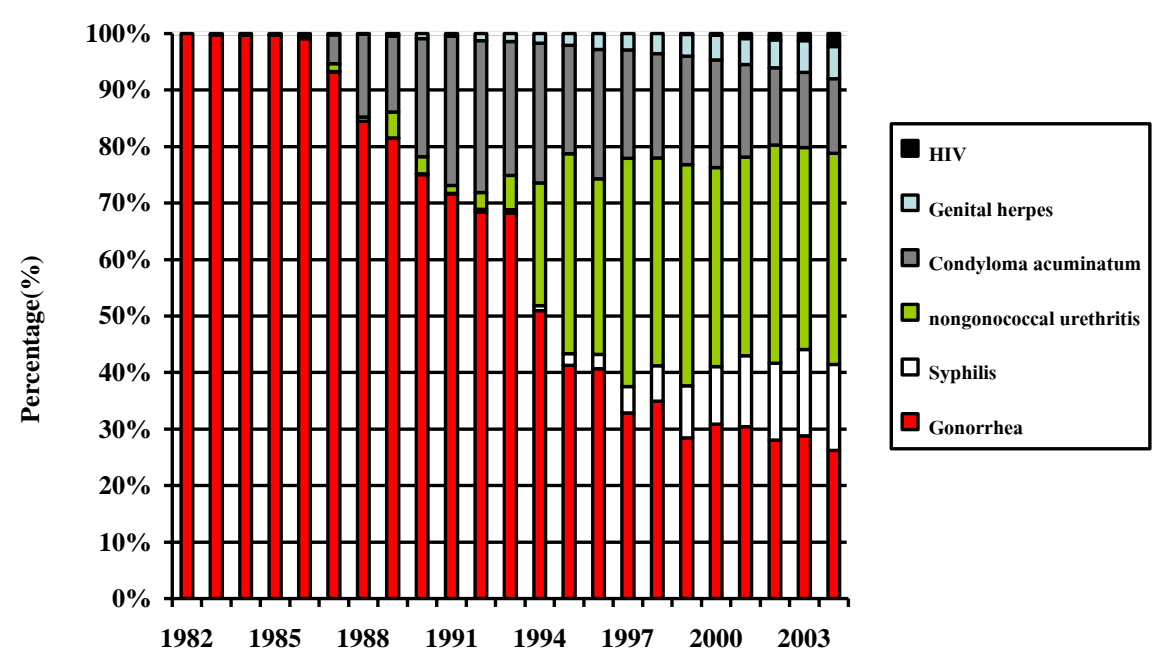

STDs are most commonly reported among patients in the 20-29 year age group (40\%) and a third of all cases are reported in the 30-39 year old age group. The proportion of STD patients in the 50+ year category has increased to almost $10 \%$ in 2004 and this is probably indicative of the fact that older men are being infected via FSWs. About two-thirds of STD cases are married and this is a strong indicator of the large-scale potential for HIV to be transmitted from husbands to wives as HIV continues to evolve into a heterosexual epidemic in Guangxi. The wide distribution of STD cases by educational and occupational status is indicative that high-risk sexual behavior is being practiced through diverse socioeconomic segments of the population of Guangxi. This is also an early warning sign of the HIV's potential to be disseminated 
widely in the general population unless aggressive action is taken to prevent this heterosexual emergence.

Figure 21 shows the rapid historical geographic expansion of STD cases throughout Guangxi. During 1982-1986 only three prefectures reported STDs and these case loads were quite low. By 1996-2004, all cities/prefectures had reported significant numbers of STD cases. The prefectures with the currently highest STD case burdens are Liuzhou, Nanning, Yulin and Beihai. Not coincidently, these are all the same prefectures in which HIV infections have been detected via STD clinic surveillance (Figure 16).

Table 7: Socio-demographic characteristics of reported STD cases, 2002-2004

\begin{tabular}{|c|c|c|c|}
\hline Characteristic & 2002 & 2003 & 2004 \\
\hline \multicolumn{4}{|l|}{ Gender: } \\
\hline Male & $55.9 \%$ & $58.3 \%$ & $55.4 \%$ \\
\hline Female & $44.1 \%$ & $41.7 \%$ & $44.6 \%$ \\
\hline \multicolumn{4}{|l|}{ Age (years): } \\
\hline$<15$ & $0.6 \%$ & $0.8 \%$ & $1.2 \%$ \\
\hline $15-19$ & $3.9 \%$ & $3.4 \%$ & $3.4 \%$ \\
\hline $20-29$ & $41.5 \%$ & $40.8 \%$ & $37.5 \%$ \\
\hline $30-39$ & $33.2 \%$ & $32.4 \%$ & $34.0 \%$ \\
\hline $40-49$ & $12.9 \%$ & $13.9 \%$ & $14.3 \%$ \\
\hline $50+$ & $7.9 \%$ & $8.6 \%$ & $9.5 \%$ \\
\hline Unknown & $0.06 \%$ & $0.08 \%$ & $0.2 \%$ \\
\hline \multicolumn{4}{|l|}{ Marital status: } \\
\hline Married & $61.4 \%$ & $67.3 \%$ & $66.0 \%$ \\
\hline Unmarried & $35.7 \%$ & $29.9 \%$ & $31.6 \%$ \\
\hline Unmarried & $2.9 \%$ & $2.7 \%$ & $2.5 \%$ \\
\hline \multicolumn{4}{|l|}{ Educational status: } \\
\hline Before school & $1.0 \%$ & $0.6 \%$ & $1.0 \%$ \\
\hline Elementary school & $12.9 \%$ & $14.1 \%$ & $15.3 \%$ \\
\hline Middle school & $69.2 \%$ & $70.4 \%$ & $67.3 \%$ \\
\hline University & $11.1 \%$ & $9.8 \%$ & $10.9 \%$ \\
\hline Illiterate & $3.2 \%$ & $1.2 \%$ & $1.5 \%$ \\
\hline Unknown & $2.6 \%$ & $3.8 \%$ & $3.9 \%$ \\
\hline \multicolumn{4}{|l|}{ Occupation: } \\
\hline Worker & $15.6 \%$ & $13.3 \%$ & $12.5 \%$ \\
\hline Farmer & $19.1 \%$ & $24.8 \%$ & $23.2 \%$ \\
\hline Public servant & $12.3 \%$ & $12.0 \%$ & $12.1 \%$ \\
\hline Business & $2.4 \%$ & $1.8 \%$ & $2.3 \%$ \\
\hline Food and service & $8.0 \%$ & $6.8 \%$ & $6.4 \%$ \\
\hline Driver & $2.8 \%$ & $3.2 \%$ & $2.7 \%$ \\
\hline Self-employed & $16.9 \%$ & $15.3 \%$ & $18.0 \%$ \\
\hline Unemployed & $16.0 \%$ & $16.5 \%$ & $15.2 \%$ \\
\hline Children & $0.5 \%$ & $0.7 \%$ & $0.7 \%$ \\
\hline Student & $0.9 \%$ & $0.9 \%$ & $1.2 \%$ \\
\hline Other/Unknown & $5.5 \%$ & $4.7 \%$ & $5.8 \%$ \\
\hline \multicolumn{4}{|l|}{ Place of residence: } \\
\hline Within Guangxi & $84.4 \%$ & $89.0 \%$ & $88.5 \%$ \\
\hline Other province & $13.8 \%$ & $10.1 \%$ & $10.4 \%$ \\
\hline Outside of China & $0.4 \%$ & $0.3 \%$ & $0.2 \%$ \\
\hline Unknown & $1.3 \%$ & $0.5 \%$ & $0.9 \%$ \\
\hline
\end{tabular}


Figure 20: Trends in reported sources of infection among reported STD cases by year, Guangxi, 2002-2004

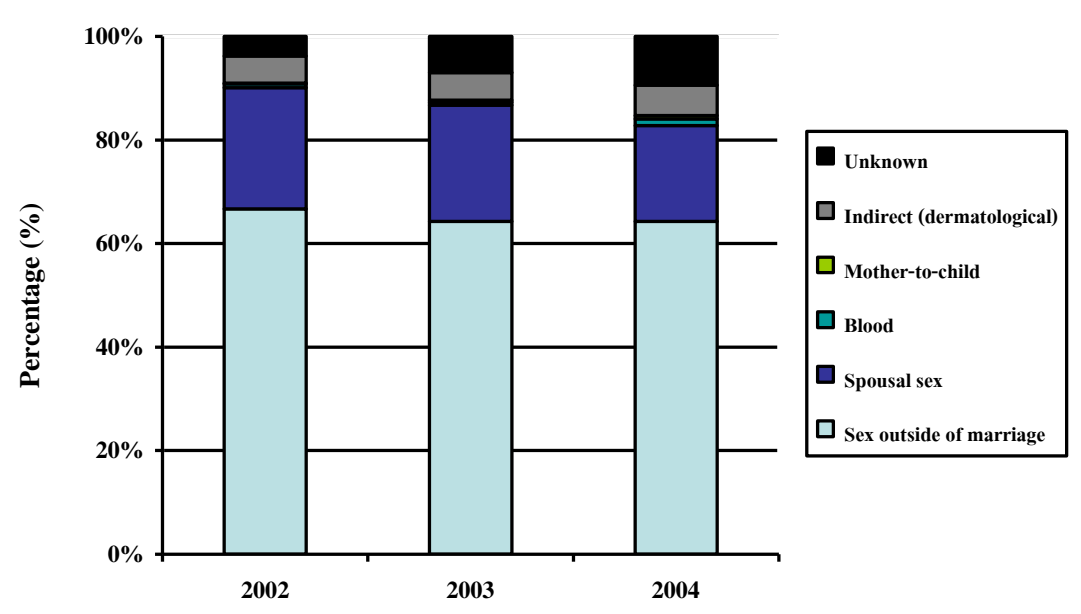

\subsection{Syphilis sentinel surveillance}

Syphilis surveillance of high risk population groups has been conducted in a limited number of sentinel sites including IDUs, FSWs and truck drivers in recent years. Figure 22 shows that syphilis prevalence at five IDU sentinel sites was high and increasing at three of the four sites were trend data are available. This indicates that IDUs in diverse locations are engaging in high-risk sexual behavior. This provides further evidence of the overlapping of risky behaviors occurring amongst the most affected population groups and the potential of IDUs to bridge the epidemic sexually to less affected groups.

Even higher syphilis prevalence rates have been documented among FSWs at select sentinel sites, which is not surprising considering their occupation (Figure 23). Over half of FSWs included in a three-city study in Guangxi also had one or more selfreported symptoms. ${ }^{33}$ A study of sex workers in neighboring Yunnan found high rates of co-infection with chlamydia and gonorrhea $(24.6 \%) .{ }^{45}$ These results are a cause for concern given the well-known role of STDs as a co-factor for HIV transmission and also in that they are indicative of high levels of unprotected sexual behavior being practiced.

Longer-standing syphilis prevalence trend data are available among STD clinic attendees at a greater number of sentinel sites (Figure 24). The trend of increasing syphilis infection rates across the diverse sites is striking and corroborates the results of the analysis conducted on the basis of STD case report analysis. Besides being a significant cause of morbidity (and potentially, of mortality) if let untreated, syphilis is also a strong cofactor for HIV transmission given its ulcerative nature. Its 
substantial prevalence among key high-risk groups in diverse sites in Guangxi is a cause for alarm.

Figure 21: Geographical distribution of reported STD cases in Guangxi, 19822004.

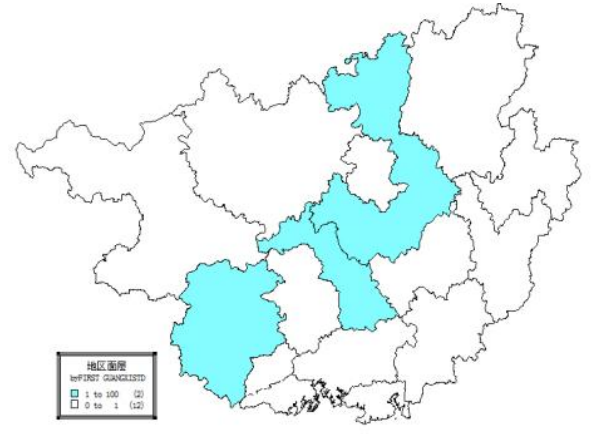

Distribution of STD cases in Guangxi, China(1991-1996)

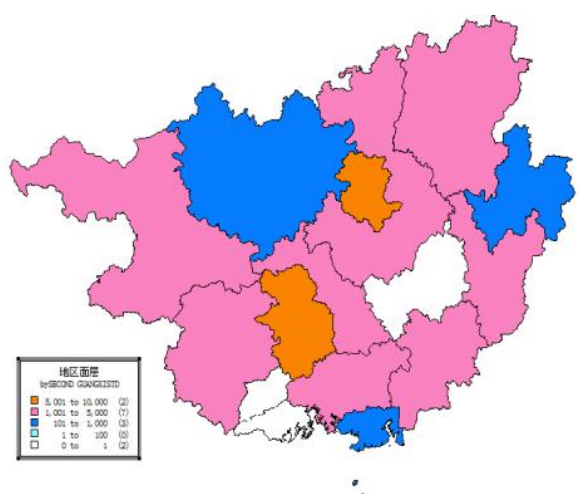

Distribution of STD cases in Guangxi, China(1996-2001)
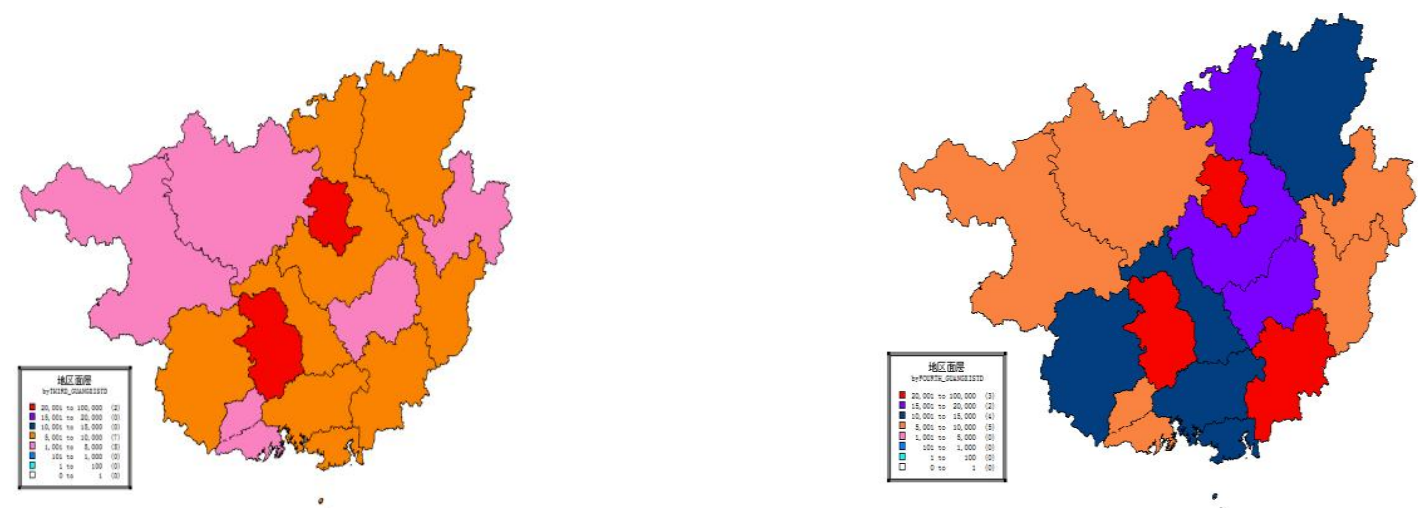

Distribution of STD cases in Guangxi, China(1996-2004)

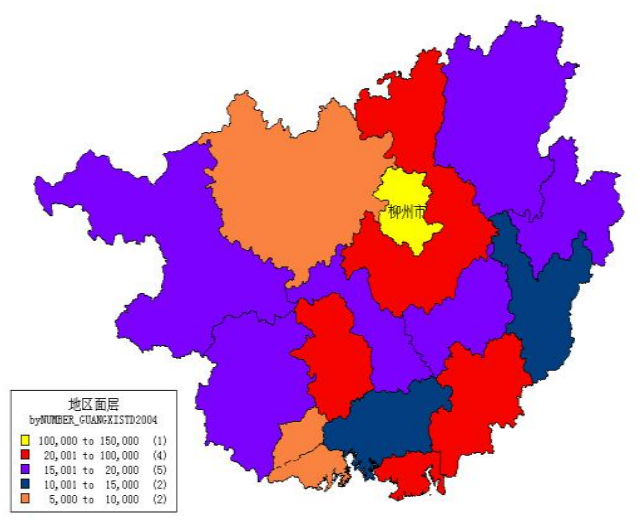


Syphilis infection rates of $0.5 \%$-to- $1.9 \%$ have also been detected among recently initiated surveillance among long-distance truck drivers in both Pingxiang and Luchuan.

Syphilis infection rates under $1 \%$ have been found among pregnant women at antenatal clinics with the exception of a peak value of $1.5 \%$ at the Lingshan site during 2005. This is a bit surprising considering the relatively higher HIV prevalence found in this subpopulation (Figure 17).

Figure 22: Trends in syphilis prevalence among injecting drug users at select sites by year, Guangxi

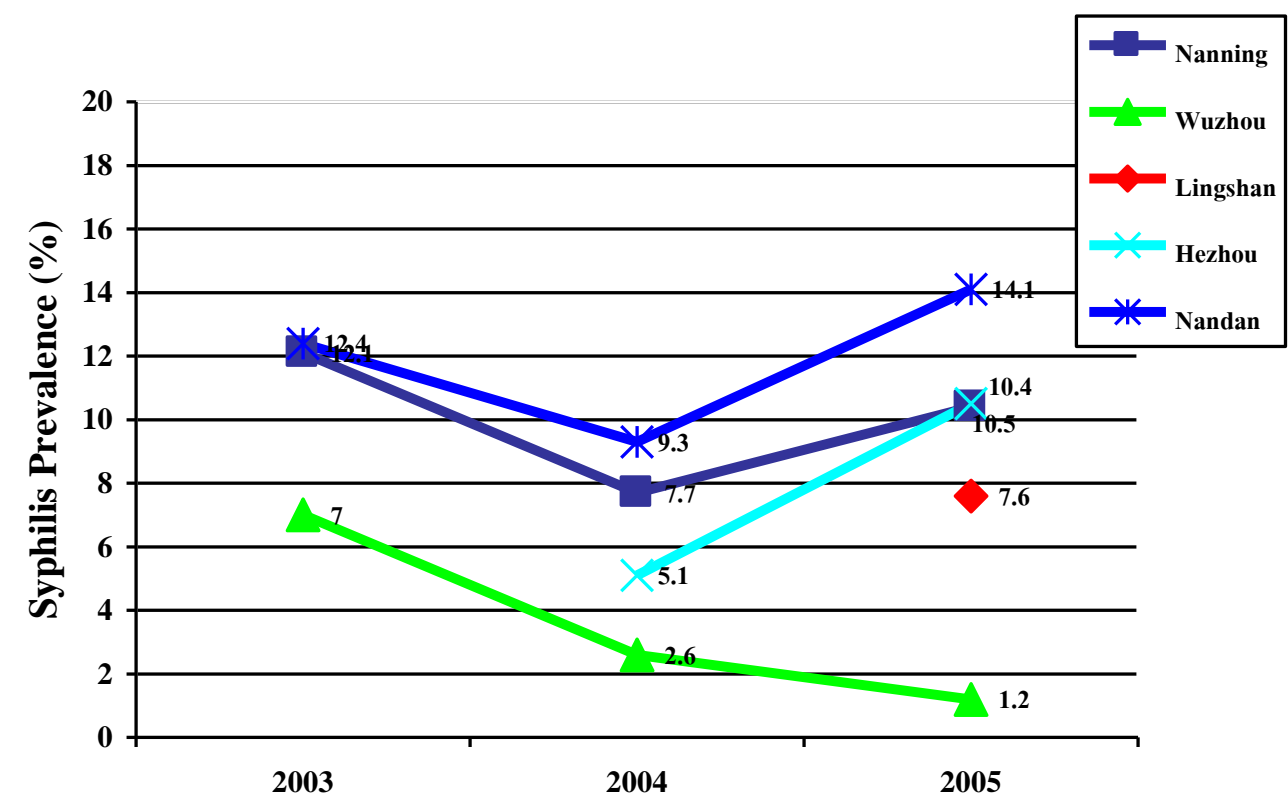


Figure 23: Trends in syphilis prevalence among female sex workers at select sites by year, Guangxi

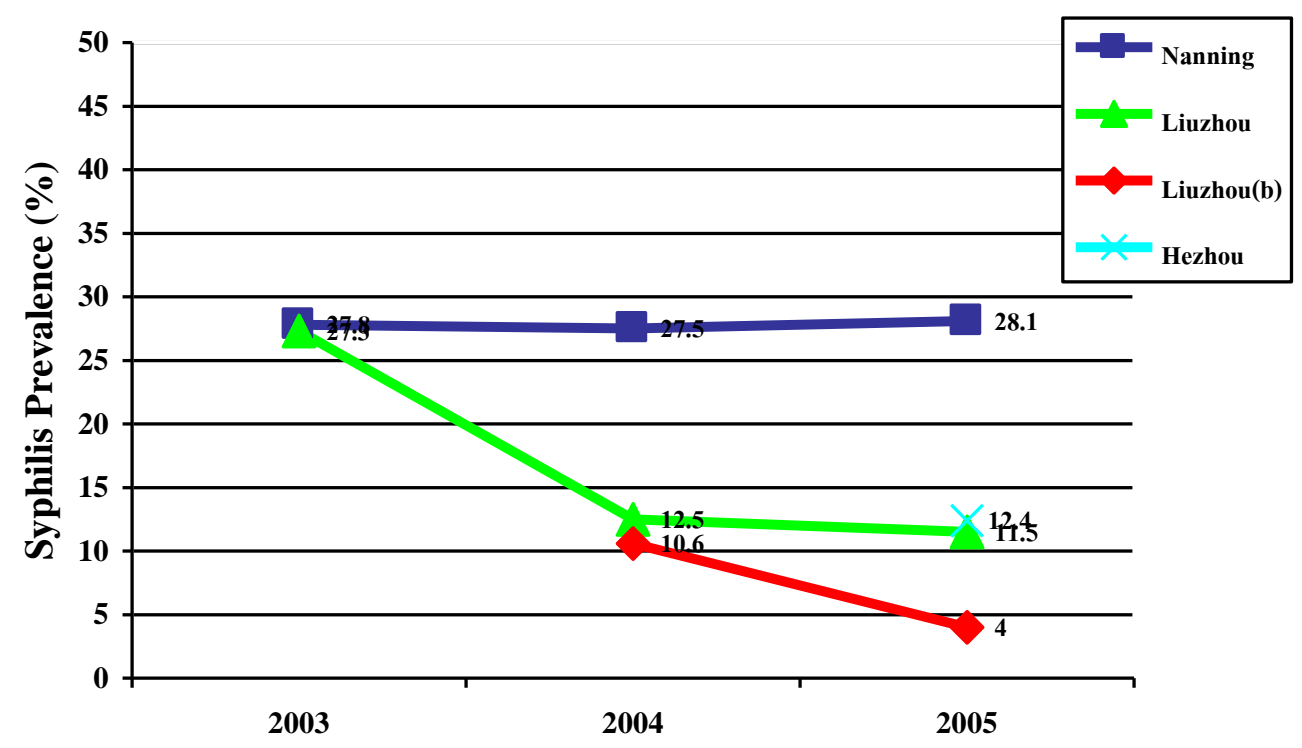

Figure 24: Trends in syphilis prevalence among STD clinic patients at select sites by year, Guangxi
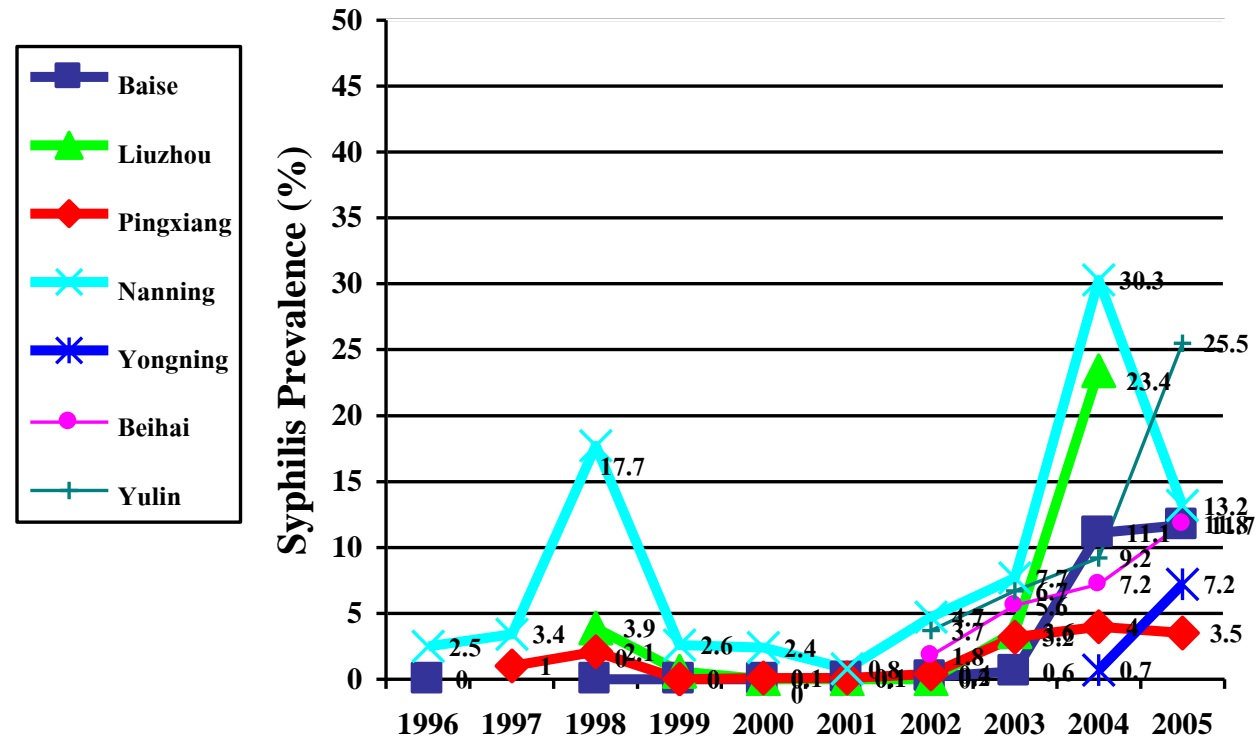
Figure 25: Trends in syphilis prevalence among pregnant women

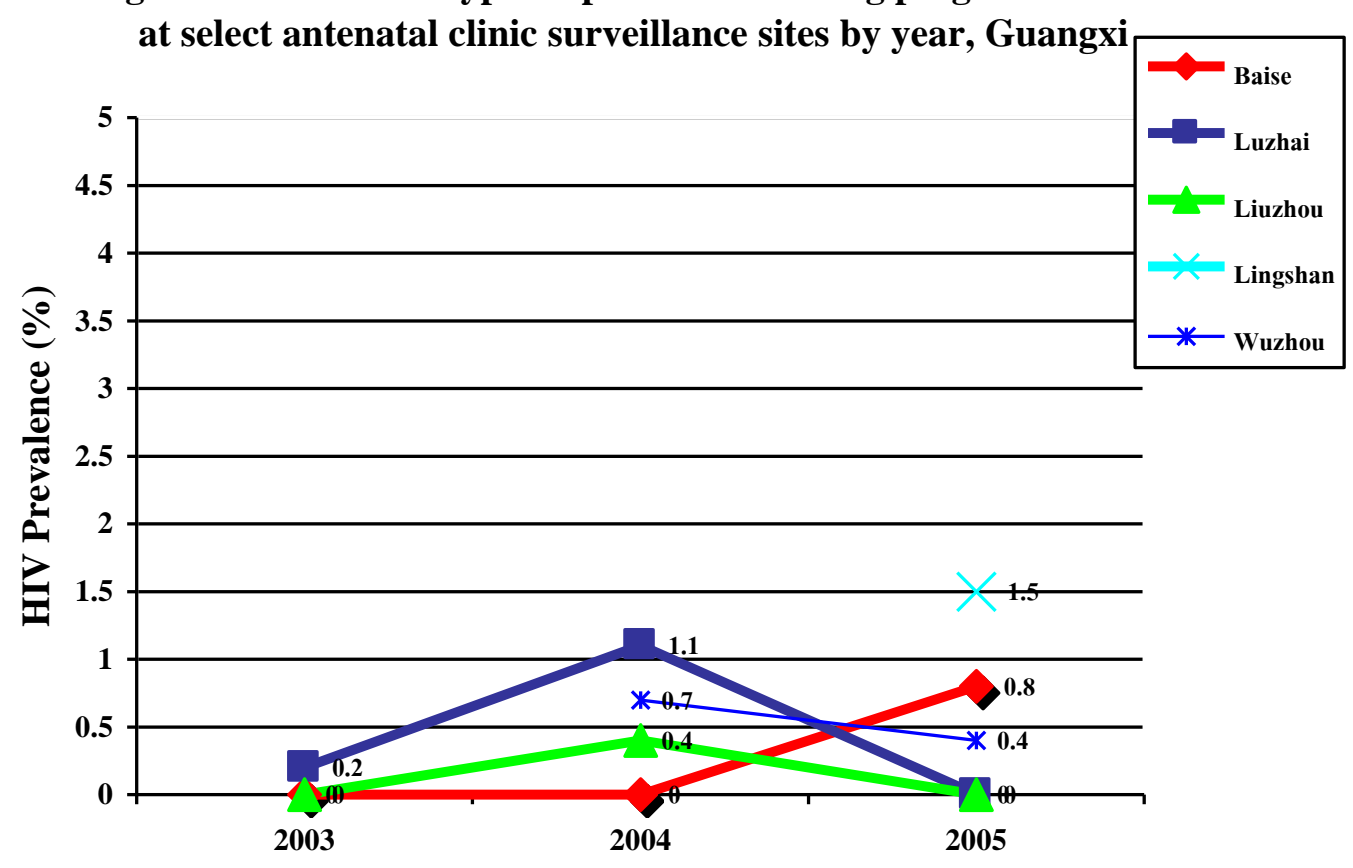

Figure 26: Trends in syphilis prevalence among pregnant women at select antenatal clinic surveillance sites by year, Guangxi

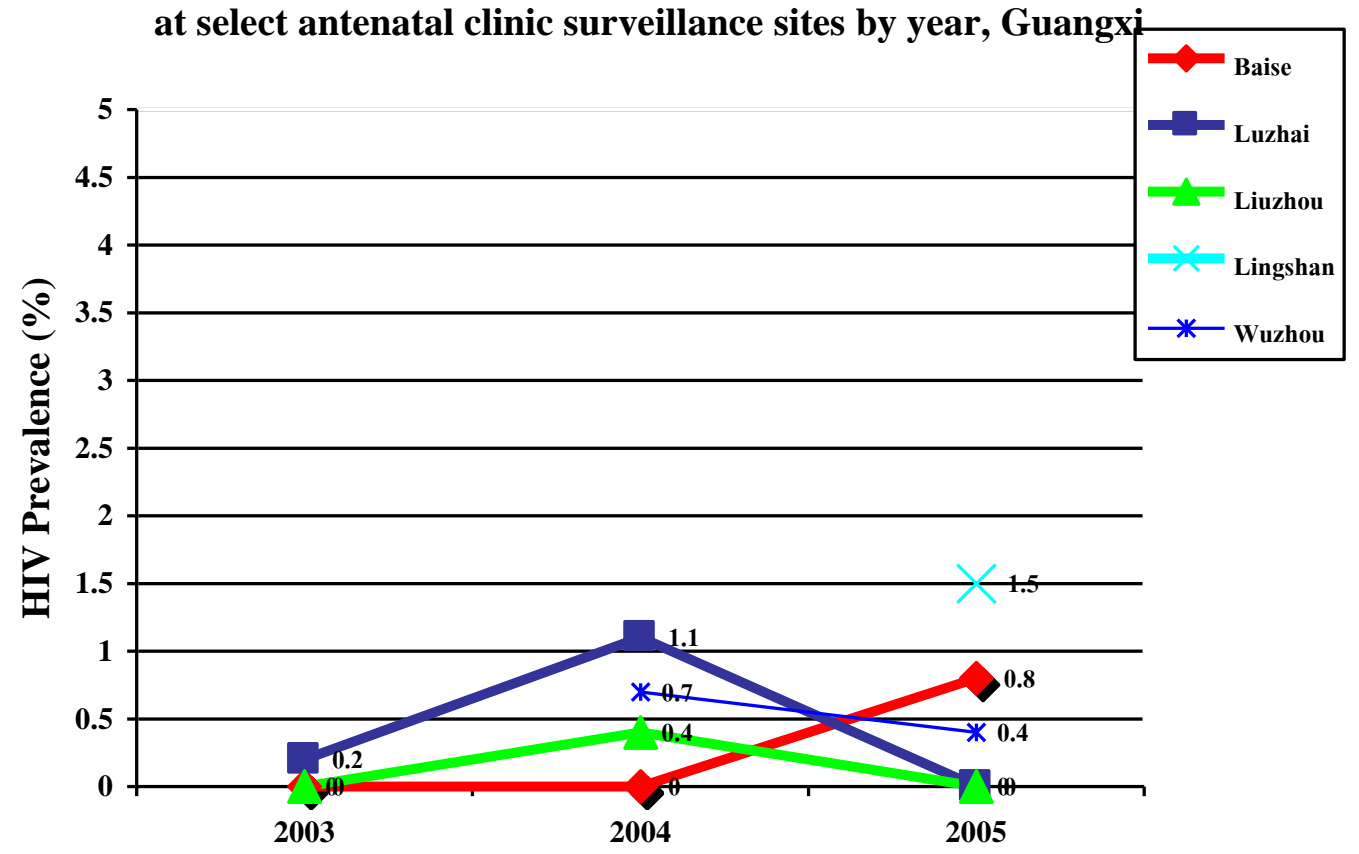




\section{Chapter 5: The Response against HIV and AIDS in Guangxi}

\subsection{Policies and environmental support for HIV prevention and control in Guangxi}

In controlling the HIV/AIDS epidemic CDC has focused on the principle of "making of prevention the first priority, using education as the main method, solving the problem thoroughly and managing it comprehensively". Governments at all levels have strengthened the leadership and cooperation on HIV/AIDS prevention, and the relevant units have worked closely to carry out various prevention and control programs. CDC has made some progress and established the basis for the next steps.

\subsubsection{Strengthen the leadership, improve the multi-sector collaboration network}

The government of Guangxi Zhuang Autonomous Region has set up a leading group for Guangxi HIV/AIDS prevention that holds regular coordination meetings. In the cities and counties with serious epidemics local governments have also set up a leading and working group. A system based on government leadership, multi-sector collaboration and the involvement of the whole society has been set up. In June 2004 a Guangxi HIV/AIDS prevention and control committee was created. In order to meet the needs for HIV prevention and control the members of the HIV prevention and control working group increased from 29 to 44. Steps to identify the responsibilities of each unit and strengthen the cooperation between relevant sectors included: (1) a "Working Rule of Guangxi Zhuang Autonomous Region HIV/AIDS Prevention and Control Working Group" and an "Outline for HIV/AIDS Prevention and Control Working Group members task of 2005" were issued; (2) "Fifteen measures of HIV/AIDS Prevention of Guangxi Zhuang Autonomous Region" were adopted; (3) coordination meetings were held for the working group to identify the responsibilities of each of the members and to discuss the future plan.

\subsubsection{Supportive Policies and Documents}

- "Detailed Rules of HIV/AIDS Surveillance and Management in Guangxi"

- "Notion of Strengthening HIV/AIDS Prevention and Control"

- "Long-Term strategic plan for Guangxi HIV/AIDS Prevention (1999-2010)"

- "Responsibility of HIV/AIDS/STD Prevention of relevant sectors (organizations) in Guangxi Zhuang Autonomous Region"

- "Guideline for Public Education on HIV/AIDS Prevention and Control of Guangxi Zhuang Autonomous Region"

- "Plans for Guangxi HIV/AIDS Prevention and Control 2002-2006"

- "Statute of Blood Donation of Guangxi Zhuang Autonomous Region"

- "Decree of Commend and Encouragement of Unpaid Blood Donation in Guangxi Zhuang Autonomous Region” 
Under the lead of the provincial government a "Decree for HIV/AIDS Prevention and Control of Guangxi Zhuang Autonomous Region" has been drafted by the PHB and the provincial legislation office, and passed the deliberation of the provincial government standing committee on December 24th, 2004. This document would push the implementation of the HIV/AIDS Prevention and Control program of Guangxi Zhuang Autonomous Region forward.

\subsubsection{Increasing Funding Inputs}

In order to ensure that prevention of HIV/AIDS activities are implemented smoothly the Guangxi Zhuang Autonomous Region government keeps on increasing the resources for HIV/AIDS prevention: from 1 to 1.3 million RMB between 1998 and 1999, and from 3.8 million RMB in 2004 to 8 million RMB in 2005. Meanwhile, the central government has constituted a special fund, including 9.85 million RMB in 2004 and 35.84 million RMB in 2005 for Guangxi HIV/AIDS prevention work through payment transfers. These funds would ensure the implementation of HIV/AIDS prevention and control activities.

\subsubsection{Government leading, multi-sector collaboration and whole society involvement}

Government Departments and NGOs, including the Youth League, the Women federation, the Labor Union, the Guangxi Branch of the Chinese Preventive Medical Association, the Red Cross and the Family Planning Association, have made remarkable efforts on prevention and care-related projects.

\subsubsection{Public Education}

In recent years, government departments of public health and TV and radio broadcasting channels have carried out public education programs on harm reduction and prevention of HIV/AIDS through posters, radio broadcasting, TV programs, videos and all kinds of IEC materials. Health education is provided to students, mobile populations and other high risk groups. Health education, peer education and volunteers have been brought into school lectures. The Science and Technology Bureau has also organized an initiative called "Sending HIV/AIDS knowledge to the countryside". All these activities are greatly helping improve awareness and knowledge of HIV/AIDS in Guangxi. In 2004, 8 mass media including "Health", the "Guangxi Daily" and the "Southern Morning" have reported prevention of HIV/AIDS activities in Guangxi. On November 28th, 2004, a forum on prevention of HIV/AIDS for women was held to motivate this group to actively act in preventing HIV/AIDS. On December 1st large scale propaganda was carried out in the Chaoyang Plaza in Nanning, with the participation of the working team members. 
According to incomplete statistical data, government departments of public health, public security, judicature, traffic, family planning, the women federation and the labor union have given over 20 thousand lectures, printed and distributed more than 13 million IEC material, and set up more than 28 thousand bill boards. Additionally over 6 thousand advertisement and 9 hundred pieces of news about HIV/AIDS prevention and unpaid blood donation have been broadcasted, and more than 100 radio or TV programs on HIV/AIDS have been produced and broadcasted.

\subsubsection{Intervention for High Risk Population and Vulnerable population}

Needles/syringes exchange programs for injection drug users. Under the cooperation of PHB and PSB, clean needle/syringe exchange for injection drug users programs have been carried out in Luzhai, Tiandong, Ningming and Guigang to reduce the harm of drugs and change the high risk behaviors among users. In the places mentioned above, drug users could buy clean syringe at a price lower than the market one in some appointed pharmacies. Local PHB would reimburse the difference to the pharmacies according to the number of used syringes. Meanwhile, peer educators are recruited among drug users to sparkplug the other drug users to stop sharing syringes. Since the project started, the rate of syringe sharing in project sites has decreased; the risk of drug users infecting with HIV has also decreased as a result.

Methadone treatment. In April 2004, under the approval of the provincial government, PHB, PSB and FDA selected a community in Nanning to conduct the methadone treatment by using the international successful experience to alleviate drug users' dependency on heroin and control the epidemic of HIV/AIDS among drug users. The next three project sites would be Liuzhou city, Wuzhou city and Hechi city, where the program would start in 2005.

Condom promotion in entertainment places. Guangxi CDC has carried out a health education and condom promotion program in Pingxinag, Dongxing, Beihai, Heng County, Hezhou and Yizhou. The Provincial Family Planning Association has also implemented a $100 \%$ condoms use project in Liuzhou city. In these interventions, CDC staffs went to the entertainment places to distribute IEC material and condoms, offer face to face counseling, demonstrate the right way of using condoms and provide counseling on reproductive health and HIV/AIDS/STD treatment to CSW. Through these interventions, CSW's knowledge on HIV/AIDS has improved, unsafe sex has decreased, the rate of using condoms increased and the prevalence of STD decreased.

Other. Based on STI clinics, STD/HIV/AIDS intervention has also been conducted in hair salons, KTV bars for high risk and vulnerable population. Activities carried out include the broadcast of a video on HIV/AIDS/STD prevention and control regularly, teaching STD patients how to use condoms correctly and dispensing health education prescriptions. 


\subsubsection{Treatment and Care}

The Chinese government has committed to provide "Four Free and One Care" on the General Assembly High-Class Conference on HIV/AIDS, which translates into free anti-virus treatment for poor patients, free VCT, free PMTCT and free testing for their babies and free education for AIDS orphans. In 2003, four national China CARE sites were set up in Pingxiang, Baise, Hezhou and Heng County, to implement comprehensive prevention and interventions, such as the anti-virus treatment with domestic medicine, care, health education, PMTCT and VCT, and to implement the policy of "Four Free and One Care". This will allow accumulating experience for the further expansion of the centers in Guangxi.

In response to the situation of the epidemic in Guangxi, an anti-virus treatment expert group at the provincial, city and county level has been set up. Additionally 15 hospitals at the city level and 80 at the county level were assigned to become centers for anti-virus treatment and the relevant staffs were trained for that. So far, anti-virus treatment and anti-opportunistic infection treatment is being carried out for more than 400 AIDS patients in Nanning, Liuzhou, Hezhou, and Pingxiang. Meanwhile the PMTCT is being carried out in the four national China CARE sites.

The civil affairs department has conducted general investigation on AIDS orphans and helped more than 160 AIDS orphans. The department will also provide 700 thousand RMB to build centers for AIDS orphans.

\subsubsection{Intensifying the Surveillance for better Understanding the Trend of Epidemic}

The surveillance of HIV/AIDS epidemic in Guangxi started in 1986, and was one of the earliest surveillance sentinels in China. Guangxi CDC as center for HIV anti-body screening network has checked 61 units which had applied to become HIV anti-body screening laboratories. So far 44 of them have been approved.

In 200582 VCT sites have been set up in Guangxi to provide counseling and HIV/AIDS screening for free. Meanwhile, 22 national and 28 provincial HIV/AIDS and STD surveillance sentinels are being fully used to carry out serological and behavioral surveillance, to understand the complete and exact epidemics of HIV/AIDS in Guangxi in time.

\subsubsection{International Communication and Cooperation}

In recent years Guangxi has been working closely with many countries and international organizations on HIV/AIDS prevention and control. Through these intervention projects Guangxi received substantial assistance, both financial and 
technical. Collaboration fields included behavior change, drug-related harm reduction, public education, condom promotion, STD Prevention and control and PMTCT. These projects are of great help to accumulate experience on HIV/AIDS prevention and to promote the implementation of prevention of HIV/AIDS in project sites (see appendix).

Though China is devoting increasing efforts to HIV/AIDS prevention in Guangxi and has achieved some progress to date, still HIV epidemics in Guangxi is serious. It is now facing the key period of HIV spreading from high risk groups to the general population. At this crucial time the Chinese authorities have to take the opportunity to develop pertinent and effective interventions in order to control the expansion of the epidemic in Guangxi. 
Table 8: Main Cooperative HIV/AIDS Intervention Projects in Guangxi

\begin{tabular}{|c|c|c|c|c|}
\hline Projects Name & Time & Sponsor & Sites & $\begin{array}{l}\text { Main } \\
\text { population }\end{array}$ \\
\hline $\begin{array}{l}\text { HIV/AIDS Prevention for CSW in } \\
\text { Dongxing }\end{array}$ & $1998-2001$ & AusAID & Dongxing & CSW \\
\hline Cohort Study on Drug Users & $1998-2005$ & NIH & $\begin{array}{l}\text { Pingxiang, } \\
\text { Binyang }\end{array}$ & DUS \\
\hline $\begin{array}{l}\text { Community-based Health Promotion of } \\
\text { HIV/AIDS Prevention Project }\end{array}$ & $2000-2002$ & $\begin{array}{l}\text { Norway Agency of } \\
\text { International Development }\end{array}$ & Tiandong & general population \\
\hline $\begin{array}{l}\text { Developing HIV/AIDS Prevention and } \\
\text { Control Strategy in Guangxi }\end{array}$ & $1999-2000$ & UNICEF & $\begin{array}{l}\text { Guangxi, } \\
\text { Liuzhou, } \\
\text { Pingxiang } \\
\end{array}$ & no \\
\hline $\begin{array}{l}\text { Risk Reduction Intervention among CSW } \\
\text { in Pingxiang }\end{array}$ & $1999-2000$ & $\begin{array}{l}\text { Netherlands Agency of } \\
\text { International Development }\end{array}$ & Pingxiang & CW \\
\hline $\begin{array}{l}\text { The Rapid Assessment for Mobile } \\
\text { Population and HIV epidemics in } \\
\text { Guangxi }\end{array}$ & $1999-2002$ & UNDP & & \\
\hline $\begin{array}{l}\text { The Public Education on HIV/AIDS } \\
\text { knowledge through Mass Media in } \\
\text { Pingxiang }\end{array}$ & 2000 & UNAIDS & Pingxiang & general population \\
\hline $\begin{array}{llll}\text { China--US } & \text { HIV } & \text { Prevention } & \text { Trail } \\
\text { Network } & & & \\
\end{array}$ & $2000-2005$ & $\mathrm{NIH}$ & Hengxian & DUS \\
\hline $\begin{array}{l}\text { China--Vietnam Cross-border HIV/AIDS } \\
\text { Prevention Project }\end{array}$ & $2001-2005$ & NIDA/Ford Foundation & Ningming & DUS \\
\hline $\begin{array}{l}\text { China--AusAID HIV/AIDS Prevention } \\
\text { and Control Program }\end{array}$ & $2002-2006$ & AusAID & $\begin{array}{l}\text { Nanning, } \\
\text { Liuzhou, } \\
\text { Wuzhou, Hepu, } \\
\text { Lingshan, Baise }\end{array}$ & DUS \\
\hline $\begin{array}{l}\text { China-USAID HIV/AIDS Prevention } \\
\text { and Control Program }\end{array}$ & $2003-2006$ & FHI supported by USAID & $\begin{array}{l}\text { Ningming, } \\
\text { Pingxiang }\end{array}$ & SW, PLHA \\
\hline Projects Name & Time & Sponsor & Sites & $\begin{array}{l}\text { Main } \\
\text { population }\end{array}$ \\
\hline $\begin{array}{l}\text { Integrated Analysis and Advocacy } \\
\text { Project in Guangxi }\end{array}$ & $2005-2006$ & FHI supported by USAID & Guangxi & \\
\hline $\begin{array}{llll}\text { China/US HIV/AIDS Vaccine Trail } \\
\text { Network }\end{array}$ & $2000-2005$ & $\mathrm{NIH}$ & & \\
\hline Free ART Treatment & $2004-2005$ & MSF & Nanning & PLHA \\
\hline $\begin{array}{l}\text { Guangxi HIV/AIDS Early Warning and } \\
\text { Rapid Response System (EWRRS) }\end{array}$ & 2004-2005 & UNDP & Luchuan, Dongxing & \\
\hline $\begin{array}{l}\text { World Bank loan Health IX Project, } \\
\text { HIV/AIDS/STD Prevention and Control } \\
\text { Sub-project }\end{array}$ & $1999-2005$ & $\begin{array}{l}\text { World Bank/ Guangxi } \\
\text { Provincial Government }\end{array}$ & $\begin{array}{lr}\text { cover } & 14 \\
\text { prefectures } & \text { and } \\
\text { include } & 33 \\
\text { counties } & \\
\end{array}$ & $\begin{array}{l}\text { DUS, SW, and blood } \\
\text { safety, STI, et al. }\end{array}$ \\
\hline China/UK HIV/AIDS CHARTS & $2005-2007$ & DFID/Norway Government & $\begin{array}{l}\text { Guangxi } \\
\text { provincial level }\end{array}$ & \\
\hline
\end{tabular}




2005-2007 Global Fund $\left|\begin{array}{lr}13 & \text { counties } \\ \text { wil1 } & \text { be selceted } \\ \text { in } 5 \text { prefectures }\end{array}\right|$ all areas

Figure 27: Geographical coverage of various HIV/AIDS intervention by country, Guangxi 2005.

Methadone maintenance program coverage by county - 2005

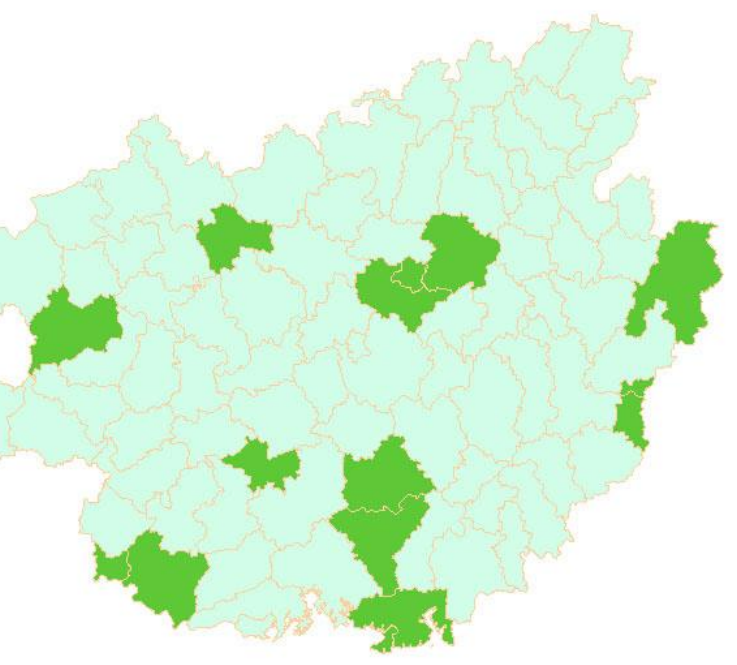

Condom distribution program coverage by county -2005

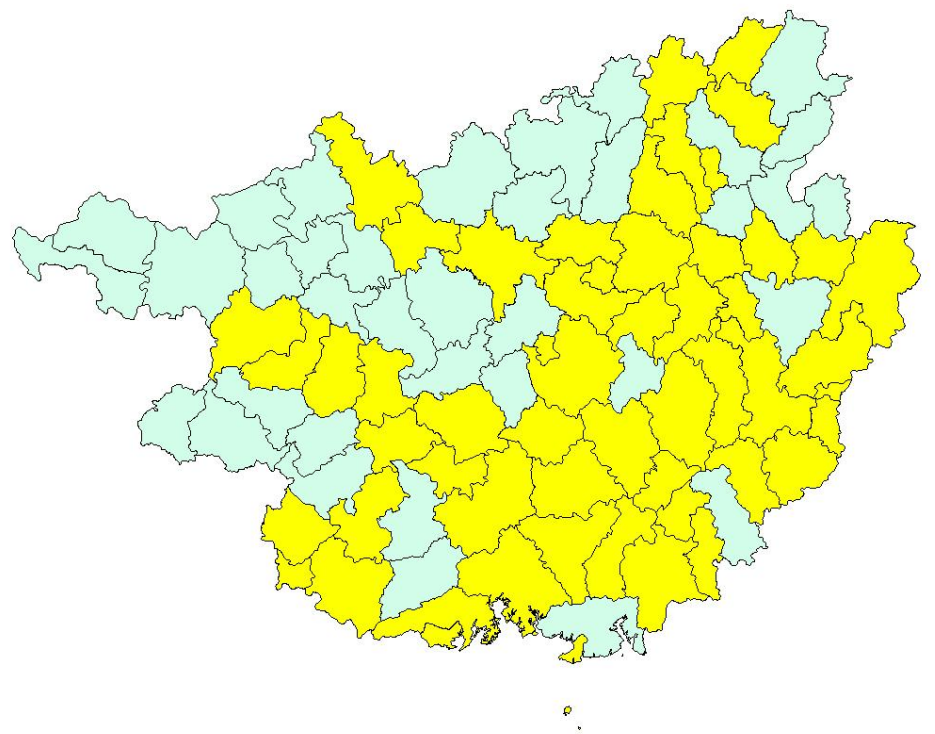


Needle and syringe exchange program coverage by county - 2005

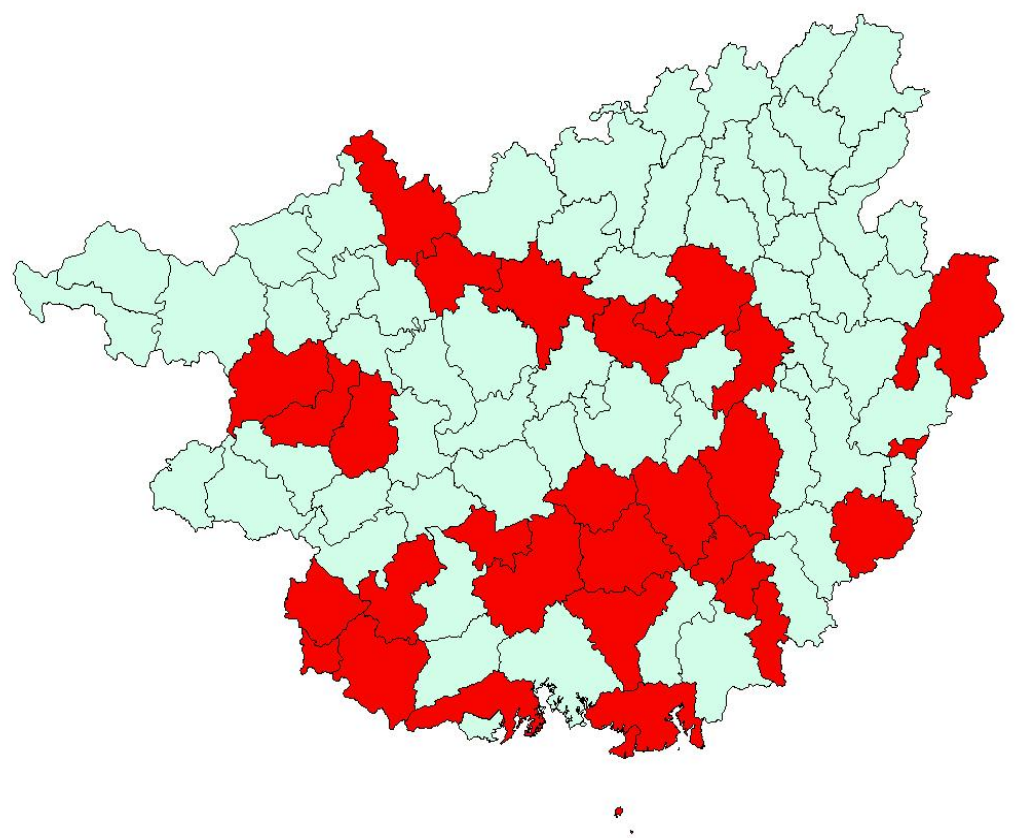


Table 9: HIV and AIDS intervention coverage by prefecture

\begin{tabular}{|c|c|c|c|c|c|c|c|}
\hline Prefecture & Country & Year & Population & $\begin{array}{l}\text { Intervention } \\
\text { activity }\end{array}$ & Data source & $\begin{array}{l}\text { Coverage } \\
\text { rate from } \\
\text { survey }\end{array}$ & $\begin{array}{l}\text { Number reached } \\
\text { through } \\
\text { intervention }\end{array}$ \\
\hline \multirow[t]{9}{*}{ Liuzhou } & Liuzhou & & IDU & methadone & & & 265 \\
\hline & Liuzhou & & IDU & Needle exchange & & & 414 \\
\hline & Liuzhou & 2004 & SW & condom & $\begin{array}{l}\text { Comprehensive } \\
\text { surveillance }\end{array}$ & $37.5 \%$ & \\
\hline & Liuzhou & 2004 & SW & lubricant & $\begin{array}{l}\text { Comprehensive } \\
\text { surveillance }\end{array}$ & $9.1 \%$ & \\
\hline & Liuzhou & 2004 & SW & STI service & $\begin{array}{l}\text { Comprehensive } \\
\text { surveillance }\end{array}$ & $25.6 \%$ & \\
\hline & Liuzhou & 2004 & SW & Counseling & $\begin{array}{l}\text { Comprehensive } \\
\text { surveillance }\end{array}$ & $22.0 \%$ & \\
\hline & Liuzhou & 2004 & SW & IEC & $\begin{array}{l}\text { Comprehensive } \\
\text { surveillance }\end{array}$ & $43.8 \%$ & \\
\hline & Liuzhou & 2004 & SW & skills training & $\begin{array}{l}\text { Comprehensive } \\
\text { surveillance }\end{array}$ & $21.5 \%$ & \\
\hline & Luzhai & & IDU & Needle exchange & & & 500 \\
\hline \multirow{2}{*}{ Wuzhou } & Wuzhou & & IDU & methadone & & & 98 \\
\hline & Wuzhou & & IDU & Needle exchange & & & 495 \\
\hline Baise & Baise & & IDU & Needle exchange & & & 423 \\
\hline Hezhou & Hezhou & & IDU & Needle exchange & & & 44 \\
\hline Qinzhou & Lingshan & & IDU & Needle exchange & & & 253 \\
\hline \multirow[t]{4}{*}{ Nanning } & Nanning & 2004 & IDU & Needle exchange & $\begin{array}{l}\text { Comprehensive } \\
\text { surveillance }\end{array}$ & 13.5 & 401 \\
\hline & Nanning & 2004 & IDU & \begin{tabular}{|ll}
$\begin{array}{l}\text { received } \\
\text { needles }\end{array}$ & clean \\
\end{tabular} & $\begin{array}{l}\text { Comprehensive } \\
\text { surveillance }\end{array}$ & 20.4 & \\
\hline & Nanning & 2004 & IDU & methadone & $\begin{array}{l}\text { Comprehensive } \\
\text { surveillance }\end{array}$ & 15.2 & 115 \\
\hline & Nanning & 2004 & IDU & condom & $\begin{array}{l}\text { Comprehensive } \\
\text { surveillance }\end{array}$ & 11.8 & \\
\hline \multirow[t]{6}{*}{ Prefecture } & Country & Year & Population & $\begin{array}{l}\text { Intervention } \\
\text { activity }\end{array}$ & Data source & $\begin{array}{l}\text { Coverage } \\
\text { rate from } \\
\text { survey }\end{array}$ & $\begin{array}{l}\text { Number reached } \\
\text { through } \\
\text { intervention }\end{array}$ \\
\hline & Nanning & 2004 & IDU & lubricant & $\begin{array}{l}\text { Comprehensive } \\
\text { surveillance }\end{array}$ & 3.8 & \\
\hline & Nanning & 2004 & IDU & STD & $\begin{array}{l}\text { Comprehensive } \\
\text { surveillance }\end{array}$ & 7.6 & \\
\hline & Nanning & 2004 & IDU & counseling & $\begin{array}{l}\text { Comprehensive } \\
\text { surveillance }\end{array}$ & 23.9 & \\
\hline & Nanning & 2004 & IDU & IEC & $\begin{array}{l}\text { Comprehensive } \\
\text { surveillance }\end{array}$ & 32.5 & \\
\hline & Nanning & 2004 & IDU & skills training & $\begin{array}{l}\text { Comprehensive } \\
\text { surveillance }\end{array}$ & 12.1 & \\
\hline \multirow[t]{4}{*}{ Chongzuo } & Ningming & 2005 & IDU & Needle exchange & Abt project & $85.2 \%$ & 500 \\
\hline & Pingxiang & Jan-00 & SW & visit woman center & condom project & 29.1 & \\
\hline & Pingxiang & Jan-00 & SW & $\begin{array}{ll}\text { know } & \text { women } \\
\text { center }\end{array}$ & condom project & 56.2 & \\
\hline & Pingxiang & Dec-00 & SW & visit woman center & condom project & 39.1 & \\
\hline
\end{tabular}




\begin{tabular}{|c|c|c|c|c|c|c|c|}
\hline & Pingxiang & Dec-00 & SW & $\begin{array}{ll}\text { know } & \text { women } \\
\text { center }\end{array}$ & condom project & 74.2 & \\
\hline & Pingxiang & 2004 & $\begin{array}{l}\text { Truck } \\
\text { driver }\end{array}$ & condom & $\begin{array}{l}\text { Comprehensive } \\
\text { surveillance }\end{array}$ & $3.1 \%$ & \\
\hline & Pingxiang & 2004 & $\begin{array}{l}\text { Truck } \\
\text { driver }\end{array}$ & lubricant & $\begin{array}{l}\text { Comprehensive } \\
\text { surveillance }\end{array}$ & $0.8 \%$ & \\
\hline & Pingxiang & 2004 & $\begin{array}{l}\text { Truck } \\
\text { driver }\end{array}$ & STI service & $\begin{array}{l}\text { Comprehensive } \\
\text { surveillance }\end{array}$ & $1.3 \%$ & \\
\hline & Pingxiang & 2004 & $\begin{array}{l}\text { Truck } \\
\text { driver }\end{array}$ & Counseling & $\begin{array}{l}\text { Comprehensive } \\
\text { surveillance }\end{array}$ & $5.0 \%$ & \\
\hline & Pingxiang & 2004 & $\begin{array}{l}\text { Truck } \\
\text { driver }\end{array}$ & IEC & $\begin{array}{l}\text { Comprehensive } \\
\text { surveillance }\end{array}$ & $3.9 \%$ & \\
\hline & Pingxiang & 2004 & $\begin{array}{l}\text { Truck } \\
\text { driver }\end{array}$ & skills training & $\begin{array}{l}\text { Comprehensive } \\
\text { surveillance }\end{array}$ & $2.1 \%$ & \\
\hline Fangchenggang & Dongxing & \begin{tabular}{|l} 
May- \\
00
\end{tabular} & SW & $\begin{array}{l}\text { recei ved IEC from } \\
\text { women center }\end{array}$ & AusAid & 87.1 & \\
\hline \multirow[t]{2}{*}{ Prefecture } & Country & Year & Population & $\begin{array}{l}\text { Intervention } \\
\text { activity }\end{array}$ & Data source & \begin{tabular}{l}
\multicolumn{2}{l}{ Coverage } \\
rate from \\
survey \\
\end{tabular} & $\begin{array}{l}\text { Number reached } \\
\text { through } \\
\text { intervention }\end{array}$ \\
\hline & Dongxing & $\begin{array}{l}\text { May- } \\
00\end{array}$ & SW & $\begin{array}{l}\text { reached trough } \\
\text { outreach by woman } \\
\text { center staff }\end{array}$ & AusAid & 71.0 & \\
\hline Hechi & Hechi & & IDU & Methadone & & & 29 \\
\hline Beihai & Hepu & & IDU & Needle exchange & & & 161 \\
\hline Guigang & Guigang & & IDU & Needle exchange & & & 440 \\
\hline
\end{tabular}




\section{References}

1. Ming Z, Liang S, Yap L, et al. Qualitative study of drug using and sexual behaviors of drug users in Guangxi. China J Epidemiol 2002; 23:111-113.

2. Walker N, Stover J, Stanecki K, et al. The workbook approach to making estimates and projecting future scenarios of HIV/AIDS in countries with lowlevel and concentrated epidemics. Sex Trans Infect 2004; 80:10-13.

3. Yu ES, Xie Q, Zhang K, et al. HIV infection and AIDS in China, 1985 through 1994. Am J Public Health 1996; 86:1141-47.

4. $\mathrm{Yu} \mathrm{XF,} \mathrm{Chen} \mathrm{F,} \mathrm{Shao} \mathrm{Y,} \mathrm{et} \mathrm{al.} \mathrm{Emerging} \mathrm{HIV} \mathrm{infections} \mathrm{with} \mathrm{distinct} \mathrm{subtypes} \mathrm{of}$ HIV-1 infection among injection drug users from geographically separate locations in Guangxi prfovince, China. J Acquir Immune Defic Syndr 1999; 22:180-8.

5. Beyrer C, Razak MH, Lisam K, et al. Overland heroin trafficking routes and HIV1 spread in south and south-east Asia. AIDS 2000; 14:75-83.

6. Qian ZH, Vermund SH, Wang N. Risk of HIV/AIDS in China: Subpopulations of special importance. Sex Trans Infect 2005; 81:442-7.

7. $\mathrm{Yu} \mathrm{A}, \mathrm{Xu} \mathrm{M}, \mathrm{Wang} \mathrm{J}$, et al. Investigation and analysis of the epidemic report and missing report of the first half of 1999 and 2000. China J Prev Control STD AIDS 2000; 6:33-4.

8. Boerma JT, Stanecki KA, Newell ML, et al. Monitoring the scale-up of antiretroviral therapy programmes: methods to estimate coverage. Bulletin of the World Health Organization 2006; 84:145-150.

9. Chen J, Young NL, Subbararo, et al. HIV type 1 subtypes in Guangxi Province, China, 1996. AIDS Res. Hum Retrovir 1996; 15:81-84.

10. Piyasirisilp S, McCutchan FE, Carr JK, et al. A recent outbreak of human immunodeficiency virus type 1 infection in Southern China was initiated by two highly homogeneous, geographically separated strains, circulating recombinant form AE and a novel BC recombinant. J of Virology 2000; 74:11286-95.

11. Kato K, Shiino T, Kusagawa S, et al. Genetic similarity of HIV type 1 subtype E in a recent outbreak among injecting drug users in Northern Vietnam to strains on Guangxi Province of Southern China. AIDS Research and Human Retroviruses 1999; 15:1157-68.

12. Kato K, Kusagawa S, Motomura K, et al. Closely related HIV-1 CRF01_AE variant among injecting drug users in Northern Vietnam: Evidence of HIV spread across the Vietnam-China Border. AIDS Research and Human Retroviruses 2001; 17:113-23.

13. Zhang GW, Laeyendecker O, Quinn TC, Garten R, et al. Clash of two HIV-1 epidemics in Guangxi, China, 10th Conf Retrovir Oppor Infect, Boston Mass USA, 2003.

14. Hammett TM, Johnston P, Kling R, et al. Correlates of HIV status among injection drug users in a border region of Southern China and Northern Vietnam. J Acquir Immune Defic Syndr 2005; 38:228-35. 
15. Hui X, Pinliang P, Ling S. Molecular epidemiological study of HIV-1 strain of subtype E in China between 1996 and 1998. China J STD/AIDS Prev Cont 2002; 8:200-3.

16. Leayendecker O, Zhang GW, Quinn TC, et al. Molecular epidemiology of HIV-1 subtypes in Southern China. J Acquir Immune Defic Syndr 2005; 38:356-62.

17. Yu XF, Liu W, Chen J, et al. Rapid dissemination of a novel B/C recombinant HIV-1 among injection drug users in southern China. AIDS 2001; 15:523-25.

18. Yu XF, Liu W, Chen J, et al. Maintaining low HIV type 1 env genetic diversity among injection drug users infected with a B/C recombinant and CRF01_AE HIV type 1 in southern China. AIDS Res. Hum Retrovir 2002; 18:167-170.

19. Takebe Y, Yang R, Kusagawa S, et al. Identification of new class of HIV-1 recombinants comprised of two circulating recombinant forms, CRF07_BC and CRFO08_BC, in China, 10th Conf Retrovir Oppor Infect, 2003.

20. Yu XF CF, Shao Y, et al. Two subtypes of HIV-1 among injection-drug users in Southern China. Lancet 1998; 351:1250.

21. Zhang G, Zheng X, Liu W, et al. The survey of HIV prevalence among drug users in Guangxi, China. China J Epidemiol 2000; 21:15-6.

22. Liu W, Chen J, Zhijun LI, et al. Analysis of HIV epidemic trends in Guangxi, China. Guangxi Prev Med 2001; 10:257-60.

23. Huajie Z, Chisen L, Hua L, et al. AIDS epidemiological survey among drug users during the past three years (1998 - 2000) in Wuzhou City. China J STD/AIDS Prev Cont 2001; 7:351-3.

24. Qu S, Sun X, Zheng X, et al. National sentinel surveillance of HIV infection in China from 1995 to 1998., Int Conf AIDS, Durban, S. Africa, 2000.

25. Lai S, Chen J, Yang J, et al. Changes in HIV-1 incidence in heroin users in Guangxi Province, China. J Acquir Immune Defic Syndr 2001; 26:365-70.

26. Liu W CJ, Rodolph MI, et al. HIV incidence, retention and changes of high-risk behaviors among rural injection drug users in Guangxi, China, 2005 [unpublished mansucript].

27. Ruan Y, Qin G, Liu S, et al. HIV incidence and factors contributed to retention in a 12-month follow-up study of injection drug users in Sichuan province, China. J Acquir Immune Defic Syndr 2005; 39:459-63.

28. Kretzchmar M, Wiessing LG. Modelling the spread of HIV in social networks of injecting drug users. AIDS 1998; 12:801-11.

29. Zhang KL, Ma SJ and Xia DY. Epidemiology of HIV and sexually transmitted infections in China. Sexual Health 2004; 16:39-46.

30. Pan SM. Reality and absurdity: underground sex industry in China: Yan Publishing House, 1999.

31. Huang YY, Henderson GE, Pan SM, et al. Brothel-based FSWs in China: variation in occupational control and risk of HIV/AIDS, Int Conf AIDS, Bangkok, Thailand, 2004.

32. Liu W, Yuejzao Z, Shaoling L, et al. Evaluation of the effectiveness of an intervention to reduce risk behaviors among women engaged in illegal commerical sex activities in frontier areas of Guangxi Province. China $\mathbf{J}$ STD/AIDS Prev Cont 2001; 7:223-9. 
33. Liao SS, He QY, Liu W, et al. Rapidly changing sex industry in rural communities of Hainan and Guangxi, China: Implications for HIV/STD interventions, Int Conf AIDS, Barcelona, Spain, 2002.

34. Liu W, Zhu QY, Chen J, et al. Drug use, sexual behavior and HIV infection among women in Guangxi, China., Int Conf AIDS, Barcelona, Spain, 2002.

35. Beyrer C. Hidden epidemic of sexually transmitted diseases in China: crisis and opportunity. JAMA 2003; 289:1303-5.

36. Qu S, Liu W, Choi KH, et al. The potential for rapid sexual transmission of HIV in China: Sexually transmitted diseases and condom failure highly prevalent among female sex workers. AIDS and Behavior 2002; 6:267-75.

37. Zhang KL. Epidemiology of HIV in China: Intravenous drug users, sex workers, and large mobile populations are high risk groups. BMJ 2002; 324:803-4.

38. Chen XS, Yin YP, Gong XD, et al. Prevalence of sexually transmitted infections among long-distance truck drivers in Tongling, China. International J of STD \& AIDS 2006; 17:304-8.

39. Male-to-male sex and HIV/AIDS in Asia. Bangkok: Monitoring the AIDS Pandemic Network, 2005.

40. Zhang BC, Li XF, Shi TX et al.. Survey on the high risk behaviors and other AIDS/STI related factors among men who have sex (MSM) in mainland China. Chin J Dermatol 2002; 35:214-7.

41. Choi HK, Liu H, Han L et al. Emerging HIV-1 epidemic in China in men who have sex with men. Lancet 2003; 361:2125-6.

42. Yao J, Zhang FJ, He ZP, et al. Subtypes of HIV infection among homosexuals in Beijing. Zhonghua Liu Xing Bing Xue Za Zhi 2003; 24:159.

43. Huang $\mathrm{P}$, Zhou Z, Zhizhi F, et al.. Research on the STD under-reporting rate and influence factors in Guangxi. China J Leprosy and Skin Diseases 2002; 20:54-55.

44. Huang P, Zhou Z, Zhizhi F, et al.. Analysis of the STD under-reporting rate and influence factors in Guangxi. Guangxi J of Prev Med 2003; 4.

45. Chen XS, Yin YP, Liang GJ, et al. Co-infection with genital gonorrhoea and genital chlamydia in female sex workers in Yunnan, China. International J of STD \& AIDS 2006; 17:329-332. 